\title{
DEVELOPMENT AND FIELD TEST OF PSYCHOPHYSICAL TESTS FOR DWI ARREST
}

\author{
V. Tharp \\ M. Burns \\ H. Moskowitz
}

Southern California Research Institute

6305 Arizona Place

Los Angeles, California 90045

Contract No. DOT-HS-8-01970

Contract Amt. \$205,579

MARCH 1981

FINAL REPORT
This document is avallabie to the U.S. public through the Natıonal Technical Information Service. Springtield, Virgınıa 22161

Prepared for

U.S. DEPARTMENT OF TRANSPORTATION

National Highway Traffic Safety Administration

Washington, D.C. 20590 
This document is disseminated under the sponsorship of the Department of Transportation in the interest of Information exchange. The United States Government assumes no liability for its contents or use thereof. 
TECHNICAL REPORT STANDARD TITLE P:

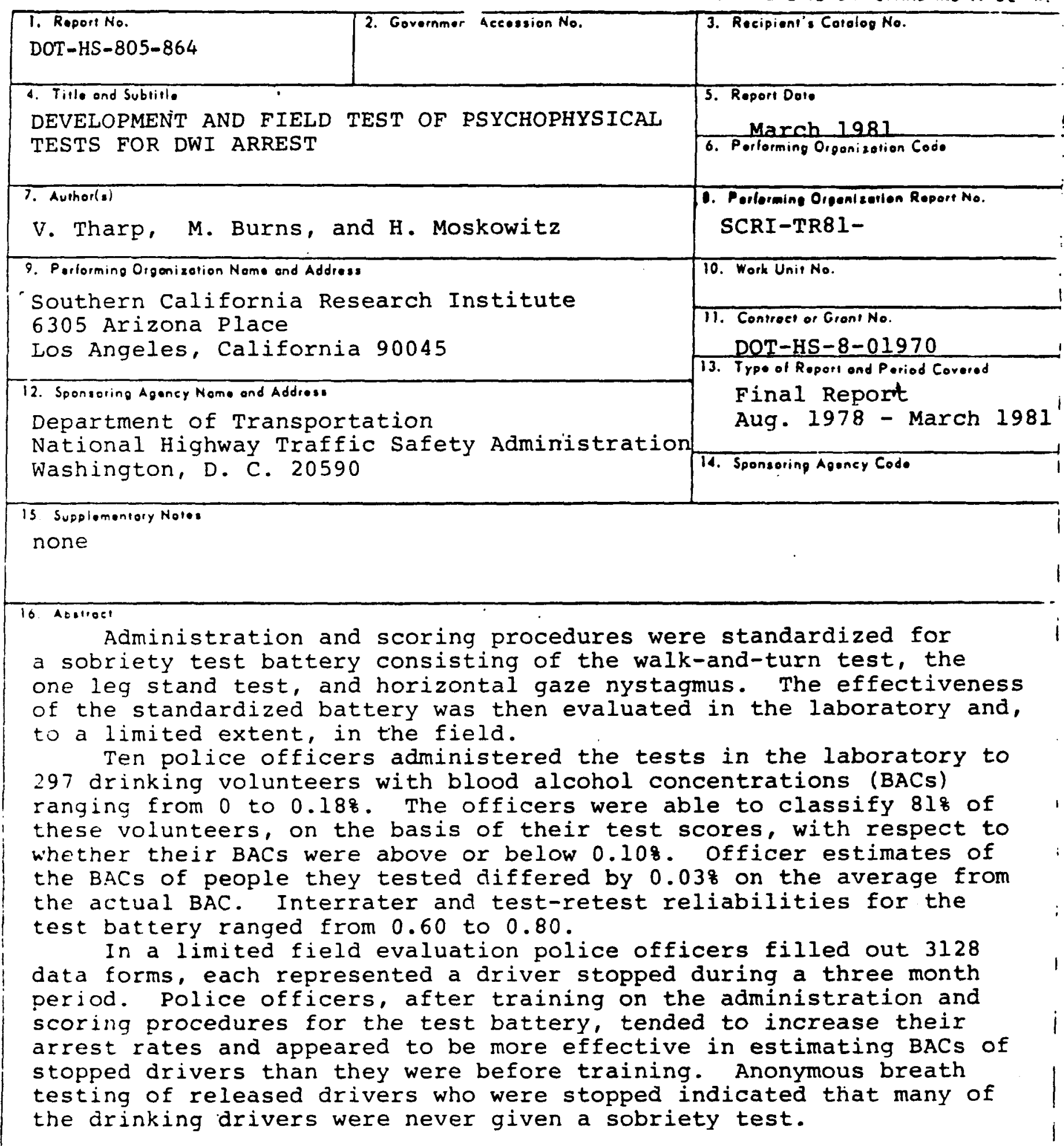

\begin{tabular}{|c|c|c|c|}
\hline $\begin{array}{l}\text { 1: xov } \\
\text { sobriety test } \\
\text { standardization } \\
\text { alcohol } \\
\text { police } \\
\text { walk and turn }\end{array}$ & $\begin{array}{c}\text { one leg stand } \\
\text { horizontal gaze- } \\
\text { nystagmus }\end{array}$ & $\begin{array}{l}\text { 18. Distribution slolement } \\
\text { This document is avail } \\
\text { U.S. public through th } \\
\text { Technical Information } \\
\text { Springfield, Virginia }\end{array}$ & $\begin{array}{l}\text { ole to the } \\
\text { National } \\
\text { ervice, } \\
2161\end{array}$ \\
\hline $\begin{array}{l}\text { 1f. Security Clonsil. (ol this coportl) } \\
\text { unclassified }\end{array}$ & $\begin{array}{l}\text { 20. Securily Cloer } \\
\text { unclass }\end{array}$ & $\begin{array}{c}\text { 21. Na. of Pages } \\
98\end{array}$ & 22. Price \\
\hline
\end{tabular}




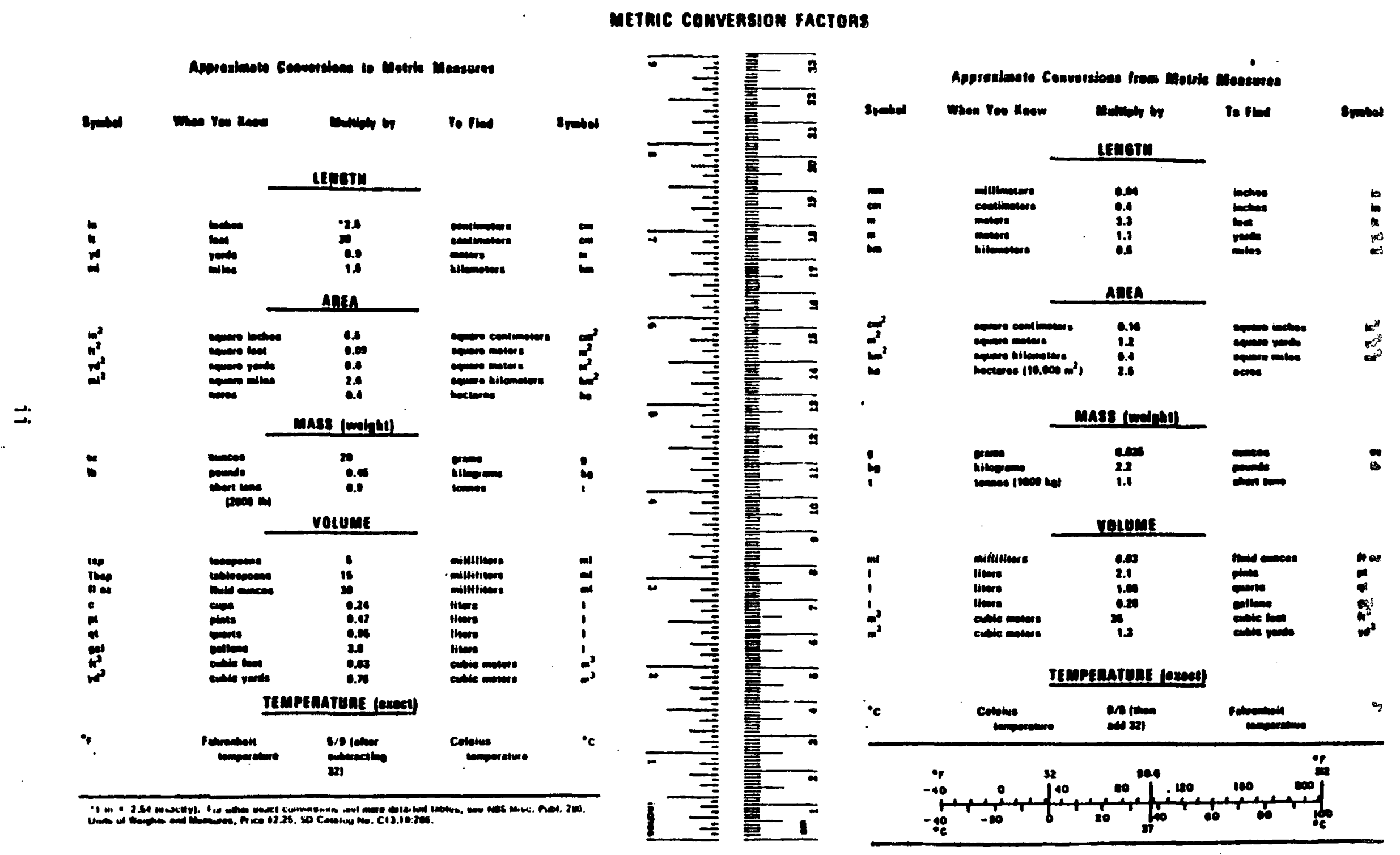




\title{
PREFACE
}

This study involved the participation of three different police agencies whose cooperation and support was essential. We are especially grateful for the exceptional contributions to the project of the administrative and patrol personnel of these agencies. The agencies, along with our principal point of contact, are listed below in alphabetical order.

\author{
California Highway Patrol, Southern Division \\ Cpt. Kenneth Rude \\ Los Angeles County Sheriff's Department \\ Sgt. Harry Douglas \\ Los Angeles Police Department, Central Traffic \\ sgt. Richard Studdard
}

\begin{abstract}
We also wish to acknowledge the contribution of two research assistants, Melinda Baille and Leslie Rosdol, whose contribution was exceptional.
\end{abstract}

The Contract Technical Managers for this project were Stephen Benson, Pamela Anikeeff, and Robert Schweitz. We appreciate their assistance and support. 
TABLE OF CONTENTS

PAGE

I. INTRODUCTION $\ldots \ldots \ldots \ldots \ldots \ldots \ldots \ldots \ldots \ldots \ldots \ldots \ldots \ldots \ldots \ldots \ldots \ldots \ldots$

A. PRELIMINARY ASSESSMENT OF FIELD SOBRIETY TESTS .... 1

B. PILOT TESTS NITH THE SELECTED TEST BATTERY ...... 2

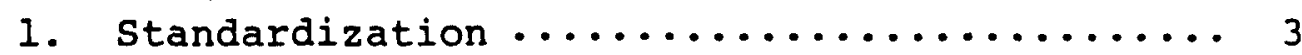

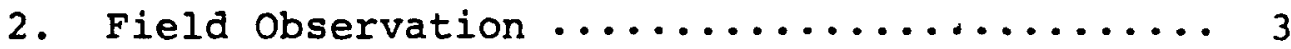

3. Pilot Subjects $\ldots \ldots \ldots \ldots \ldots \ldots \ldots \ldots \ldots \ldots \ldots \ldots$

a. Walk and Turn Test .............. 4

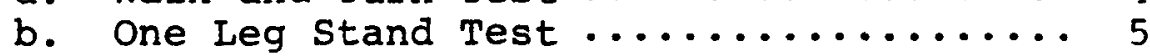

c. Gaze Nystagmus Test .............. 7

II. LABORATORY EVALUATION OF THE TEST BATTERY ......... 13

A. LABORATORY PROCEDURES ................. 13

1. Police officers, observers, and Isaboratory

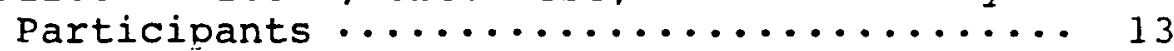

2. Training Precedures for Police officers .... 16

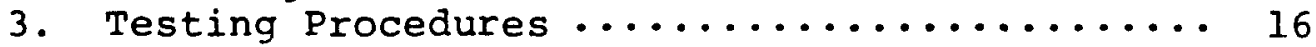

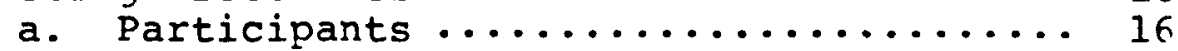

b. Officers and Observers $\ldots \ldots \ldots \ldots \ldots$ j.

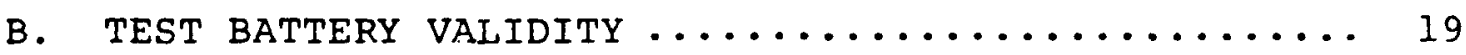

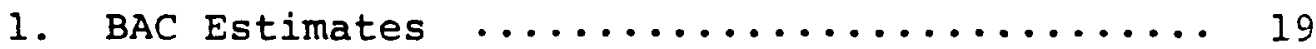

2. Impairment and Arrest Decisions .......... 20

3. Ability to Classify Subjects with Respect

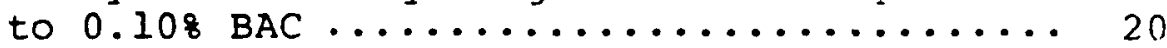

4. Nystagmus Criteria .................... 25

a. BAC Versus Angle onset ............ 25

b. Rater Estimate Versus Machine Estimate of onset ..................... 30

C. RELIABILITY ......................... 30

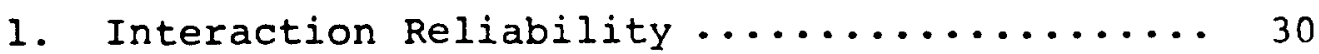

2. Test-Retcst Reliability .................. 34

III. FIELD EVALUATION PRECEDURES $\ldots \ldots \ldots \ldots \ldots \ldots \ldots \ldots \ldots$

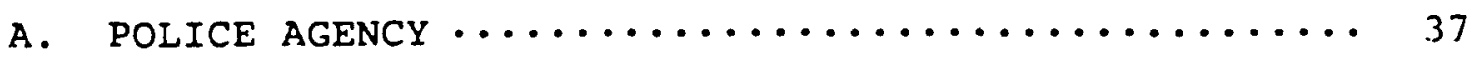


PACE

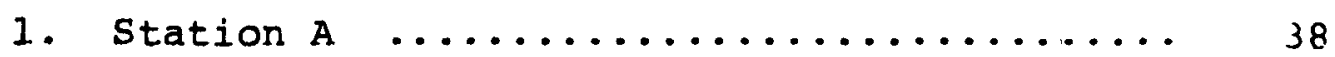

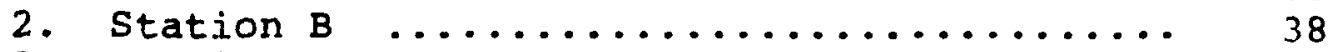

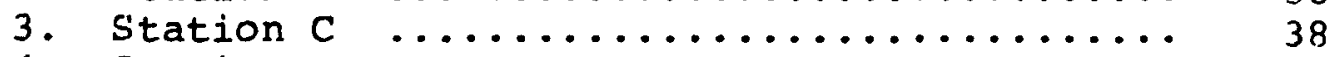

4. Station $D$....................... 38

B. STUDY DESIGN $\ldots \ldots \ldots \ldots \ldots \ldots \ldots \ldots \ldots \ldots \ldots \ldots \ldots . \ldots . \ldots . \ldots . \ldots$

C. TRAINING POIICE OfficERS ................ 41

D. DATA COLLECTION ...................... 42

1. Data Forms ...................... 42

2. Ridealong Data ...................... 45

IV. EVALUATION OF THE FIELD STUDY ............... 50

A. THE NATURE OF THE STOPEE POPULATION .......... 50

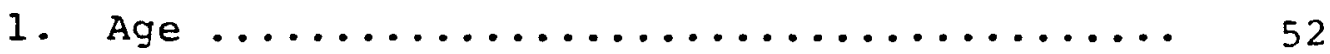

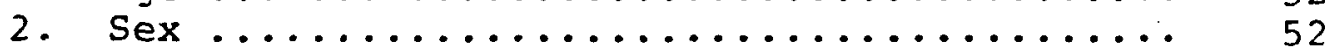

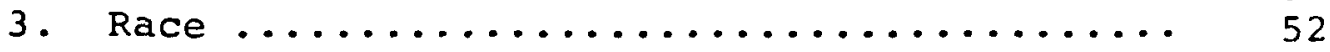

B. TEST BATTERY EFFEctivenESS ................. 54

1. Will the Percentages of the Stopees Who Are Arrested Increase after the Training

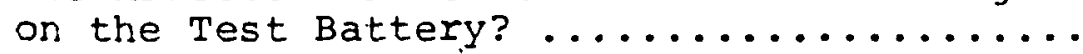

2. Will Police officers Make More Accurate Decision with Respect to a BAC of 0.108 after Being Trained on the Test Battery? .. a. Exposure to Drinking Drivers ........

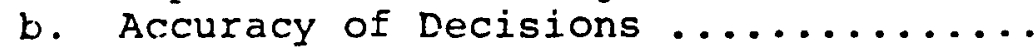

3. Will the Mean BAC of Arrested Drivers

Be Reduced after the Test Battery Is

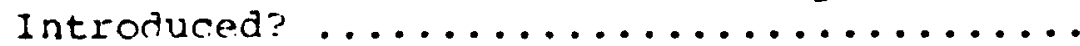

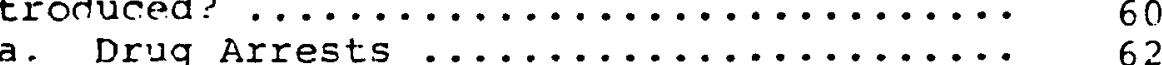

b. Refusals

4. Wil police officers More Accurately

Estimate the BAC Levels of Stopees after Being Trained on the Test

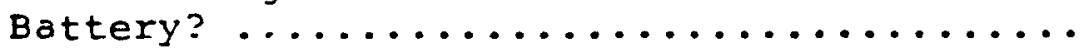

a. Few Stopees Are Tested ............ 62

b. Most officers' BAC Estimates Were Invalid ..................

c. Blood and Urine Data Were Obtained on a Biased Sample of Arrestees......

d. Given these Problems, the Accuracy of the Officers' BAC Estimates Tended To Be More Accurate after

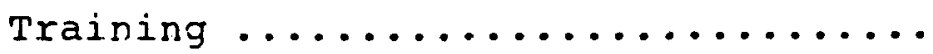


5. BAC Distribution of Police Stopees $\ldots \ldots \ldots \ldots \ldots 65$

a. Driver's BAC Versus His Arrest Probability.. 65

b. BAC During Different Phases of the Study.... 65

c. BAC Versus Type of Driving Error .........66 68

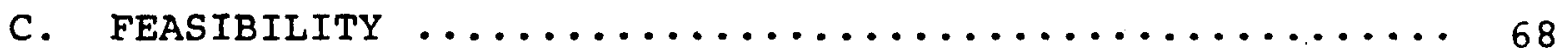

1. Police Attitude Toward DWI Arrests ........... 68

2. Police Acceptance of Standard Administration

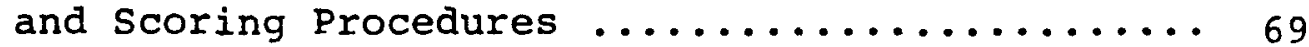

3. Set BAC Levels ....................... 70

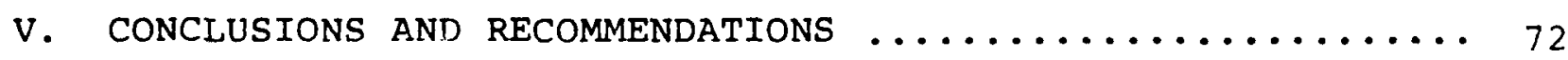

A. Conclusions $\ldots \ldots \ldots \ldots \ldots \ldots \ldots \ldots \ldots \ldots \ldots \ldots \ldots \ldots \ldots$

B. RECOMMENDATIONS ...................... 73

1. Police Attitude and Motivation ............. 73

2. Adequate Time Frame for Data Collection ....... 73

3. Other Considerations ................... 74

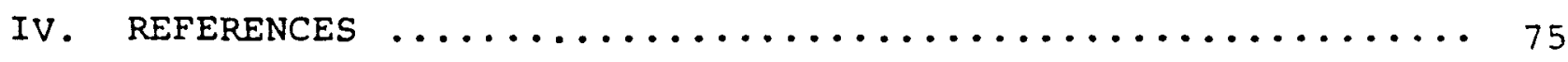

APPENDIX A: LITERATURE REVIEW ...................... 79

A. ALCOHOL AND NYSTAGMUS ....................... 79

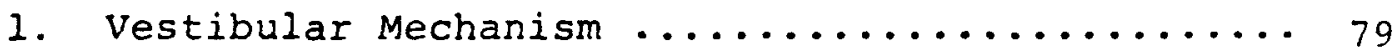

2. Neural Mechanism ...................... 81

3. Gaze Nystagmus ....................... 82

B. ALCOHOL AND BALANCE $\ldots \ldots \ldots \ldots \ldots \ldots \ldots \ldots \ldots \ldots \ldots \ldots \ldots$

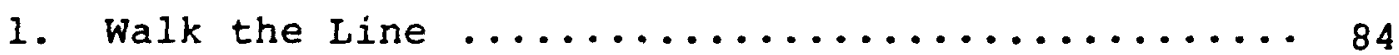

2 . One Leg stand ........................ 84

APPENDIX B: INSTRUCTIONS AND SCORING SHEET........... 85 


\section{LIST OF TABLES}

TABLE

PAGE

1. Backround of officers Who Scored and Administered the Field Sobriety Test Battery.. 12

2. Age and Sex Comparison of Laboratory Participants with Stopees from the Fiela Evaluation .....................14

3. Mean Absolute Value of the Difference Between the Actual BAC and the Estimated BAC of Each Rater .................... 21

4. Percentage of Subjects Classified as

"Arrested" or "Impaired" at Each Alcohol

Dose ........................... 22

5. Rater's Criterion for the Arrest/No Arrest

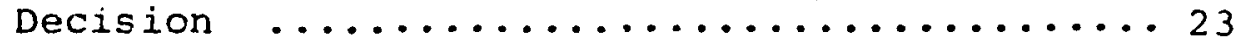

6. Rater's Criterion for the Impaired/Not Impaired Decision .................. 24

7. Classification Percentages with Respect to a BAC of . 108 for Individual Raters ........ 26

8. Decision Matrix for Police officers ....... 27

9. Decisjon Matrix for Observers ........... 28

10. Correlation between Machine Nystagmus Readings and Blood Alcohol Concentration ....29

11. Correlation between Machine Angle of Nystagmus Onset and Individual Rater Estimates of Onset, the Rank of these Correlations, and the Rank of Each Rater's Classification Ability .. 31

12. Interrater Reliability on Each Session ..... 32

13. Interrater Reliability: Individual officerobserver Correlations .................. 33

14. Test-Retest Reliabilities for Decision and

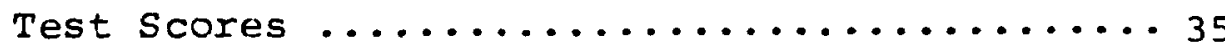


15. Analyses of Variance for Between Session Rater

BAC Estimates for Officer-Same, officerDifferent, Observer-Same, Observer-Different .... 36

16. Pre-Training Data Form .................. 43

17. Post-Training Data Form .................. 44

18. Data obtained from Stopees during Ridealongs ..... 51

19. Age and Sex Distribution of Four Groups of Stopees during the Field Evaluation ........... 53

20. Stops and Arrests Made during the Field Evaluation as a Function of Officer Grouping and study Phase ...................... 56

21. BACs of Released Stopees as a Function of Officer Grouping and Phase of the study ........ 58

22. Before Training Decision Matrix ............. 59

23. Arrests, Available BAC's, and Mean BAC as a function of officer Grouping and

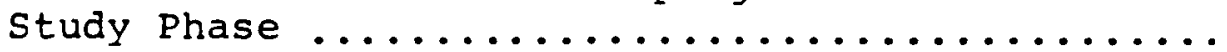

24. Mean Absolute Value Difference Between Estimated BACs and Actual BACs of arrestees giving blood or

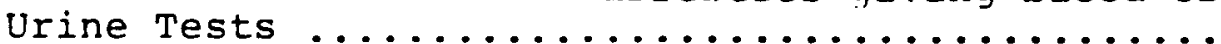

25. Distribution of Stopees According to $B A C$ and Arrest Probability Before and After Training as a Function of $\mathrm{BAC}$

26. Most Common Reasons for Stopping a Driver

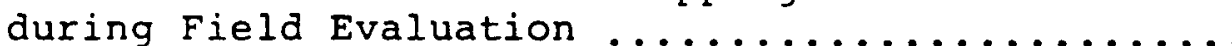

\section{LIST OF FIGURES}

FIGURE

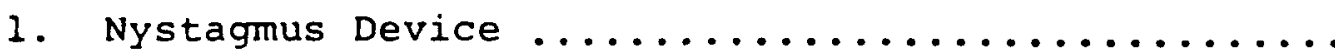

2. Regression of Angle of onset on BAC for the Right and Left Eyes

3. Angle of Onset as a Function of Time of Day for the Right and Left Eyes under Two Alcohol Conditions 
4. Assignment of Participants to Cells According to $B A C$ and Drinking History on Session 1

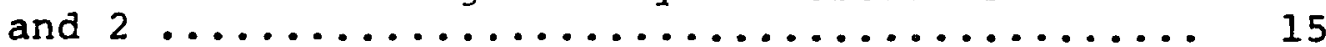

5. Three Phase Design .................... 40

6. Device for Obtaining Anonymous Breath Samples... 46 
Alcobol use contributes to a large proportion of the fatal and injurs related accidents nationwide. Currently, attempts to deter the drinking driver consist of informing the public of the harards of driving while impaired (DWI) and of the threat and consequences of being arrested. Onfortunately, the perceived risk by the public j. quite low, since the combined probability of having an accident or of being arrested for one DWI trip is estimated to be 0.00089 (summers and Harris, 1978) or less than one in 1000 .

One reason for the low probabilitg of being arrested in a DWI trip is that large deficiencies exist in the detection and arrest of drivers with blood alcohol concentrations (BACs) over $0.10 \%$. Drivers on the road, as estimated by Beitel, sharp, and Glauz (1975), are three times as likely to have a BAC in the range of $0.10 \%$ to $0.14 \%$ as in the $0.15 \%$ to $0.19 \%$ range. In contrast, the probabilitg of an arrested driver having a BAC in the $0.10 \%$ to $0.14 \pi$ range is half as $8 \mathrm{reat} a \mathrm{~s}$ that of having a BAC in the $0.15 \%$ to $0.19 \%$ range. This deficit may be directly attributed to the police officex in the field, who must detect and arrest the alcohol impaited driver.

The discrepancy between the distribution of BACs among drivers and the distribution of BACs among arrestees results from the following: (1) the high BAC driver makes more frequent driving errors which are detected by the police; (2) decisions to arrest are easier to make with the highly intoxicated stopee; and (3) many police officers are not motivated to arrest drunk drivers, especially those with lower BACs. These discrepancies may be at least partialiy offset by training police officers to discriminate BAC levels more effectively by using a standardized field sobriety test batterg.

\section{A. PRELIMINARY ASSESSMENT OF FIELD SOBRIETY TESTS}

Much of the svailable literature on sobriety testing comes from couatries in which a medical examination by a phaician is required to determine intoxication. For example, Finland has no otatutory blood alcobol limits for driving, but the courts give severe penalties for driving under the influence of alcohol. Pentilla, Tenhu, and Rataja (1971) examined the sobrietg test performance of 6839 Finnish drivers suspected of driving under the influence of alcohol. In this study, the test battery included: walking, gait in turning, balance, finger-to-nose, picking up matches, counting backwaxds, time and place orientation, and observations of opeech and genersl behsvior. The three most sengitive tests were counting backwards by threes from 102, balancing with the eyes open, and walking down corridor with eyes closed. The counting test, however, was particularly difficult for people of low socioeconomic background. 
In a subsequent study, these investigators (Pentilla, Tenhu, and Rataja, 1974) analyzed the test records of 495 individuals in order to develop an optimal test batterg. The most important change from previousiy used test was the inclusion of observations of the eyes, (e.g., gaze nystagmus, post-rotational nystagmus, pupillary diameter, and pupillary reaction to light) and the valk-the-line test. The gaze nystagmus and the walk-the-line testa proved to be the best for predicting the BAC, whereas phyicians' subjective estimates of the level of intoxication were found to be of no value.

In New zealand medical examination is given in cases where a driver suspected of driving while intoxicated pleads not-guilty. Simpon-crawford and slater (1971) have developed a clinical examination consigting entirely of ege signs of alcohol intorication. Their six point "oculiser scale" includes the following: (1) conjunctivae are suffused (i.e., "bloodshot" eyes); (2) the egelids drag behind when the eyeball moves up and down; (3) the pupillary light reflex is slowed; (4) peripheral vision is diminished; (5) nystagmus is seen when the eyes follow a moving object; and (6) the pupils tend to be dilated.

Burns and Moskowitz (1977) evaluated a number of sobriety tests currentig used by police in the Dnited states to determine their relationship to intoxication. Based upon preliminary pilot work, the following tests were Belected for an evaluation study: one-leg stand; walk-and-turn; finger-to-nose; finger count, alcohol gaze nystagms; tracing; Romberg body sway; subtraction; backward counting; and letter cancellation. Ten police officers administered these tests to 238 participants. The participants were light, moderate, and heavy drinkers who had consumed enough alcohol to produce a BAC in the range of $0 \%$ to $0.15 \%$. All of the tests were found to be sensitive to slcohol, but a reduced "best test set" was determined by means of stepwise discriminant analgses. The three "best" tests were (1) the one-leg-stand; (2) the walk-and-turn; and ( 3 ) alcohol gaze nystagmus. This recommended test battery could correctly classify more than $83 \%$ of the evaluation otudg participants with respect to whether they were above or below a BAC of $0.10 \%$.

\section{B. PILOT WORR WITH IBE SELECTED TEST BATTERY}

The purpose of phase I of this contract (DOT-BS-8-1970) was to complete the laboratory development and validation of the sobriety test battery identified by Burns and Moskowitz (1977). Pirst, the development of the test battery involved identifying variables, in addition to alcohol, which influence performance on the test battery. As a result of this identification, standardized adminiotration and scoring procedures were developed. A literature review of the variables affecting the three test battery is included in Appendix $\Delta$. A summary of the pilot vork aiming at atandardiring the scoring and administration procedures is included in this chapter. 
Cronbach (1970) defines a standardized test as being "one in whisl: the procedures, apparatus, and scoring have been fixed so that precisely the same testing procedures can be followed at different times and places." The process of gathering normative data is also called "standardization," but this process is not very profitable until the procedures and scoring have been standardized.

The first step in standardizing a field sobriety test battery is to determine what aspects of the test battery make the tests particularly sensitive to alcohol intoxication. That is, the first step is to fine-tune the tests to best discriminate between the intoxicated person and the sober person. These variables most sensitive to alcohol intoxication are discussed in Appendix A.

Testing is a social relationship in which the interactions between the tester and the testee are very important. These interactions between stopee and police officer will be impossible to standardize. For example, we have found during police ridealongs that mogt stopees are fairly calm about getting a ticket, although $30 \%$ to $40 \%$ will argue with the officer. About $5 \%$ of the stopees can be very hostile, however, displaying behavior ranging from temper tantrums to hysterics. Intoxicated stopees, who are generally the ones given sobriety tests, are much more likely to display these behavior extremes. Hostile behavior, or the police reactions to it, is impossible to duplicate in the laboratory situation for purposes of standardization.

The police officer, in scoring the field sobriety tests, is interested both in how well the suspect can perform (i.e., is the individual inpaired?) and how well the stopee's performance compares with that expected from drivers at various BACs. The primary reason that a field sobriety battery is given (i.e., instead of using a portable breath analyzer) is to show that the driver's performance is impaired. In this sense, the field subriety teats wut be content referenced, so that the police officer can observe what the suspect can do. However, the police officer in oome areas also may know from experience that no matter how impaired the suspect's performance is, the suspect will not be convicted of draving wile intoxicated unless the individual's BAC is above $0.15 z$ or convicted of reckless driving unless the individual's BAC is above $0.10 \%$. Thus, the police officer is also ioterested in norm-referenced test 80 that he can estimate the BuBpect'B BAC.

\section{Field Observation}

A critical phase of our pilot testing involved observing a highly efficient traffic team working out of the Los Angeles Central Police Facility which opecializes in arresting intoxicated drivers. These officers were all using nystagmus in their sobriety testing. We noticed from observing their arrestees that the angle of onset of the nystagmus, which occurs as they follow a moving object to the side with their eyes, occurs with fewer degrees of lateral 
deviation (i.e., with lesa lateral movement) as the BAC jncreases. In addition, the magnitude of the nystagmus at extreme lateral deviations is much larger with increasing BACs (i.e., the jerking, movement is 1 arger).

Second, we learned that a divided attention task could be incorporated into the walk-and-turn test by having the suspect stand heel-to-toe on the line while the directions of the test are being explained. An intoxicated person can typically either listen to the instructions or keep his balance, but cannot do both.

\section{Pilot Subjects}

Twenty-five subjects were given alcohol and run as pilot subjects in the laboratory. Initially, three subjects were used to rule out many of the unimportant variables in the three tests. Fifteen subjects were then run to determine the effectiveness of the more important variables and to aid in determining how the test battery should be scored. Five subjects were tested hourly for 18 hours - both sober and at a BAC of $0.10 \%$-. to determine the combined influence of alcohol and fatigue. Finally, we also tested 42 sobet subjects for nystagmus in order to determine the effects of age, visual acuity, and alcoholism history on the incidence of nystagmu in sober subjects. The results of these pilot studies are summarized below as they relate to each of the three tests in the sobriety test battery.

a. Walk-and-TuIn Test. The suspect is asked to assume a heel-to-toe position on a designated line, with his/her arms at the sides, while the remainder of the instructions are given. He or she is then told to make nine heel-to-toe steps on the line, ts: turn around keeping one foot on the line, and to return in nine heel-to-toe steps. The suspect is requested to watch his/her feet at all times, making sure that every step is heel-to-toe and that the steps are taken in a straight line.

Asking the suspect to balance heel-to-toe while listening to the rest of the task instructions effectively creates a divided attention task in this test. We found that this addition greatly ioprcued the sensitivity of the test to alcohol. Intoxicated cubjects either keep their balance, while ignoring the subsequent instructions, or are unable to keep their balance while listening to the instructions. The sensitivity of this addition to the task supports the contention of Moskowitz (1973) that divided attention tasks are vers ansitive to alcohol intoxication.

Requesting that people "watch their feet" while performing this test slso increases its sensitivity to alcohol, but makes the task difficult for people with monocular vision (i.e., poor depth perception). Performing the walk-and-turn task with the eyes open with enough light to see some frame of reference is essential if sober individuals are to perform the test without difficulty. Finally, we found that the time taken to walk the line and the number of steps taken were relatively unimportant variables in terms of altering the sensitivity of the test to alcohol. 
Certain individuals have difficulty with this test when sober, including: people over 65 gears of age; people with back, leg, or middle-ear problems; and people with high-heeled shoes (over two inches). We recommend that only the nystagmus test be used with the first four categories of stopees, while people with high-heeled shoes should be asked to remove them.

Standerdizing this test for every posaible road condition bas beyond the cope of ehi project, so we recommend that the walkmandturn test be performed on a dry, hard, levei, nonsilppery surface and under relatively safe conditons. If these requirements cannot be met at roadside, we recommend that the suspect be asked to perform the test elsewhere or that only the nystagmus test be used. The test also requires a line which the police officer can manufacture. Finally, the police officer and the suspect should be able to comminicate fluently. Performance of this test was not worse under the combination of alcohol and fatigue in the 24 hour pilot study of circadian effects, than under alcohol alone.

b. One-Leg Stand Test. The suspect is asked to stand with his/her heels together, feet at a slight angle and arms at the sides. He or she is then asked to raise one leg about six inches off the ground (i.e., with both legs kept straight) and to hold that position while counting rapidly from 1001 tol030. Either leg mas be $r$ aised.

Generally, few variables alter the sensitivity of the one-leg stand test. The most sensitive variable was time. We found that a suspect at a BAC of $0.10 \%$ might easily keep his/her balance for 20-25 seconds, but would likely falter after that time period. Consequently, the officer must ask the stopee to count aloud from 1001 to 1030 in order to estimate the pasage of 30 seconds.

Two other important variables are that: (1) the suspect must be able to see in order to orient himself or herself; and (2) the police officer must stand back from the suspect in order not to provide an artifical reference frame which could distract the suspect. Generally, if the stopee cannot see or orient with respect to a perpendicular frame of reference, then this test will be difficult to perform even if sober.

Certain individusls will have difficulty performing this test under sober conditions, including: people over 65 gears of age; people vith leg, back, or middle ear problems; people who are overweight by 50 or more pounds. These individuals ohould only be given the nystagmus test. Suspects who are wearing over two-inch hefls should remove them before performing the test.

The one-leg stand test should be performed only on a hard, dry, level, nonslippery surface under relatively safe conditions. When these requirements are not met at roadside, then the stopee shoula be asked to perform the test elsewhere or only the nystagmus test should be used. Performance on the one-leg stand test was no worse than alcohol alone under the combination of alcohol and fatigue in the 24 hout circadian pilot study. 


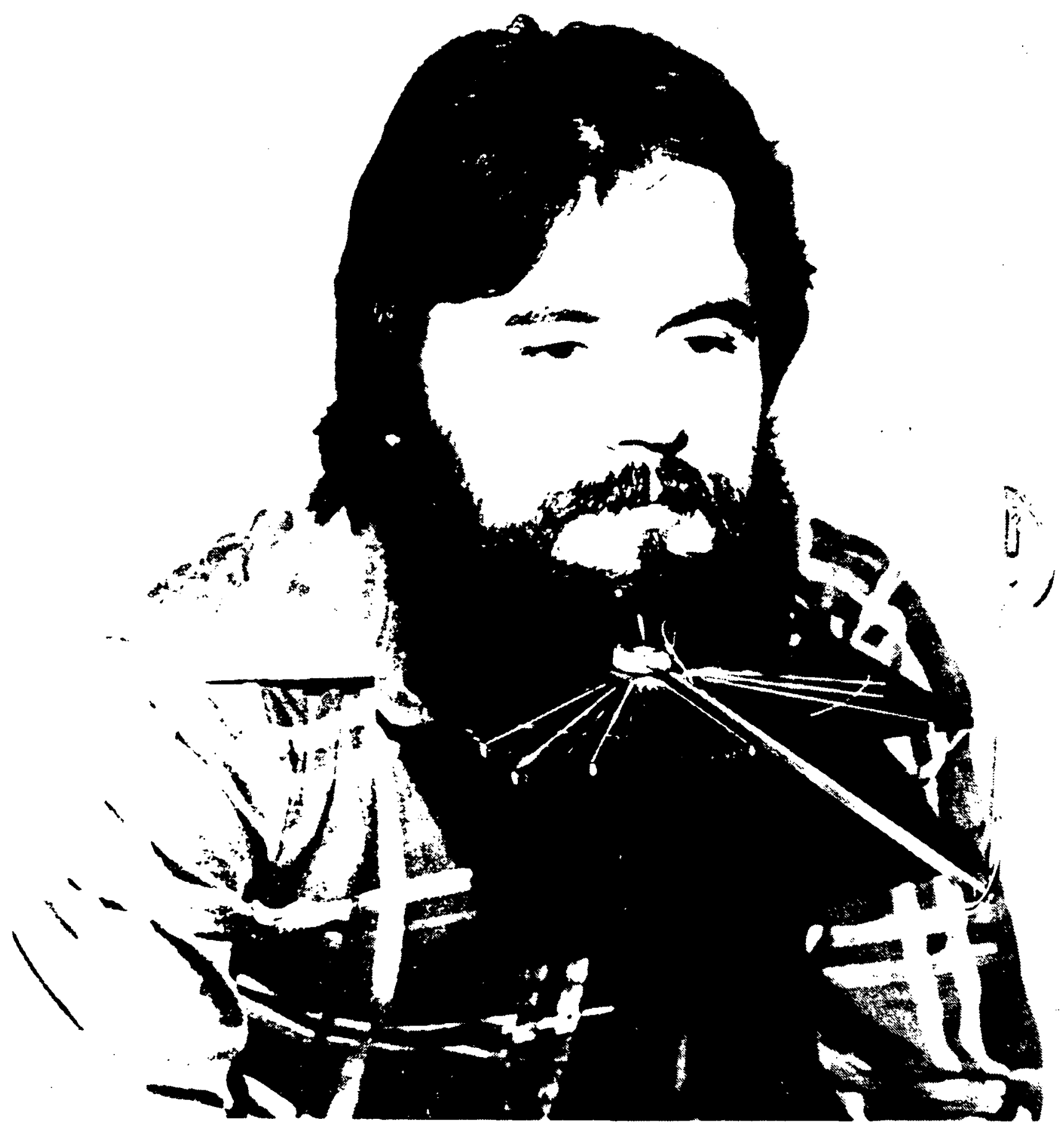

FIGURE 1 NYSTAGMUS DEVICE. ANGLES ARE PRINTED ON THE FRONT OF THE DEVICE FOR EASIER READING. 
c. Gaze lystagmus Test. Gaze nystagmus is a jerking movement of the eyes that sometimes can be seen when the eyes are deviated to theit lateral extremes (Toglia, 1976). The jerking has a slow and fast phase, with the fast phase being in the direction of the gaze (Goldberg, j.963). Gaze nystagmus is considered to be pathological when it occurs at a less extreme lateral gaze (Toglia, 1976), such as with brain damage or depressant drugs.

We ahecked for nystagus in 42 sober individuals, including 27 former alcoholica and 25 at af members. Approximately half of the people tested showed a slight nystagmus in at least one eye when their eyer were deviated maximally. The occurrence of nystagmus in these sober individuals was not related to (1) age, (2) visual acuity, or (3) a bistory of alcoholism. We did notice that the maximal. angle of deviation, measured trice by each of two observers using the device shown in Fjgure 1 was 3.03 degrees 1 arger in the left eye than in the right eye $(t, 40,=5.8, p .001)$. This occurred jo 28 of the 42 subjects and was not related to hauledneso. We aw no tendency for nystagmus to occur more often in one eje than the other.

A strorg cctrelution exists between the BAC and the angle of onset of the njstagus. Regression lines for the right and left eyes are illustrated in Figure 2. The correlation between the angle of $0 \delta s e l$ and the $B A C$ was -0.78 for the left eye and -0.74 for the right eye. In every pilot subject, the angle of onset decreased as the BAC increased and vice versa. Both correlations obtained were quite close to the -0.788 correlation reported by Lehti (1976) between the BAC and the angle of onset (measured in five degree increatits) for 56 arrestees at the time of arrest. We found that at a BA? of $0,10 \%$ nyetagmus onset occurs at about 41 degrees of lateral deviatiza.

In our initial filot work with gaze nystagmus in intoxicated subjecte, ve were able to rule out a number of unimportant variables. These variables include: (1) stimulus brightness; (2) rocu trightness; (3) fixation distance; (4) velocity of the stimul:s woiedent; (5) monocular versus binocular fixation; (6) inetiurtinns to inhibit nystagmus; and (7) the vertical fosifioniry of the eyes. Some of these variables, however, are importan: in aiding an observer to record the occurrence of ny6:agius. As a rebult, we recommend the following edministration piocedure:

Firat. Lirrective lenses should be removed. The stimulus should be placej bove the eyes in order to elevate them and reduce squintigg. At: night, if the street lighting is inadequate, a penligit mist be used as the stimulus or a flashlight is required to illumirate the face. In looking for the onset of nystagmus, we recompend that the etimulus be moved fairly slowly (i.e., at about 10 degrees per second), but not too slowly, otherwise normal oscillotion of the eyeball may be mistaken for nystagmus. The suspect sholi?d keep bis/her head still. The officer's free hand maker a good chin rest for suspects who persist in moving his/her head. The officer should move the stimulus twice to the left and 
FIGI'RE ?

REGRFSSION OF ANGLT. OF ONSET ON BAC

rOR TIE R: TI: AID LETT EYES

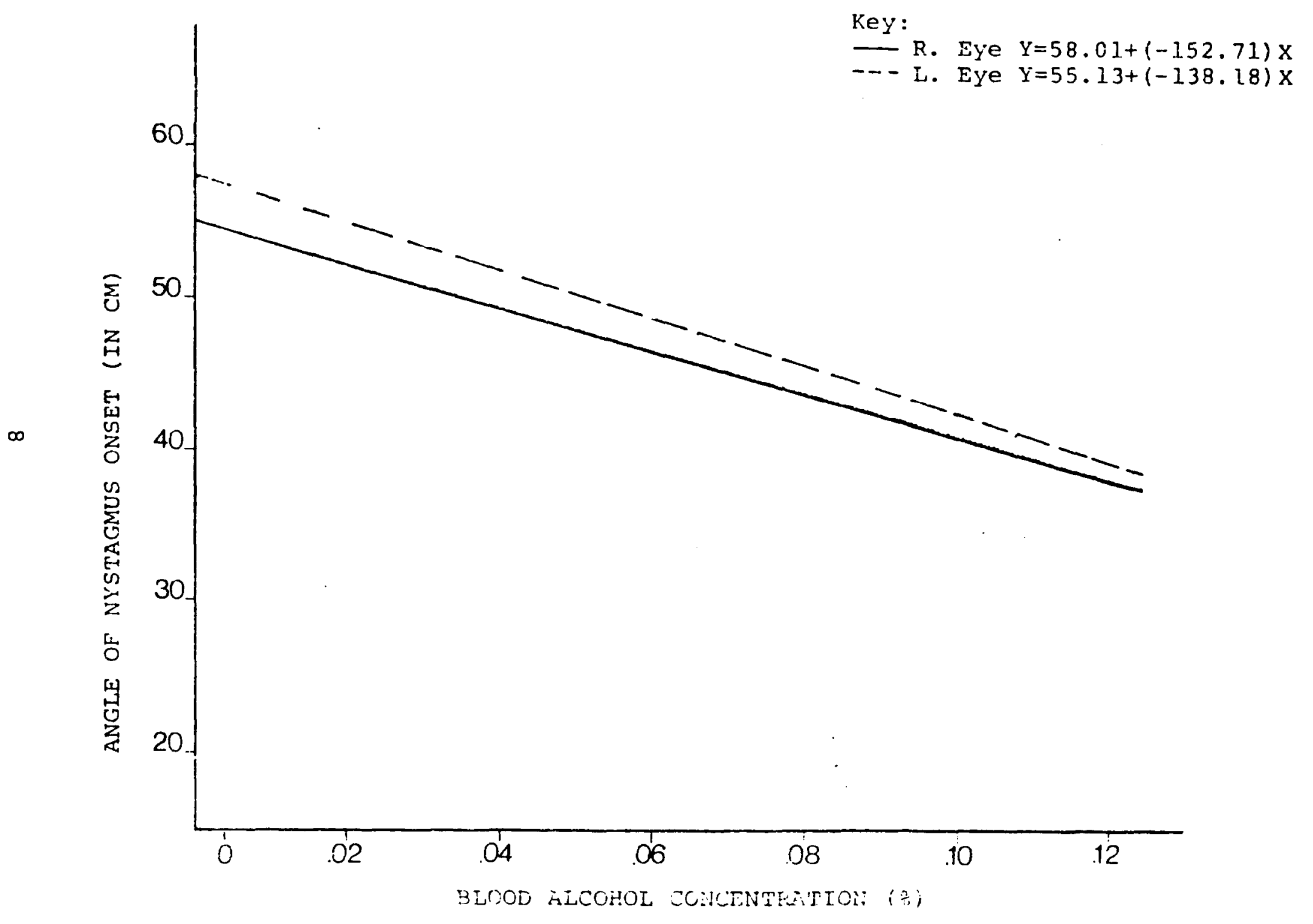


twice to the right, looking at the eye on the side of the head to wich he is moving the stimulus. On the first movement, the officer should observe whether or not the onset of the nystagmus occurs before 45 degrees with at least $10 \%$ of the conjunctiva (i.e., the white of the ege) ghowing. The 45 degree angle is easy to estimate as it splits the angle connecting the tip of the nose and the center of the ear with the middle of the head. Some individuals cannot deviate their eyes more than 45 degrees, so at least $10 \%$ of the white of the eye must show to ascertain that nystagmus is not occurring at the most extreme deviation for that individual.

The second movement in each direction should be faster (about 20 degrees per second) and the observer should note whether or not the suspect can follow smoothly and how distinct the ngatagmus is at the maximum lateral deviation. The breakdown of the smooth pursuit and greater amplitude nyatagmus at maximum deviation are also good signs of a BAC over $0.10 \%$. Thus, the police offier has three eye Bigns to look for: (1) onset of nystagmus before 45 degrees; the distinctaess of the nystagmus at the maximum lateral deviation; and (3) the breakdown of smooth pursuit eye movements.

The gaze nystagmus test may not be applicable to individuals wearing contact lenses, Bince hard contacts may prevent extreme lateral ege movements. About 37 of the population will show earlg-onget ngotagmus, and impaired balance, with no alcohol in their system. This nystagmus could be the result of drugs other than alcobol (e.g., barbiturates or phencyclidine), the result of brain damage, of iliness (e.g., Rorsakoff"s gyndrome), or of unknown etiology.

Since police officers often arrest intoxicated persons after midnight, poseible effects of fatigue or circadian rhythms on gaze ngstagmus could be oignificant. Five subjects were individually checked for ngstagmus each hour between 9 a.m. and $4 \mathrm{p} . \mathrm{m}$. and between $5 \mathrm{p} . m$. and 4 a.m., at a BAC of $0.10 \%$ and without alcohol. Thus, bubjects came to the laboratory four times: (1) between 9 a.m. and 5 p.m. with no alcohol; (2) between 9 a.m. and 5 p.m. at a maintained $B A C$ of 0.107 ; ( 3 ) between $5 \mathrm{p} . \mathrm{m}$. and $4 \mathrm{a} \cdot \mathrm{m}$. when sober; and (4) between 5 p.m. and 4 a.m. at a maintained BAC of 0.102 .

Figure 3 illugtrates the angle of onset plotted against time for al four conditions. Onder sober conditions when no nystagmus was seen, the maximum lateral deviation was recorded. These data were divided into four-hour segments and analyzed with a fully repeated ANOPA, with the factors being alcohol and time. There was a significant alcohol effect on angle of onset with the drug decreasing the angle of onset by about 15 degrees. There was also a significant interaction between the effects of alcohol and time in that the alcohol dose decreased the angle of onset by an additonal 5 degrees (i.e., by 20 degrees) aftermidnight. In all cases the angle of onget had returned to the baseline level at about 9 a.m. the following morning, at which time the BAC was 0.027 or less and the subject had slept 5 bours. The average BAC 


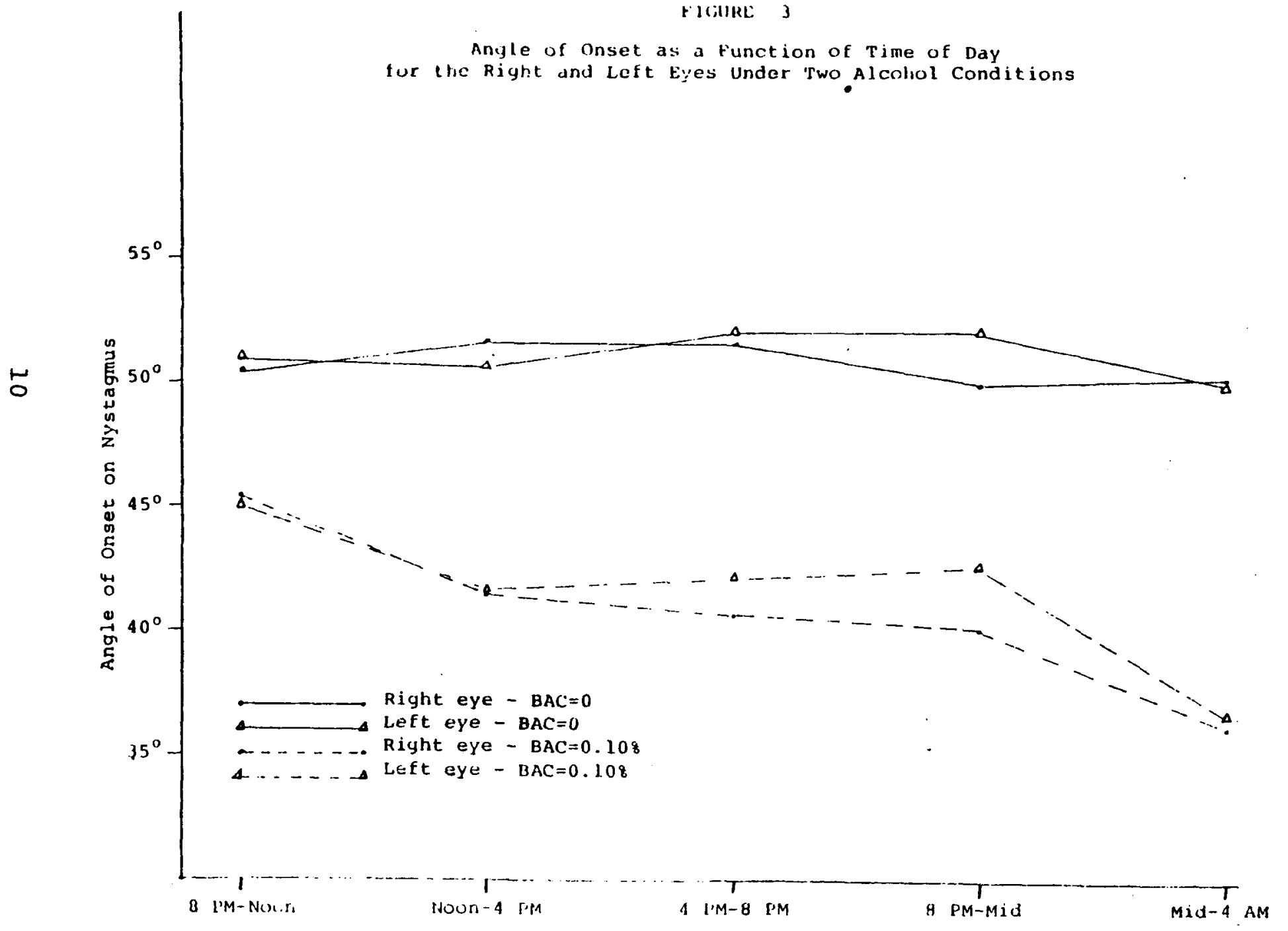


fluctuation between test periods under alcohol was less than 0.017 . When the observed BAC was introduced as a covariate, only the interaction between the effects of the drug and time remained significant. 
TABLE 1

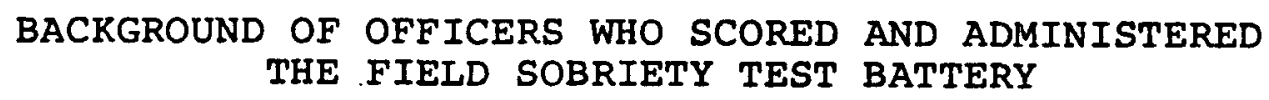

\begin{tabular}{|c|c|c|c|c|c|c|}
\hline \multicolumn{2}{|c|}{ OFFICER } & FORCE & \multirow{2}{*}{$\frac{\begin{array}{c}\text { YEARS } \\
\text { EXPERIENCE }\end{array}}{9}$} & \multirow{2}{*}{$\begin{array}{c}\text { DWI } \\
\text { STOPPEES } \\
7,000\end{array}$} & \multirow{2}{*}{$\frac{\begin{array}{c}\text { DWI } \\
\text { ARREST }\end{array}}{1,750}$} & \multirow{2}{*}{$\begin{array}{c}\text { SUBJECTS } \\
\text { TESTED } \\
46\end{array}$} \\
\hline$\#$ & 1 & LAPD & & & & \\
\hline$\#$ & 2 & LAPD & 13 & 8,000 & 2,400 & 48 \\
\hline$\#$ & 3 & LACSD & 1 & 5 & 4 & 42 \\
\hline$\#$ & 4 & LACSD & 8 & 350 & 250 & 40 \\
\hline$\#$ & 5 & CHP & 13 & 3,000 & 300 & 43 \\
\hline$\#$ & 6 & $\mathrm{CHP}$ & 7 & 3,500 & 900 & 42 \\
\hline$\#$ & 7 & CHP & 13 & 300 & 240 & 45 \\
\hline$\#$ & 8 & LACSD & 4 & 25 & 8 & 43 \\
\hline$\#$ & 9 & LAPD & 9 & 5,000 & 750 & 47 \\
\hline$\# 1$ & & LAPD & 19 & 10,000 & 3,000 & 45 \\
\hline
\end{tabular}

LAPD - Los Angeles Police Department

LACSD - Los Angeles County Sheriff's Department

CHP - California Highway Patrol 
Once the scoring and administration procedures had been standardized, a laboratory atudy was conducted to evaluate the validity and reliability of the standardized teat battery. Ten police officers administered and scored the tests. They also made judgements as to whether the subject (i.e., the testee) was too impaired to drive, whether the testee should be arrested, and estimated the person's BAC. Each police officer tested approximately 30 people with BACs ranging from zero to $0.18 \%$. The performance of each testee was also scored and evaluated by a trained observer so that interrater reliabilities could be assess8ed. In addition, half of the subjects returned to the laboratory and were retested under an identical alcobol dose. Thus, test-retest reliabilities were also assessed. This chapter details the procedures involved in the laboratory evaluation and presents conclusions regarding the validity and reliability of the test battery.

\section{A. LABORATORY PROCEDORES}

1. Police officers, Observers, and Laboratory Participants

Ten police officers were recruited to administer the test battery. The officers came from various police agencies in the los Angeles area and varied considerably in experience as indicated in Table 1. Two trained research assistants served as observers.

A total of 297 individuals participated in the study, including 202 males and 95 females. One of the 95 females, dosed to $0.05 \%$, was unable to participate in the evaluation due to illness. One hundred forty five of the 296 first-time participants returned for a second session.

Table 2 compares the age and sex of the 296 participants with the age and sex of the 3128 stopees from the field evaluation (see Chapters 3 and 4 ) and the 384 stopees who were suspected of being under the influence of alcohol by the police in the field evalustion. The distributions are quite close, except that fewer people suppeted of being under the influence of alcohol were female in the field. In addition, individuals under 21, who could not be given alcobol in the laboratorg, represented $23.8 \%$ of all stopees and $14.2 \%$ of the stopees suspected of drinking.

The experience of the SCRI staff in administering alcohol to people witb different drinking histories indicates that dosing limits must be set according to drinking historg to avoid overdosing subjects. Volunteers with a "heavg" drinking historg, as determined by the Q-P-V questionnaire of Cabalan, Cisin, and Crossley (1969), can be dosed to a maximum BAC of 0.15z; those with a "moderate" drinking bistory can be dosed to a maximum of $0.11 \%$; and those with a "light" drinking history can be dosed to a maximum of $0.05 \%$. In order to include light, moderate, and heavy drinkers in the 
TABLE 2

AGE AND SEX COMPARISON OF LABORATORY

PARTICIPANTS WITH STOPEES FROM THE FIELD EVALUATION

\section{LABORATORY}

NUMBER
MALE
FEMALE
LESS THAN 21
$21-24$
$25-34$
$35-44$
$45-54$
$55-64$
65 AND OVER

297

$68.0 \%$

32.08

0.08

$33.8 \%$

48.28

8.88

6.18

2.48

0.78
STOPEES

3128

74.58

25.58

$23.8 \%$

18.98

28.88

13.58

9.48

4.08

1.58
ALCOHOL SUSPECT STOPEES

384

89.18 10.9 \%

$14.2 \%$

$18.4 \%$

32.18

18.28

$13.2 \%$

3.28

$0.8 \%$ 


\section{FIGURE 4}

\section{DRINKING HISTORY}

(n)

FIGURE 4 Assignment of participants to cells according to BAC and drinking history on session $1 \& 2$ (in parentheses). 
laboratory evaluation, together with a wide range of alcohol doses (i.e., placebo to $0.15 \%$ ), the design illustrated in Figure 4 was used. Each cell should contain appoximately 33 first-session participant and 17 returnees (in parentheses in the figure), so the greatest shortfall in any cell was 3 subjects.

Of the 296 original participants, $60(20.37)$ reported being stopped by the police while driving after drinking. These 60 participants included 44 heavy drinkers, 14 moderate drinkers, and 2 light drinkers.

\section{Training Procedures for Police officers}

officers were trained in pairs during a balf day training session Beveral days prior to testing participants. Each officer was given a copy of the training manual, which was similar to the manual submitted as volume 2 of this report, and was requested to read it. At the training session held at SCRI, the Project Director then went through the manual page by page with each officer, clarifying difficulties and emphasizing important items.

The officers were then asked to estimate lateral deviation angles of the eyes using the device illustrated in Bigure 1 . This procedure amounted to covering the markings on the device and asking the officers to estimate 30 and 45 degrees of lateral deviation on the eyes of various staff members. For this training ve tgpicalig used one staff member whose eyes would only deviate to about 43 degrees and another whose eyes would deviate as much as 65 degrees. The officers were given immediate feedback on their estimations and, if they had trouble, other people were brought in for testing until they could estimate the angles within three degrees of the reading on the device three consecutive times.

Finally, two to four people, several of whom had been drinking, vere tested with the entire field sobriety test battery. One staff member with no vision in his left eye and a bad left inner-ear (i.e., his ability to balance when bober was markedly impaired) was always included anong the people tested. This preliminary testing allowed the Project Director to observe each officer administering the test battery. This training procedure brought all officers to a criterion level of performance in test battery administration.

\section{Testing Procedures}

B. Participants. Subjects were required to agree not to consume any alcobol for 24 hours prior to arriving at SCRI and not to consume any food for at least four hours prior to their arrival. Approximately 957 to 977 of the volunteers complied with these requests. Three people arrived at SCRI with a BAC of $0.05 \%$ or greater and 12 people admitted eating prior to their arrival at SCRI.

Volunteers were 180 asked not to consume any drugs for 24 hours prior to their testing. We were especially concerned about drugs which might produce additive effects with alcohol, so each subject 
was tested for ngstagmus using the device pictured in Figure 1 prior to being given alcohol. Individuals showing moderate to trong njotagus at their maximum deviation were given a placebo dose. These people vere high risks for being "false positive" classifications (i.e., the police officers would claseify them as being over $0.10 \%$ when they were not) when tested. Thus, the placebo group was actualig biased so that actual roadside decisions might be better than the laboratory decision, depending upon the unknown factor of the incidence of drug use among police stopees. SCRI chose to increase the probability of a false positive classification with these people rather than risk that they had consumed drugg which.might cause them to become seriously il if they also consumed alcohol in the laboratory. However, only 13 such individuals were found representing $4.4 \%$ of our subjects. Although actually at a zero BAC, only one of these individuals was estimated to be over $0.10 \%$ by the officers and four of them were estimated to be over $0.10 \%$ by the SCRI observers.

Participants were scheduled on weekend days between May 6, 1979, and July 1, 1979. During each of these sessions, two subjects were asked to arrive at SCRI at the same time at prescheduled 15 minute intervals between 7:30 a.m. and noon. Thirty eight time slots per digy thus were allowed for subjects, estimating that approximately $30^{\circ}$ pople would actualig cometo the laboratory.

Subjects were each given three drinks containing orange juice mixed with rodka according to their assigned dose level. Each of the tbree drinks was to be consumed in half hour. The importance of drinking all three drinks for the study was stressed, but subjects were also advised to stop drinking if they thought that continuing might make them ill. Eight people (2.9\%) failed to consume all three drinks. These subjects, except for the female who became ill and was never tested, were reclassified into a lower alcohol dose group.

One half hour after finishing the 1 ast drink, a subject's BAC, as measured by analyois of breath samples by an Intoximeter, and angle of onset for njstagmus, measured with the device measured in Figure 1, were determined by a trained resesrch assistant. This information was withbeld from the participants, who were then shown to a room where an officer and an observer were located for testing purposes. After the testing had been completed, a second BAC was taken on the Intoximeter and the subject was told the approximate time he or she could leave the laboratory. No subject was allowed to leave until bis or her BAC fell below $0.03 \%$. Subjects were then given lunch (also dinner for those staging long enough). Each participant, prior to leaving, was asked whether or not he or she wished to participate a second time. Returnees were then selected by the Project Director from a list of those desiring to return. Those who fit the needs of the study in terms of dose (i.e., subjects were given the same dose on the return session) and drinking bistory were asked to return. No subject desiring to return was given feedback about his or her performance or dose level until the completion of the second session. 
b. Officers and ubservers. Officers and observers reported to the laboratory about 9 a. to set themselves up in the testing rooms. Bach officer-observer pair was isolated from contact with the participants and with the other officer-observer pair. On the first teating day officer-observer pairs remained together the entire day. On the second testing day the two observers owitched places. Finally, on the third testing day (i,e., the repeat session), the two observers switched places after testing about seven participants. Officers and observers are collectively called "raters" or "testers" in the remainder of this report.

Participants were teated at 15 minute intervals between 9 a.m. and 2 p.m. When a suject reported for testing, he or she was quizzed by the officer (1) on how much alcohol had been consumed; (2) on how intoricated he or she felt; and (3) on any medical problems which might contribute to poor performance. The officers also asked the participant to blow into his hand to determine if an odor of alcohol was present. Appendix B contains the entire list of questions asked by the officer, together with the test instructions, the scoring sheet and the decision sheet. The observers generally asked whatever questions the officer might have skipped or forgotten.

A number of the participants, despite being advised to behave as they would if they had been stopped at roadside by a police officer, promptis informed the testers that they vere much too drunk to drive a car. This information was often very misleading, because the placebo effect for light drinkers in this study was very strong. Heavg drinkers, on the other hand, tended to say that they would have no trouble driving even when they had been dosed to 0.157 . All participants were given three drinks, regardless of the alcohol dose, so they generally informed the police officer that they had consumed three drinks. The testers were not able to get much more information from questioning the laboratory participants than they would from questioning roadside stopees. Some of the responses to the officers' questions may have been quite unusual for roadside stopees, since our subjects were not afraid of being arrested and a strong placebo effect is not likely to occur at roadside. When questioned about the content of the drinks, the answers included the following: "orange juice;" "they were about like you would get at a bar" ( $t h i s$ was a placebo subject); "the firat two just tasted like water, but I'd tip the bartender for tbe last one."

After questioning the participant, the officer administered the field sobriety tests described in chapter I using the instructions given in Appendix B. Finaly, after the participant left the testing room, the officer and the observer independently (1) decided vhether they would arrest the individual, if that person had been stopped at roadside; (2) decided whether the individual was too impaired.to drive; and ( 3 ) attempted to estimate the BAC of the individual to within $0.01 \%$. For the latter two judgements tbey 180 included a confidence rating, consisting of a number from one to ten with ten being the most confident. Decision criteria, based on the pilot tests for the project, were included on the 
decision sheet (also given in Appendix B) but were not necessarily followed by the testers. After the participants left the room, the observer was allowed to comment upon the officer's administration of the test battery if such comments seemed warranted.

\section{B. TEST BATTERY VALIDITY}

Validity refers to the degree to which o test messures what it is designed to measure, which in the case of field sobriety tests, is the impairment produced by alcohol. The primary criterion by which the test battery was evaluated, the Intoximeter reading, presents a problem because no absolute impaiment threshold exists for alcohol. Individuals vary in alcohol tolerance. An infrequent drinker mag be severely impaired at a BAC of $0.05 \%$, whereas a heavy drinker may show only minimal impairment at this level. Experienced traffic officers in Los Angeles claim they do not use BAC as an arrest criterion and only arrest when they feel that a driver is too impaired to drive. Their only concern for BAC is that a conviction may not be obtained, regardless of the amount of impairment, if the BAC is too low. This is a common problem in otates that do not have per se laws (i.e., automatic conviction when the BAC is above a particular level).

The average BAC of those arrested for DWI across the United States is $0.17 \%$ (NHTSA, 1972). The primary goals of atandardized field sobriety test battery are to lower the average BAC of the arrestees, to give police officers a more sensitive index of impairment, and to give police officers more consistent evidence for court use. Because of the problems mentioned above, these gosis are not synonymous. Thus, the criteria for determining the validity of the test battery are not straightorward. The Intoximeter reading, the most objective criterion available, is used in this report.

\section{BAC Estimates}

Since both police officers and observers estimated the BAC of each participant, one measure of the validity of the test battery is to compare the estimated BAC with the actual BAC. The mean difference between these two measures indicates whether or not their errors of estimation were unbiased ( $i$,es, were consistently overestimated or underestimated). The mean absolute difference between these two measures indicates the average amount of error.

The mean BAC eBtimate of the officers differed from the actual BAC readings by 0.00057 . None of the officer's estimates were ignificantly different from the actual BAC reading. That is, overestimates and underestimates cancelled each other, indicating that the errors were unbiased. One observer, however, consistently overestimated the BAC by an average of 0.01267 (t $221=4.67$, p< $.001)$.

The means for the absolute value of the differences between the 
estimated BAC and the actual BAC for each officer and each observer are given in Table 3. The absolute value of the differences between the officer estimates and the actual BAC averaged $0.030 \%$ $(a=0.026)$ and the same average was obtained for the absolute differences between the observer estimates and the actual BACs.

\section{Impairment and Arrest Decigiong.}

The officers and observers were also asked to decide whether or not an individual was too impaired to drive and whether or not the individual should be arrested. The raters agreed that they would "arrest" participants estimated in the range of 0.067 to 0.087 who were obviously impaired. Test performance, using the criteria given in Appendix B, was used to index impairment.

Ho officer ever arrested a person that he did not also rate as being impaired. Conversely, few participants were rated as being impaired who vere not also "arrested." The three officers from the Los Angeles County Sheriff's Department, who generally had the least field experience, were exceptions and only "arrested" $60 \%$ to $75 \%$ of those they considered to be too impaired to drive. The data indicate that when an officer made a "no arrest" or a "not impaired" decision, his estimated BAC on the average was less than the actual BAC. On the other hand, when an officer made a decision to "arrest" or decided that the participant was "impaired", then bis estimate of the BAC was generalig higher than the actual BAC. This trend is probably even more pronounced in the field evaluation.

Table 4 gives the percentage of subjects at each dose level who vere "arrested" or considered "impaired". These dataclearly indicate that the officers used more conservative criteria than the observers. Consequently, observers "hit" virtually all participant given bigher doses of alcohol, but at the cost of "arresting" more lov dose subjects.

Tbe individual rater's "arrest" and "impaired" criteria were calculated by determining the estimated BAC at which these decisions were made. Tables 5 and 6 present each rater's "arrest" and "impaired" criteria, respectively. Some officers vere not consistent with theit criteria, so the value was taken to be the eBtimated BAC for which more "arrest" (or "impaired") decisions were made than "nonarrest" (or "nonimpaired") decisions. Overall, tbe officers' arreat criterion was $0.08 \%$. However, a few placebo oubjects vere "arrested" because their performance indicated substantial impairment. In many caseb, these were genuine placebo effects.

3. Ability to Clasoify Subjects with Respect to 0.107 BAC.

If the sole criterion used by an officer for arresting a driver under the influence of alcohol were a BAC of $0.10 \%$, then how accuratelg could BACs be judged using the test battery scores? In contract DOT-BS-5-01242, officers vere able to correctly classify $76 z$ of the participants with regard to a BAC of $0.10 \%$, using the 
TABLE 3

MEAN ABSOLUTE VALUE OF THE DIFFERENCE BETWEEN THE ACTUAL BAC AND THE ESTIMATED BAC OF EACH RATER

\#CASES DIFFERENCE

OBSERVER

\# 1

$\# 2$

OFFICER

$\# 1$

$\# 2$

\#3

$\# 4$

$\# 5$

$\$ 6$

$\# 7$

\# 8

$\# 9$

\#10
222

219
.0328

.0278
.0263

.0261
45

48

42

40

43

42

45

43

47

45
.0278

.0230

.0331

.0379

.0324

.0237

.0265

.0319

.0344

.0325
.0251

.0185

.0237

.0286

.0343

.0211

.0250

.0272

.0259

.0304 
TABLE 4

\begin{abstract}
PERCENTAGE OF SUBJECTS CLASSIFIED AS "ARRESTED" OR "IMPAIRED" AT EACH ALCOHOL DOSE
\end{abstract}

\author{
FIRST TEST SUBJECTS
}

ARRESTED IMPAIRED
RETEST SUBJECTS

ARRESTED IMPAIRED

PLACEBO DOSE

$\begin{array}{lccrr}\begin{array}{l}\text { OFFICERS } \\ \text { OBSERVERS }\end{array} & 118 & 188 & 68 & 108 \\ .058 \text { DOSE } & 168 & 218 & 148 & 168 \\ \begin{array}{l}\text { OFFICERS } \\ \text { OBSERVERS }\end{array} & 228 & 318 & & \\ .11 \text { DOSE } & 328 & 388 & 198 & 218 \\ \text { OFFICERS } & & & 328 & 348 \\ \text { OBSERVERS } & 698 & 798 & & 698 \\ \text { ISz DOSE } & 798 & 818 & 628 & 938 \\ \text { OFFICERS } & & & 938 & \\ \text { OBSERVERS } & 858 & 858 & 898 & 948 \\ & 918 & 978 & 1008 & 1008\end{array}$




\section{TABLE 5}

\section{RATER'S CRITERION* FOR THE ARREST/NO ARREST DECISION}

\begin{tabular}{|c|c|c|c|c|}
\hline \multicolumn{3}{|c|}{ CRITERION } & RANGE-ARREST & RANGE-NO ARREST \\
\hline OBSERVER & 1 & .0858 & $(.058-.1658)$ & $(0-.108)$ \\
\hline OBSERVER & 2 & .0758 & $(.008-.1808)$ & $(0-.108)$ \\
\hline & $\bar{x}$ & $.08 \%$ & & \\
\hline OFF ICER & 1 & $.07 \%$ & $(.07-.198)$ & $(0-.078)$ \\
\hline OFF ICER & 2 & .078 & $(.07-.178)$ & $(0-.078)$ \\
\hline OFFICER & 3 & .078 & $(.07-.178)$ & $(0-.14 \%)$ \\
\hline OFFICER & 4 & .088 & $(.05-.168)$ & $(0-.11 \%)$ \\
\hline OFFICER & 5 & .108 & $(.10-.188)$ & $(0-.098)$ \\
\hline OFFICER & 6 & .108 & $(.10-.168)$ & $(0-.098)$ \\
\hline OFF ICER & 7 & .098 & $(.06-.168)$ & $(0-.108)$ \\
\hline OFF ICER & 8 & .098 & $(.085-.148)$ & $(0-.098)$ \\
\hline OFF ICER & 9 & .078 & $(.05-.148)$ & $(0-.068)$ \\
\hline OFF ICER & 10 & .088 & $(.08-.158)$ & $(0-.068)$ \\
\hline & $\bar{x}$ & .0828 & & \\
\hline
\end{tabular}

* ESTIMATED BAC FOR WHICH MORE ARREST THAN NO ARREST DECISIONS WERE MADE 


\section{TABLE 6}

RATER'S CRITERION* FOR THE IMPAIRED/NOT IMPAIRED DECISION

\section{CRITERION RANGE-IMPAIRED RANGE-NOT IMPAIRED}

$\begin{array}{lllll}\text { OBSERVER } & 1 & .088 & (.05-.1658) & (0-.188) \\ \text { OBSERVER } & 2 & .088 & (0-.188) & (0-.118) \\ & \bar{x} & .088 & & \\ \text { OFFICER } & 1 & .058 & (.05-.198) & (0-.058) \\ \text { OFFICER } & 2 & .078 & (.03-.178) & (0-.078) \\ \text { OFFICER } & 3 & .058 & (.05-.178) & (0-.088) \\ \text { OFFICER } & 4 & .068 & (.05-.168) & (0-.088) \\ \text { OFFICER } & 5 & .098 & (.09-.188) & (0-.078) \\ \text { OFFICER } & 6 & .108 & (.10-.168) & (0-.098) \\ \text { OFFICER } & 7 & .098 & (.06-.168) & (0-.108) \\ \text { OFFICER } & 8 & .078 & (.06-.148) & (0-.078) \\ \text { OFFICER } & 9 & .078 & (.01-.148) & (0-.068) \\ \text { OFFICER } & 10 & .088 & (.08-.158) & (0-.068) \\ & \bar{x} & .0738 & & \end{array}$

* ESTIMATED BAC FOR WHICH MORE IMPAIRED THAN NOT IMPAIRED DECISIONS WERE MADE 
same sobriety tests. Burns and Moskowitz (1977), using a discriminant analygis program, predicted that the officers could correctly clasify 837 of the subjects by making the best possible use of the information in the test baterg. The discriminant analysis essentially finds the best linear combination of scores in order to classify caser into groups based upon some criterion score, i.e., in this case based upon an actual BAC of $0.10 \%$.

Table 7 presents the percentage of correct clasifications, false positives (i.e., individuals classified as being equal to or above $0.10 \%$ who were below this level), and false hegatives (i.e., individuals who were.classified as being below $0.10 \%$ who were equal to or above this level) for each of the raters. Overall, observers correctly classified participants $82 \%$ of the time, while officers correctly classified 817 of the time. These percentages are quite similar to the value predicted by Burns and Moskowitz (1977). The officers' classifications included $9 \%$ false positives and $10 \%$ false negatives. The observer clasifications included $7 \pi$ false negatives and 117 false positives. Decision matrices for officers and observers are given in Tables 8 and 9 , respectively.

Both the police-scored data and the observer-scored data were analyzed with a discriminant analysis. This statistical procedure was not able to improve upon the clasification of subjects with respect to $0.10 \%$ for either the officers or the observers. The discriminant analysis was able to correctly classify $82 \%$ of the cases with respect to an actual BAC of $0.10 \%$ for the officer-scored data (i.e., as opposed to $81 \%$ correctly classified by the officers) and $83 \%$ of the cases using the observer-scored data (i.e.s as opposed to $82 \%$ correctly classified by the observers). The fact that the discriminant analysis cannot classify much better than the officers suggests that they did an excellent job of interpreting the test scores.

\section{Nystagmug Criteria}

Since the angle of onset of gaze nystagmus was measured on all participans witb the nystagmus device both before and after they consumed their drinks, a number of tests of the validity of this measurement can be made.

a) BAC versug angle of onset For both eyes a regression equation was calculated for the angle of onset after drinking versus the BAC and the $0.10 z$ intercept was determined. In addition, equations were calculated for the change in angle of onset versus the BAC for each eye. All four equations are given in Table 10 . Clearly, angle of onset is as good a predictor as the change in the angle of onset. The expected angle of onget for a BAC of $0.10 \%$ is 40.2 degrees for the right eye and 40.1 degrees for the left eye. These estimates are quite similar to those calculated in the pilot study of 43 and 41 degrees for the right and left eyes, respectively (i.e., see chapter I). If an angle of onset of 45 degrees as measured by the nyotagmus device prior to testing by the officers is used as the bole classification criterion (i.e., how many subjects with an onset of 45 degrees or less have a BAC of $0.10 \%$ or 
TABLE 7

CLASSIFICATION PERCENTAGES WITH RESPECT

TO A BAC OF . 108 FOR INDIVIDUAL RATERS

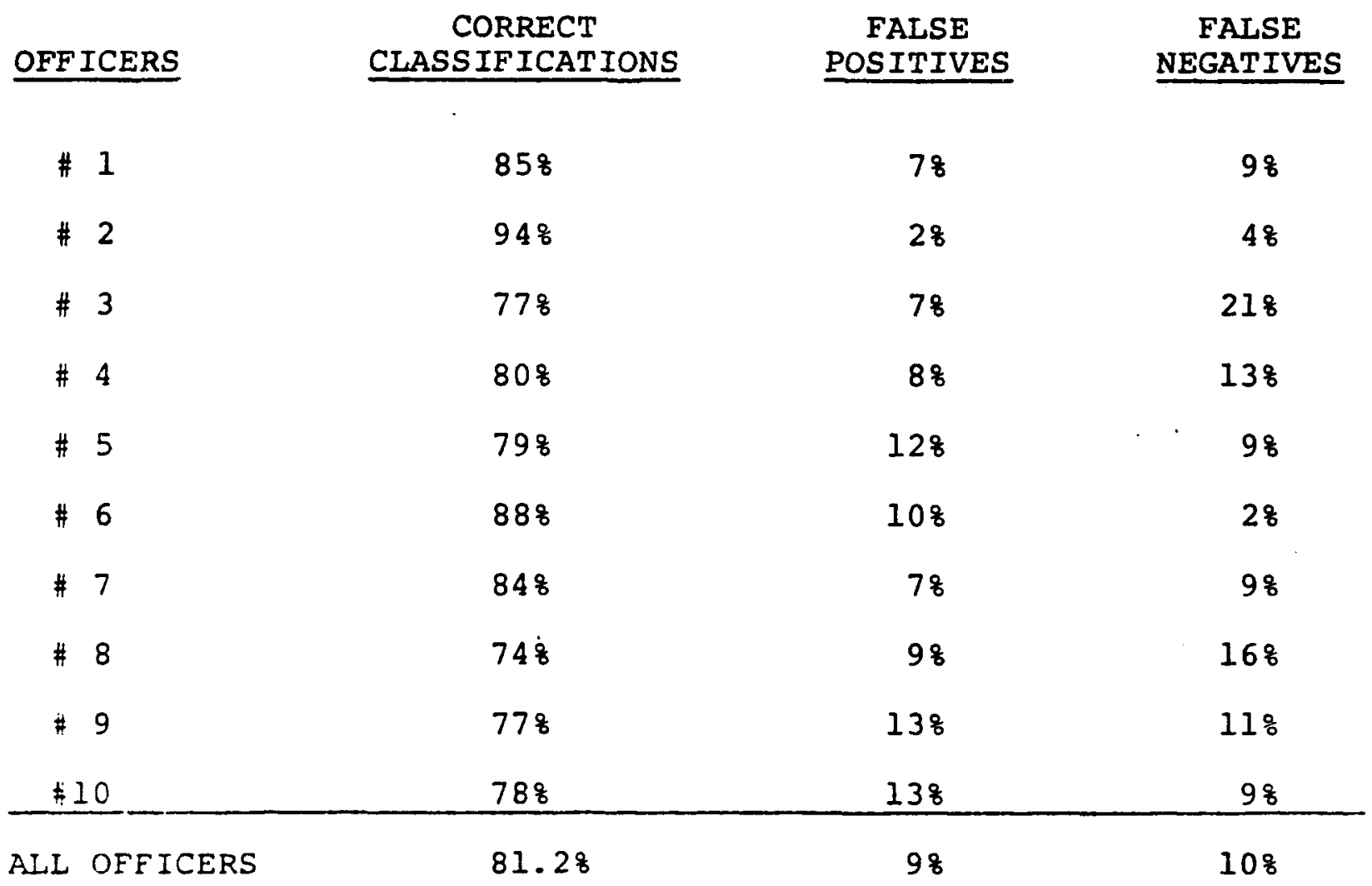

OBSERVERS

\begin{tabular}{cccc}
$\# 1$ & 808 & 148 & 68 \\
$\# 2$ & 848 & 88 & 88 \\
\hline ALL OBSERVERS & 828 & 118 & 78
\end{tabular}


TABLE 8

DECISION MATRIX FOR POLICE OFFICERS

OFFICER ESTIIIATED BAC
2.108
$<.108$
$\&$ Correct

\begin{tabular}{|c|c|c|c|c|c|}
\hline $\begin{array}{l}A \\
C \\
T \\
U\end{array}$ & $>.108$ & $\begin{array}{l}\text { HIT } \\
n=80 \\
188\end{array}$ & $\begin{array}{l}\text { FALSE } \\
\text { NEGATIVE } \\
n=45 \\
10 \%\end{array}$ & $n=125$ & $\begin{array}{c}648 \\
.\end{array}$ \\
\hline $\begin{array}{l}\text { A } \\
\text { L } \\
\text { B }\end{array}$ & $\therefore 108$ & $\begin{array}{l}\text { FALSE } \\
\text { POSITIVE } \\
n=38 \\
98\end{array}$ & $\begin{array}{l}\text { CORRECT } \\
\text { REJECTION } \\
n=278 \\
638\end{array}$ & $n=316$ & $88 \%$ \\
\hline $\begin{array}{l}\text { A } \\
\text { C }\end{array}$ & Correct & $\begin{array}{l}n=1 i 8 \\
688\end{array}$ & $\begin{array}{l}n=323 \\
868\end{array}$ & & $81 \%$ \\
\hline
\end{tabular}


TABLE 9

DECISION MATRIX FOR OBSERVERS

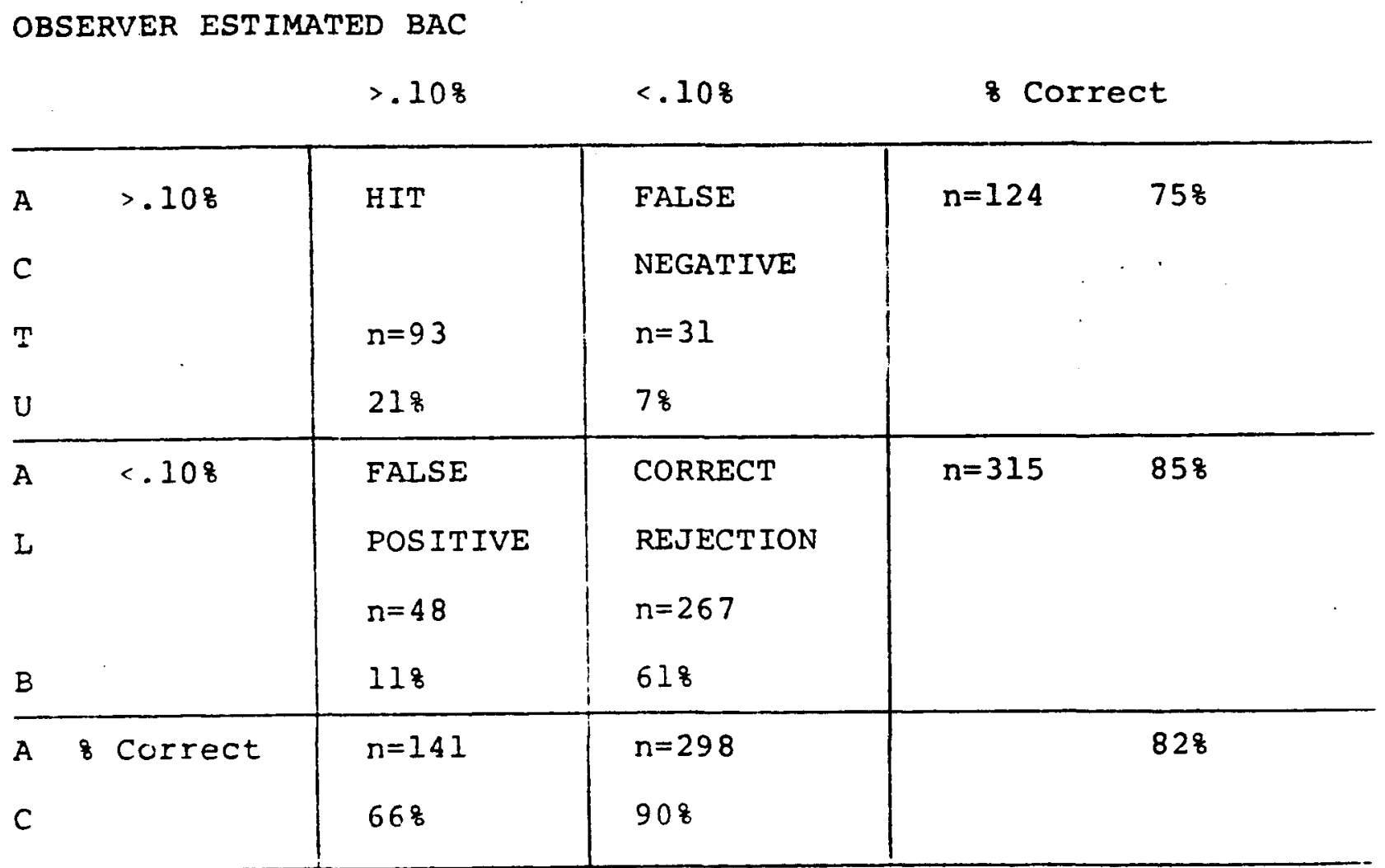


TABLE 10

CORRELATION BETWEEN MACHINE NYSTAGMUS READINGS AND BLOOD ALCOHOL CONCENTRATION

CORRELATION REGRESSION EQUATION RESIDUAL MEAN SQUARE

RIGHT EYE ONSET
LEFT EYE ONSET
RIGHT EYE CHANGE

$\begin{array}{rl}-.710 & \mathrm{Y}=50.82-100.62(\mathrm{BAC}) \\ -.717 & \mathrm{Y}=51.03-109.44(\mathrm{BAC}) \\ .664 & \mathrm{Y}=.193+96.377(\mathrm{BAC}) \\ .689 & \mathrm{Y}=.224+109.66(\mathrm{BAC})\end{array}$

25.19

438 
more, etc?), then $78 \%$ of the participante car be coriecily classified with respect to a BAC of $0.10 \%$. When the machine angle of onset is entered into a discriminant analysis, $88.2 \%$ of the participants could be correctly classified with respect to a BAC of $0.10 \%$. Clearly, nystagmus angle of onset is an excellent tool for predicting the BAC when it is messured with oufficient precision.

b) Rater entimate versus machine estimste of onset Table 11 presents correlations between the machine and rater estimates of nystagmus onset. In addition, police officers and observers were ranked 1) according to their ability to estimate the angle of onset (i.e., the correlations were ranked) and were ranked 2) according to their ability to correctly classify participants with respect to a BAC of 0.107 . These two sets of ranks (also in Table 11 ) were compared with a Spearman rank correlation. This rank correlation of 0.58 was significant ouggesting that ability to estimate angle of onset is a critical factor in making accurate decisions from the sobrietg test battery performance.

\section{RELIABILITY}

The reliability of the field sobriety tests was measured in two ways. Pirst, an experienced research assistant observed and independently ocored the subject's performance during each test administration. Observer-officer pairs were rotated and both observers worked with every officer. Thus, an interrater. reliability could be calculated for each officer-observer pairing, and, in general, between officers and between observers. Second, balf of our participants returned to be retested at the same alcobol dose. Balf of the returnees were tested by the same officer and the remainder were tested by a different officer. Similarly, half the returnees were tested by the same observer and the remainder were tested by the other observer. Thus, test-retest reliability can be calculated for the same tester and for different testers on the two sessions.

\section{Interrater Reliability}

Interrater reliability was calculated for each decision (i.e., arrest, impaired, and estimated BAC), for the total test score, and for the individual scores of each test. Note that these items range from quite objective observations such as individual test scores to decisions derived from criteria applied to the test scores (i.e., the BAC estimate) to subjective decisions remotely related to the test scores (i.e., whether the subject is impaired or should be arrested).

Iable 12 presents the overall officer-observer correlations for decisiors and test scores on each session. Several aspects of these data stand out: 1) interrater reliabilities improve on the second session; 2) total test score reliability is higher than reliability for any decision, reflecting the need to interpret the total test score to make a decision; 3) the interrater reliability is bigher for the decisions, such as the BAC estimate, that are 
TABLE 11

CORRELATION BETWEEN MACHINE ANGLE OF NYSTAGMUS ONSET AND INDIVIDUAL RATER ESTIMATES OF ONSET

\begin{tabular}{|c|c|c|c|c|}
\hline \multicolumn{2}{|l|}{ RATER } & \multicolumn{2}{|c|}{ CORRELATION } & $\begin{array}{c}\text { RANK OF } \\
\text { CLASS IFICATION } \\
\text { ABILITY } \\
\end{array}$ \\
\hline OBSERVER & 1 & .349 & 8 & 6 \\
\hline OBSERVER & 2 & .469 & 6 & 5 \\
\hline OFE ICER & 1 & .719 & 1 & 3 \\
\hline OFF ICER & 2 & .650 & 2 & 1 \\
\hline OFFICER & 3 & .583 & 4 & 12 \\
\hline OFFICER & 4 & .234 & 12 & 7 \\
\hline OFF ICER & 5 & .260 & 11 & 8 \\
\hline OFFICER & 6 & .550 & 3 & 2 \\
\hline OFE ICER & 7 & .568 & 5 & 4 \\
\hline OFF ICER & 8 & .309 & 10 & 11 \\
\hline OFEILEP. & 9 & .432 & 7 & 10 \\
\hline OFEICER I & 0 & .346 & 9 & 9 \\
\hline
\end{tabular}


TABLE 12

INTERRATER RELIABILITIES ON EACH SESSION

SESSION \#1

\section{CASES INCLUDED}

CASES EXCLUDED

NYSTAGMUS SCORE

WALK \& TURN SCORE

1-LEG STAND SCORE

TOTAL SCORE

IMPAIRED DECISION

ARREST DECISION

ESTIMATED DECISION
291

5

.62

.74

.70

.78

.58

.59

.72
SESSION \#2

143

2

.66

.83

.86

.86

.61

.58

.80 
TABLE 13

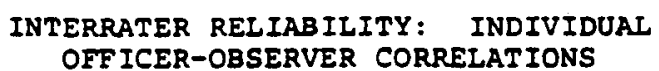
OFF ICER-OBSERVER CORRELATIONS

$\frac{\text { NUMBER OF CASES }}{\text { OBS. } 11 \text { OBS. } \$ 2} \quad \frac{\text { ESTIMATED BAC }}{\text { OBS.11 OBS. } \$ 2} \quad \frac{\text { TOTAL SCORE }}{\text { OBS. } \$ 1 \text { OBS. } \$ 2}$

\begin{tabular}{|c|c|c|c|c|c|c|c|}
\hline OFF ICER & $* 1$ & 23 & 23 & .68 & .72 & .86 & .83 \\
\hline OFFICER & 12 & 24 & 23 & .81 & .80 & .88 & .76 \\
\hline OFFICER & 43 & 19 & 23 & .81 & .77 & .87 & .82 \\
\hline OFF ICER & 14 & 20 & 19 & .66 & .78 & .81 & .83 \\
\hline OFFICER & 15 & 21 & 22 & .86 & .87 & .94 & .86 \\
\hline OFFICER & 16 & 22 & 20 & .76 & .76 & .81 & .92 \\
\hline OFFICER & 17 & 20 & 25 & .89 & .48 & .88 & .87 \\
\hline OFF ICER & 18 & 24 & 19 & .80 & .80 & .64 & .66 \\
\hline OFFICER & 19 & 25 & 22 & .77 & .76 & .93 & .80 \\
\hline OFFICER & 110 & 23 & 22 & .64 & .72 & .89 & .87 \\
\hline
\end{tabular}

NYSTAGMUS OBS. 11 OBS.

\begin{tabular}{|c|c|c|c|}
\hline OFF ICER & 1 & .61 & .49 \\
\hline OFFICER & 12 & .64 & .60 \\
\hline OFF ICER & 13 & .85 & .46 \\
\hline OFF ICER & 14 & .48 & .57 \\
\hline OFF ICER & 15 & .63 & .73 \\
\hline OFFICER & 16 & .72 & .67 \\
\hline OFE ICER & 17 & .73 & .67 \\
\hline OFF ICER & 18 & .31 & .75 \\
\hline OFTICER & 19 & .74 & .83 \\
\hline OFFICER & 110 & .67 & .5 \\
\hline
\end{tabular}

\section{1-LEG STAND} OBS. II OBS. 2
WALK \& TURN OBS. II OBS.\$2

$\begin{array}{rrrr}.85 & .81 & .92 & .85 \\ .86 & .79 & .68 & .64 \\ .85 & .90 & .76 & .71 \\ .76 & .88 & .72 & .78 \\ .81 & .82 & .67 & .92 \\ .80 & .78 & .67 & .81 \\ .85 & .91 & .79 & .79 \\ .55 & .32 & .60 & .75 \\ .81 & .71 & .85 & .66 \\ .76 & .87 & .95 & .89 \\ r=.77 & r=.76\end{array}$


most directly related to objective criteria such as the EAC estinate; and 4) the interrater reliability for the nystagmus score is not as high as expected, suggesting that the officers would profit from further training and practice with nystagmu.

The interrater reliabilities are clearly related to the extent to which the item is objective or objectively based. For example, test cores, which are behavioral ratings, reflect 1) the participant's performance; 2) the rater's understanding of the behavior being rated ( $i . e$., how well the rater understands what constitutes "putting one's foot down"); and 3) the rater's ability and motivation to record what happens. Decision scores, on the other hand, are based upon the test scores plus a subjective interpretation of the test scores in terms of some criteria. Thus, the results are not surprising.

Poor observations on the part of several individuals could lower the overall within-session correlation between the officer and the observer. Thus, correlations were computed for each officer-observer pairing for the individual test scores and for the BAC estimate. These correlations are presented in Table 13. overall, these data are quite encouraging. For the estimated BAC, $80 \pi$ of the Pearson correlations are above 0.7 with only one below 0.6. For the total test Bcores, $85 \%$ of the correlations are above 0.8 and all of them are above 0.6 .

\section{TeBt-retest Reliability}

Since 145 parcicipants returned a second time to be tested under the same alcohol dose, a test-retest reliability was calculated: 1) for those participants retested by the same officer; 2) for those retested by a different officer; 3 ) for those retested by the same observer; and 4) ior those retested by a different observer. These data are given in Table 14 for test scores and for decision scores. In addition, the correlation between the peak BACs of the two sesBions is given to illustrate that the differences in scores are not due to differences in BAC.

Note that only about $70 \pi$ of the participants agreed to return a second time and returning participant were selected based upon the needs of the study. Thus, the returnees represent a biased sample. Test-retest reliability for psychomotor tests are typically on the order of 0.7 (Guilford and Fruchter, 1978). As can be seen in Table 14, the obtained reliability is of the same order, an acceptable level under these test-retest conditions.

Between-sesion BAC estimates were compared using one-way analyses of variance and intraclas correlations, which are given in Table 15. These data indicate that BAC estimates on the same individual given the same dose vere not significantly different when made by the same rater on each session or when made by a different rater on each session. Only two of the ten officers bad aignificantly different BAC estimates when they rated the same subjects a second time. Test-retest reliability, determined by the intraclass correlation, is again on the order of 0.7 . 
TABLE 14

TEST-RETEST RELIABILITIES FOR DECISION AND TEST SCORES

OFFICERS

SAME OFFICERS

DIFFERENT OFFICERS

CASES INCLUDED

CASES EXCLUDED

77

3

64

I

NYSTAGMUS SCORE WALK \& TURN SCORE 1-LEG STAND SCORE TOTAL SCORE IMPAIRED DECISION ARREST DECISION

ESTIMATED BAC

.66

.72

.61

.77

.49

.54

.68

.59

.34

.60

.57

.56

.71

.59

BAC

.97

.96

OBSERVERS

\section{SAME OBSERVERS}

CASES IRCLUJDED

CASES EXCLUDED

NYSTAGMUS SCOPE

WALK \& TURN SCORE

I-LEG STAND SCORE

TOT'AI SCORE

IMERIRED DECISION

ARREST DECISION

ESTINATED BAC

BAC
71

2

.55

.39

.72

.73

.59

.58

.61

.96
DIFFERENT OBSERVERS

72

0

.61

.53

.55

.62

.58

.54

.67

.97 


\section{ANALYSES OF VARIANCE FOR BETWEEN-SESSION RATER BAC ESTIMATES FOR OFFICER-SAME, OFFICER-DIFFERENT, OBSERVER-SAME， OBSERVER-DIFFERENT}

\begin{tabular}{|c|c|c|c|c|}
\hline OBSERVERS & $\begin{array}{l}\text { INTERCLASS } \\
\text { CORRELATION }\end{array}$ & $\mathrm{F}$ & $d f$ & ERRORS MS \\
\hline$\frac{\text { SAME }}{\text { OBS. \#I }}$ & .515 & 0.16 & 1,38 & .00134 \\
\hline OBS.\# 2 & .738 & 3.40 & 1,33 & .00066 \\
\hline OVERALL & .674 & 1.82 & 1,72 & .00102 \\
\hline$\frac{\text { DIFFERENT }}{\text { OBS.\#I }}$ & .552 & 0.45 & 1,36 & .00076 \\
\hline OBS. \#2 & .759 & 0.52 & 1,34 & .00067 \\
\hline OVERALL & .678 & 0.00 & 1,71 & .00071 \\
\hline$\frac{\text { OFF ICER }}{\# 1}$ & .783 & 3.72 & 1,7 & .00038 \\
\hline$\# 2$ & .945 & 0.11 & 1,8 & .00020 \\
\hline$\# 3$ & .443 & 3.00 & 1,8 & .00094 \\
\hline$\# 4$ & .426 & 1.40 & 1,6 & .00165 \\
\hline$\# 5$ & .645 & 1.05 & 1,6 & .00068 \\
\hline$\# 6$ & .788 & 1.48 & 1,9 & .00076 \\
\hline$\# 7$ & .570 & $8.70^{\star}$ & 1,7 & .00045 \\
\hline$\# 8$ & .800 & $11.56^{\star}$ & 1,7 & .00016 \\
\hline$\# 9$ & .742 & 3.94 & 1,7 & .00031 \\
\hline$\$ 10$ & .459 & 0.50 & 1,5 & .00201 \\
\hline OVERALL & .665 & 1.60 & 1,79 & .00081 \\
\hline$\frac{\text { DIFFERENT }}{\text { OVERALL }}$ & .709 & 0.90 & 1,63 & .00076 \\
\hline
\end{tabular}


The primarg question addressed by the field evaluation was whether police officers, by using the sobriety test batterg, can improve theit arrest/release decisions at roadside. Three types of data were collected to anower this question. First, feasibility data were collected by talking to police officers and their superiors about the test batterg, observing the test batterg being administered and cored in the field, and talking to police officers bout their court experiences. Second, participating officers vere asked to complete data forms on every traffic stop they made during the three month study. Third, SCRI staff members rode with each participating officer at lesst three times during the study. Breath oamples vere obtained from released stopees during the ridealongs.

\section{A. POLICE $\triangle$ GENCY}

Four of the 17 stations of the Los Angeles County Sheriff's Department vere selected for participation in the study. The four stations were selected by the traffic division of the Sheriff's Department. We were told that the primary selection criteria were: (1) a cooperative administration within the station; and (2) the availability of traffic cars to be assigned to the project.

The Sheriff's Department aervices unincorporated areas of Los Angeles Count and cities within the county that contract with them for police oervices. Traffic work is only done in contract cities that request it. The California Bighway Patrol provides traffic services to unincorporated county areas.

The Sheriff's Department has been providing traffic services in this maner since 1956. Due to the major emphasis of the agency on crime and the relatively short amount of time that traffic services bave been provided, traffic duty is not highly regarded by most of the deputies. One deputy said that the general attitude is that "the only thing lower than a trafic cop is a meter maid." Thus, we were not surprised that most of the better traffic deputies that we rode with talked about leaving police work as soon as they found something better to do. We believe that the deputies participating in the study probably still are quite representative of the average traffic officer in the Dnited states, based upon our experiences working with police officers nationalig.

The traffic Bergeant we worked with were highly dedicated men who are concerned about the DWI problem and about traffic enforcement in general. In addition, the Los Angeles Count sheriff's Department was the California otate agency inpolved in the ASAP program, which may have contributed to their eagerness to participate in this program.

The four stations assigned to help SCRI with the field evaluation represented different bections of the Los Angeles Metropolitan 
1. Station A. Station A serviced an uppermiddle class city of 42,000 . The population is about $95 \%$ caucasian and about $5 \%$ Bispanic. Although the city is ourrounded by Metropolitan Los Angeles, it is quite like a rural mid-America city. The traffic 1 ights otart to flash red at $10 \mathrm{p} . \mathrm{m}$. and few cars can be seen except on one of the state highways which runs through the city. Much of the drinking and driving found in the city results from intoricated people driving away from a nearby racetrack. A secondary problem results from teenage parties in which as many as several hundred teenagers flock to a house where a drinking (drug?) party is being held. The police usually break up these parties, making few or no arrests, although we estimate that a majority of the drivers leaving these parties are legally intoxicated.

Five traffic officers from station A participated in the field eraluation. Three deputies worked shifts from 2 p.m. to 10 p.m. or from 3 p.m. to 11 p.m. The remaining two deputies worked 11 P.m. to 7 a.m. shifts.

2. Station B. We worked with three traffic deputies from Station B patroling a working class citg of approximately 29,000. The population is about $75 \pi$ Caucasian with the other $25 \%$ being composed of various minority groups. A lot of young people, who would like to live near the beach but cannot afford beach rentals, live in this citg. Drinking and driving is a common probiem in this section of Los Angeles.

The traffic sergeant at this station is very dedicated to keeping statistics on traffic accidents and tickets written. He has convinced his deputies that the more tickets they write the fewer accidents the city will have. Three traffic deputies working this citg participated in the field evaluation. They work shifts of 2 p.m. to 10 p.m., 3 p.m. to 11 p.m., and 4 p.m. to midnight.

3. Station C Station C services a heavy industrial community of about 100,000 people. Its population is $40 \%$ middle class white, $40 \%$ middle clas black, and $20 \%$ other minorities. Deputies eatimate that the city has well over 100 bars.

Six trafic deputies participated in the program, excluding one of the original aeven who was eliminated for lack of cooperation. Eacb of the deputie. worked p.m. shifts, ranging from 2 p.m. to 10 p.m. and 6 p.m. to 2 a.m. Station C has a wellorganized and cooperatze traffic administration.

4. Station D. This station services several contract cities and five trafic cars from the entire area participated in the program at the beginning. Two cars regularly worked 11 p.m. to 7 a.m. sbifts and specialized in arresting intoricated drivers. The other 
three officers vere from crime units, but were reassigned to traffic cars to participate in the field evaluation. These three deputies had sone interest in making drunk driving arrests, but no interest in making traffic stops. All of them, during ridealongs, expressed desire to return to crime unit duty.

Ve received little cooperation from the traffic administration at this station, and that administration changed twice during the field evaluation. During the course of the study the evening shift deputies filled out very few forms. When we questioned them, they claimed the forms were "at home." By the time we discovered that these deputies actually were not filling out forms, the trafic administration had been changed. Thus, the three pom. deputies were dropped from the study for noncooperation. In addition, one of the a.m. Bhift deputies stopped filling out forms as soon as he was trained on the test battery. As a result, only one deputy from this atation completed the field evaluation. Ironically, while these problems were occurring, three deputies from station c were disabled from two separate accidents involving intoricated drivers.

\section{B. STODY DESIGR}

The requirements of the field evaluation included: (1) obtaining officient baseline data againat which the officers' performance folloving training could be compared; (2) having a control group to account for such factors as the time of year (i.e., the Chribtmas Bolidays) during which the study was undertaken; and (3) the need to train all the participating deputies as a reward to the participating stations for their cooperation. Thus, a three phase design, illuatrated in Figure 5, was undertaken.

Phase I began between December 7 th and $12 t b$ of 1979 . The different starting dates were due to the fact that staff members could only visit one station at a time for startup instructions. In addition, moot atation bad to be vibited more than once because all deputies involved usully were not present at the first visit. During Phase I baseline information was collected by all deputies.

Phase II began between January $12 t h$ and $19 t h$ of 1980 . Officers from Station $\Delta$ and Station D were trained on the test battery on the weekend of January $12 \mathrm{th}$. Officers from station B were trained on the teat battery on January $19 \mathrm{th}$. One officer from station vent into the boepital for surgery on January 13 th and did not retura to duty until late January. Consequently, he was trained witb the control group. Since four deputies from station $D$ were dropped from the study (see discussion above), a total of eight officers vere trained at the beginning of Phase II and these constituted the experimental group. Seven officers (i.e., six from station C plus the one from Station A) constituted the control group.

Phase III began on Pebrusry $18 t$ group deputies were trained. continued filling out forms and at which time all of the control The experimental group deputies using the test battery during Phase 


\section{FIGURE 5 THREE PHASE DESIGN}

\begin{tabular}{c} 
CONTROL \\
GROUP \\
\hline
\end{tabular}

PHASE I

PHASE II

PHASE III
Untrained

Untrained

Trained
EXPERIMENTAL

GROUP

Untrained

Trained

Trained 
III. Phase III ended on February $16 t h$ for the six station $C$ deputies, as a nuber of them were transferred to new assignments at this time. The remaining deputies continued to collect data until February $29 t$.

\section{TRAIIIIG POLICE OFFICERS}

The deputies were trained in small groups during half day sessions. Each deputy was given training manual, similar to the one used in the laboratory evaluation. This training manual covered the history and purpose of a standardized field sobriety test; the meaning and importance of the nystagmus test; administrative procedures, including conditions under which the tests had to be administered to be considered valid; scoring procedures; and decision criteria.

The Project Director reviewed the reasons for a standardized test battery quite thoroughig so that the deputies would show as little resistance as possible to learning and using standardized scoring and administrative procedures. This review included the fact that: (1) If every officer ocored and administered the test battery in the some yay, then every officer should get the same score for a given intoxicated driver. AB a result, the test battery scores would be more meaningful as court evidence and would also allow police departments to collect their own data and develop norms. (2) General acceptance of a given test score by the courts as indicative of impairment could also help officers in filing drug charges for low BAC cases, since the test ocores would still show that the stopee was impaired.

The Project Director then reviewed the meaning and importance of the nystagmus test, covering various signs of intoxication that can be seen in the eyes. The officers were informed of theoretical speculations about the reason that nyatagmus occurs under alcohol and the differences between Alcohol Gaze Nystagmus, which appears to be Deural in origin, and Positional Alcohol Nystagmus, which is vestibular in origin. This information is given in the literature review in Appendix A of this report. In addition, the officers were informed of other potential cauber of gaze nystagmus (e.g.) drugs, brain damage, etc.).

The deputies vere then informed of what to look for in the eyes in order to determine whether or not to arrest a bopee (oee gaze nystagmus section, Chapter I). Half the deputies present then went to another room where they were informed of the importance of estimating the angle of onset of nystagmus and practiced estimating 35, 40, and 45 degrees using the device pictured in Figure 1 . Officers working a.m. obifts were told to use 35 degrees as a criterion, while p.m. shift officers vere told to use 45 degrees a a criterion. Officers were required to practice on each other until they could estimate all three angles on each other within three degrees on three consecutive occasions.

The other balf of the deputies viewed a videotape in which subjects 
performed the two balance testo. The deputies viewed the test administration and performance of three subject at a time, scoring each performance as they saw it. The Project Director and the deputies then discused the scoring until there was some agreement. The tape of the three cases was then replaged so that the deputies could see why it should be scored the way it was. Then, the videotape was played for the next three subjects in the same manner. This proces was repeated until the end of the videotape. We found that the majority of the deputies had little problem with the scoring by the time the last section of the tape was played. Those with problems generally knew how to bcore a given subject, but disagreed on pecific criteria.

The two groups of deputies reversed training when both sections had finished. That is, the first group of deputies viewed the videotape, and the second group of deputies practiced estimating angles with the nystagmus device.

At the end of the session, all the deputies were brought back to a central location for questions and summay statements. SCRI staff members then made every effort to ride with each newly trained officer to observe them administrating and scoring the test battery in the field. On-the-spot corrections were made at this time and all additional questions concerning administration and scoring were answered. Answers to questions which were not covered in the original training session were then incorporated into subsequent training sesions. Since total of four training sessions were given during the field evaluation, very few questions remained by the time the fourth session was conducted.

\section{DATA COLLECTION}

1. Date Forms

During baseline data collection (i.e., Phase I for the experimental group and Phase I and II for the control group), officersfilled out the data forms indicated in Table 16. For most stopees, officers were only asked to fill in basic information contained in the top half of the form. Thus, they might check that a stopee was a 25 pear old, Black male, who was stoped at 2235 hours on a Wednesday for speeding on a residential city street. The rest of the form would be left blank unless the officer suspected that the stopee bad been drinking or taking drugs, in which case he would make the appropriate check mark on the form. If behavioral tests were given, then the officer would indicate the nature of the tests and whether or not the stopee passed each test. If the stopee was arrested, then the type of chemical analysis was indicated, the BAC was recorded, and the officer checked. whether the supect was released or booked.

If blood or urine was taken, then the fluid was sent to the Sheriff's Forensic Crime Laboratory for analysis. Often results would not be available for four to bix weeks. Deputies were asked to pot a file number (i.e., the police case number) on the form if 
TABLE 16

PRE-TRAINING DATA FORM

DRIVER

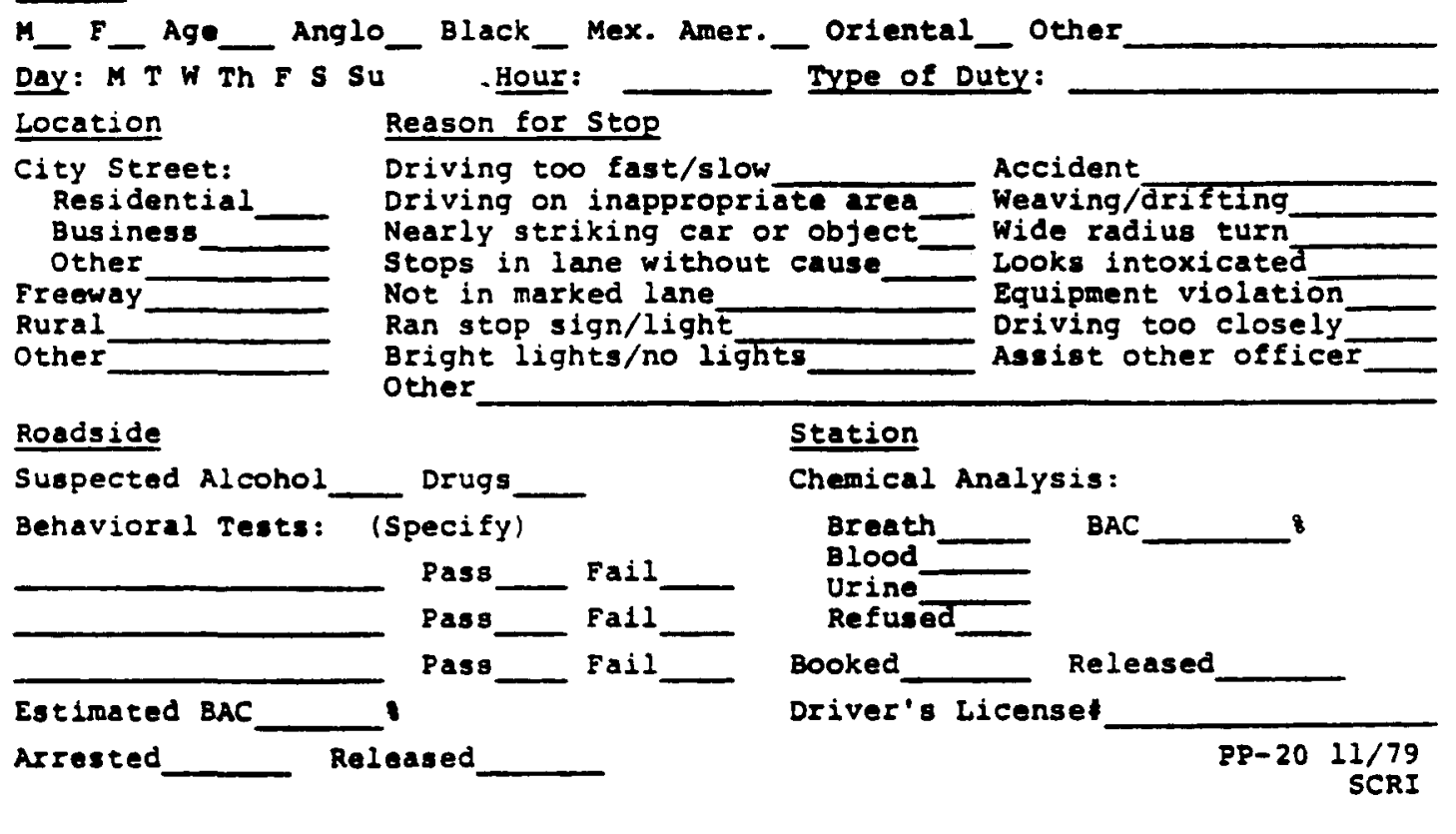


TABLE 17

POST-TRAINING DATA FORM

\section{DRIVER}

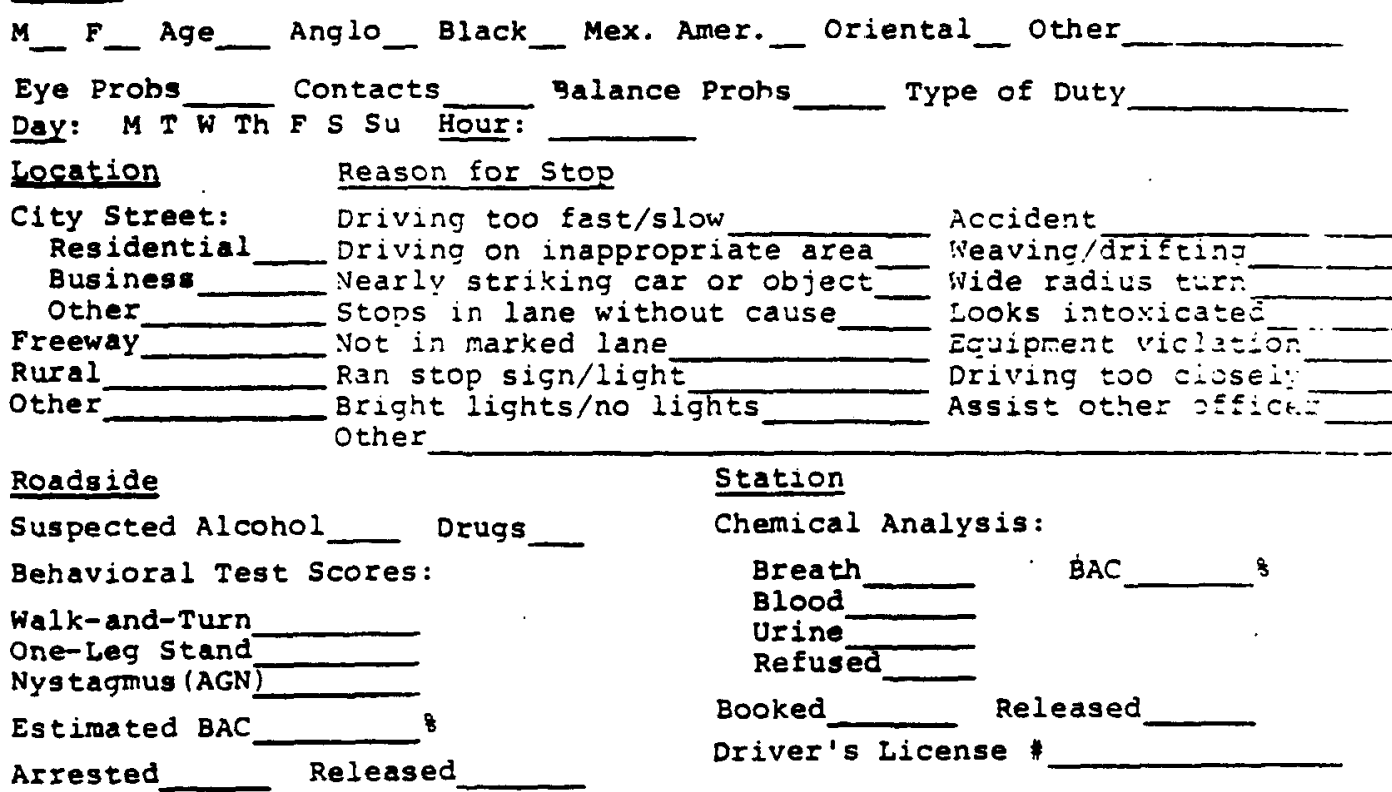

Scoring Sheet for FST Battery

Walk-and-Turn:

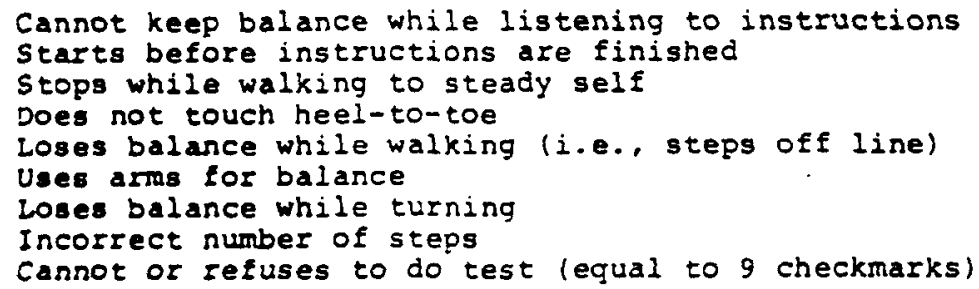

One-Leg Stand:

Swaying while balancing

Uses arms to balance

Qu: :e unsteady

Puts foot down

cannot or refuses to do test (equal to 5 checkmarks)

Alcohol Gaze Nystagmus (AGN):

RIGHT EYE LEFT EYE

Onset of AGN at less than $45^{\circ}$ and at least 108 of

the white showing

Estimated angle of onset

Eyes cannot follow smoothly

AGN at maximim lateral deviation:

Absent R_ L_ Minimal R_ L_ Moderate $R_{-} L_{\text {_ }}$ _ Heavy $R_{-} L_{-}$ $A G N$ at maximum lateral deviation is moderate or heavy 
blood or urine was taken so we could obtain the results of the analyis. The data on several arrests during Phase I were not available to us because the deputies forgot to include this information. Probably more blood samples than normal were taken during the course of this study because the Sheriff's Department switched from using the Intoximeter to the Intoxilyzer at about the same time the field evaluation began. Many deputies were unfamiliar with the operation of the Intoxilgzer.

After the deputies were trained in the sobriety test battery, they were asked to fill out the forms given in Table 17 . This form is exactly like the previous form except that it includes a scoring sheet for the three test battery. Thus, when giving a field sobriety test, officers were asked to check the problems the stopee bad with each test and record the number of checkmarks for each test and the total test score.

Officers were not required to identify themselves on the data forms before they had been trained on the test battery. Thus, an officer who frequently released drivers he or she suspects to be legally intoricsted would not be inhibited from indicating this on his/her data forms. After the officers were trained, however, we required them to initial their data forms so that we could determine if any of them were having difficulty scoring the sobriety tests. In addition, the officers' initials enabled us to identify each officer's pre-training data forms. Only one officer seemed inhibited by the need to identify himself, and tended to fill out more forms after we requested that the forms be initialed.

One problem that arose in filling out both data forms was that most deputies waited until the end of their shift tofill out their forms. At this point in time all forms were completed at once from their police logs. We urged the deputies tofill out the forms immediately, but our urgings did not help as most of them continued to fill out the forms at the end of the shift. We then stressed the importance of filling out forms for suspects given sobriety tests, so that the tests would be properly scored. We doubt that most officers complied with this request except when observers were in the car.

\section{Rideglong Deta}

Two staff members from SCRI rode with the participating deputies throughout the field evaluation. The two staff members included the Project Director and one of the observers from the laboratory evaluation. One staff member rode with each deputy one or two times during every phase of the field evaluation.

One purpose of the ridealongs was to obtain feasibility data on the cobriety test battery, including the deputies attitudes about arresting intoxicated drivers, their ability to administer and score the test battery at roadside, and the reaction of the stopees to the test battery. Some of the deputies were a little nervous about having an observer with them at first. But they vere told to do everything thay normally did and pretend that we were not in the 

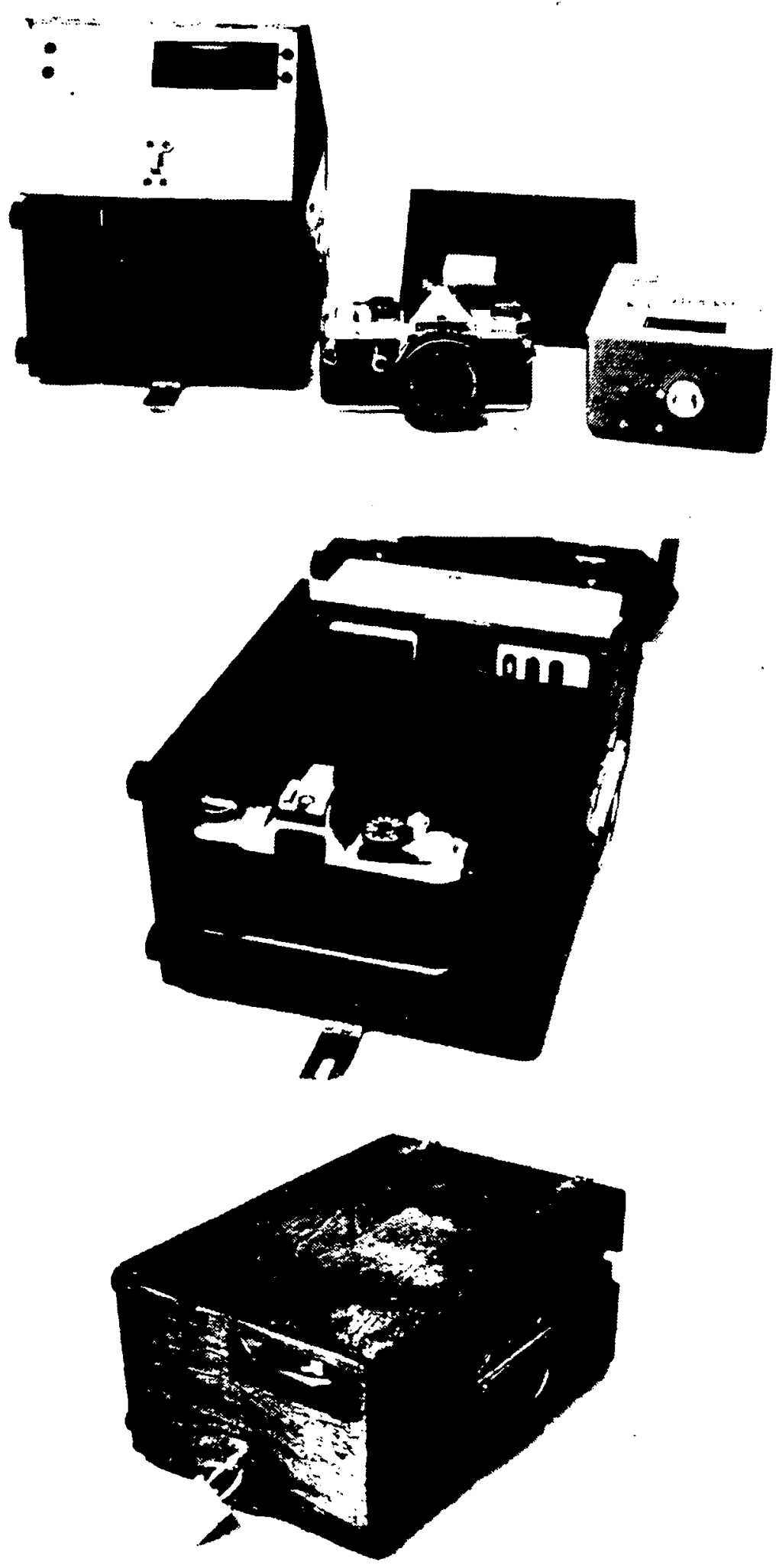

FIGURE 6 DEVICE FOR OBTAINING ANONYMOUS BREATH SAMPLES 
car. By the second or third ridealong, none of the deputies seemed to be influenced by our presence.

The second purpose of the ridealongs was to obtain breath samples from released stopees. Various police agencies vere concerned ( 1 ) about the legality of the police officers knowing the BAC of a released stopee who might be legally intoxicated; or (2) the possibility that a released stopee who was intoxicated might later crash bis car and then try to sue the police for not arresting him. Thus, an anongmous breath testing system was designed for use in the field evaluation.

The device used is il lustrated in Pigure 6. It consists of an ALERT J3 Digital Breathtester, mounted in an enclosed box, with a camera. Openings in the box allow the observer to operate the breath tester and the camera, but both the J3 Digital readout and the camera viewfinder were blocked from view by the locked box. Each time a box was opened or closed, it was sealed and the time and date were recorded by a notary public. No information was recorded about ang of the stopees by the observer. The only information that was recorded were the first and last numbers of the film each night. Thus, the only data obtained were distributions of readings by the J3 Digital for each deputy during each phase of the study. The J3 Digital was chosen because of its small size, its relative accuracy, and the fact that it has not been approved for evidential breath testing in the state of California (i.e., the manufacturer has not submitted it to the otate for approval).

Police officers talked to all stopees before anyone was approached by a SCRI observer. Once the officer finished writing the citation, he or she asked the stopee to get out of the car to sign the citation. The deputy was instructed to inform the stopee, once the citation bad been signed, that an observer was in his/her car from Southern California Reserrch Institute who was doing research for the O.S. Department of Transportation. The deputies were then asked to bay, "I would like you to talk to the observer, but your cooperation has nothing to do with the ticket you received." Individual officers frequently expanded upon this statement by explaining that we would require a breath sample and indicating how their cooperation would help the police. Officers were requested only to ask btopees for their cooperation once they were certain they were not going to make an arrest.

We estimate that police officers asked approximately $77.5 \%$ of the stopees to cooperate (see Table 18, Chapter IV). The remaining 22.57 consisted of arrestees, people involved in accidents, people the officer forgot to ask or didn't have time to ask because of an emergency call; and people the officer refused to ask (i.e., "Oh, I didn't ask him because I knew he wouldn't cooperate anyway" or "Oh, he was police officer just getting off dutg, so he didn't have to do it" or "Be was a friend of mine, so I didn't ask"). If the officer asked for the stopees' cooperation, then the stopee usualig would talk to the observer. A few notable exceptions refused because they were extremelg hostile about getting a 
citation.

The observer approached each stopee and made the following statenent:

\begin{abstract}
HELLO, I'M .......FROM SOUTHERN...... CALIFORIIA RESEARCB INSTITUTE. WE ARE... DOING A RESEARCH PROJECT FOR THE U.S... DEPARTMENT OR TRANSPORTATION. AS PART... OF THIS RESEARCB, I AM ASRING EVERYONE.. STOPPED BY THIS OFFICER TONIGHT TO BLOW. INTO THE MOOTHPIECE OF THIS BOX. AS YOU. CAN SEE, THE BOX IS LOCRED AND SEALED... SO THAT IF YOD HAVE BEEN DRINRING WE.... WON'T RNOW ABOUT IT ONTIL THE FILM IN... THE CAMERA IS DEVELOPED IN A WEER OR TWO EVEN AFTER THE FILM IS DEVELOPED, WE.... WON'T HAVE ANY WAY TO ASSOCIATE THE .... READING OBTAINED WITH YOO............
\end{abstract}

At this point, the device was held up with the mouthpiece in the direction of the stopee. Often we would have to answer additional questiona, such as:

o... Is the mouthpiece clean?

ANSWER: YES, WE POT A NEW MOUTHPIECE ON FOR EVERY PERSON.

o... Why are you doing this research?

ANSWER: TO OBTAJN A DISTRIBUTION OF ALCOHOL READINGS ON PEOPLE STOPPED TONIGET TEAT THE OFFICER BAS DECIDED NOT TO ARREST.

o... Bow does tbis thing work? (meaning the anongmous breath test Bystem).

ANSHER: YOD BLOW INTO THIS MOUTHPIECE WHICH OPERATES A PORTABLE BREATE TESTER LOCATED HERE. AFTER ABOUT FOUR SECONDS, THIS LIGHT WILL GO OFP AND THE MACHINE WILL INDICATE HOW MOCB ALCOHOL IT READS. TEE READING APPEARS DOWN HERE SO NEITHER YOU NOR I CAN SEE IT BOWEVER, THIS CAMERA IS POINTED TOWARD THE READING, SO I WILL JOST TARE A PICTORE OF IT. ONCE THE FILM IS DEVELOPED, WE WILL RNOW WBAT TEE READING IS, BOT WILL NO LONGER RNOW WBO YOD ARE.

o... I bad a couple of drinks tonight, how do I know you are telling we the trutb and aren't going to have me arrested if the reading is above a particular level?

ANSWER: WE EXPLAINED AS MUCH AS POSSIBLE ABOUT THE ANONYMITY OF THB SYSTEM AND EMPHASIZED THAT THE BOX WAS SEALED, SO TBAT WE WOOLD NOT BE ABLE TO OPEN IT ORTIL THE SEAL WAS BROREN. IN ADDITION, WE INDICATED THAT THE BREATH TESTING DEVICE WAS NOT APPROVED BY THE 
STATE, SO THAT THE READING CODLD NOT BE OSED IN COORT.

0...Hill gou bend me the results of this test?

AESWER: MO, WE WILL REVER BE ABLE TO ASSOCIATE ANY PARTICULAR
READIMG WITE YOO.

Approximately $85 \%$ of the stopees who were asked agreed to provide us with saple. Most of the refusals were people who were still vexy hostile about getting a citation, although approximately $5 \%$ of the refusals were people (usually female) who claimed it was too embarasiing to be seen giving a breath sample at roadside. In every case, whenever a supect showed some hesitancy by admitting to drinking, we were able to convince them of their anonymity and obtain a breath sample. Occasionaly, admitted drinkers would not blow hard erough to enable us to obtain a valid Bample. After three bad $B a m f l e a$ we stopped requesting additional blows.

People involyed in traffic occidents were never asked to provide breath paples. Thus, we avoided the possibility of having civil buits brougbt against us or having our data subpoenaed. 
Fifteen police officers completed the field evaluation, filling out a total of 3128 forms during the three phase study. The fifteen officers worked 685.5 eight-hour shifts in total during the study. Thus, the officers averaged 4.56 data forms per shift during the three phase study (ranging from 0.47 to 9.02 forms per shift). We calculated the number of traffic stops per ridealong, defining a traffic stop as one for which a form should have been completed. The deputies, on the average, made 7.00 traffic stops per ridealong. This estimate may be slightly inflated, since some of the officers probably were making more stops than normal during the ridealongs. However, we estimate, using this conservative figure, that deputies filled out forms for approximately $65.1 \%$ of the stops for wich they should have completed data forms. Four officers filled out forms at a rate of less than $40 z$ of that which we projected from the ridealongs. Based upon discussions with the various traffic sergeant, we feel that our data are very incomplete for three of these deputies, but that the fourth deputy made more stops than normal during the ridealongs.

The deputies made 413 traffic stops during the 59 ridealongs. A breakdown of the data available from these stops is given in Table 18 for each group of officers during each phase of the evaluation. In summary, $6.5 \%$ of the stopees were arrested during each of the ridealong sessions (as compared with $7.4 \%$ of the stopees for which we have data forms). Another $6.8 \%$ of the stopees were involved in. traffic accidents but not arrested; $9.2 \%$ were not asked by the officers to provide breath samples; $11.4 \%$ were asked to provide breath samples, but refused; and $66.1 \%$ of the stopees provided anonymous breath samples. Thus, we have BAC information on $72.6 \%$ of the stopees--those who were arrested and those who voluntarily provided samples. Among the released stopees who were asked to provide breatb 8 amples, $85.3 \%$ agreed. The majority of the refusals said they would not cooperate because they were given a citation.

These data were analyzed with regard to three basic issues:

What is the nature of the stopee population?; (2) Is the test battery effective?; and (3) Is large scale implementation of the test batterg feasible?

\section{A. TBE NATURE OF TBE STOPEE POPULATION}

One of the objectives of the field study was to determine the nature of the stopee population. The police dataforms were designed ith this objective in mind in that information was requested on the age, sex, and race of each stopee. Data on the characteristics of the stopee population, derived from the 3128 forms completed by the officers, were tabulated. Given that the officers did not fill out forms on all of their stopees, the data may be somewhat biased. Por example, certain officers filled out many more forms than other officers, so their biases, if any, could be reflected in the data presented in this report. However, our estimates seem comparable to other estimates of the stopee population (e.8., Harris et al., 1980). 
TABLE 18

DATA OBTAINED FROM STOPEES DURING RIDEALONGS

PHASE I PHASE II PHASE III

Control Experimental Control Experimental Control Experimental

\begin{tabular}{|c|c|c|c|c|c|c|}
\hline Traftid stops & 78 & 101 & 62 & 71 & 48 & 53 \\
\hline Acciclents & 8 & 7 & 1 & 2 & 7 & 3 \\
\hline DUI Arrest & 5 & 6 & 4 & 8 & 2 & 2 \\
\hline $\begin{array}{l}\text { Officer jid } \\
\text { nat asi for } \\
\text { breath sample }\end{array}$ & 9 & 5 & 2 & 7 & 5 & 10 \\
\hline $\begin{array}{l}\text { Refused to } \\
\text { give gample }\end{array}$ & 3 & 13 & 7 & 11 & 7 & $\therefore$ \\
\hline $\begin{array}{l}\text { jaye treat! } \\
\text { sanfla }\end{array}$ & 53 & 70 & 48 & 41 & 20 & 32 \\
\hline
\end{tabular}




\section{Age}

The age distributions of four population samples are given in table 19. These samples include: (1) all of the stopees; (2) stopees suspected of consuming alcohol or drugo; ( 3 ) arrested stopees; and (4) people involved in accidents during the study.

The stopees as a whole tend to be younger than the people involved in accidents or the DWI arrestees. Those suspected of consuming alcohol fall between the stopees and arrestees in terms of age. Bowever, for all four groups the mode fell into the 20-24 year old age group.

People over 65 represented only $1.5 \%$ of the stopees, and only one person in this age range as suspected of consuming alcohol prior to driving. People over 60 constituted $3.4 \%$ of the stopee population, but accounted for $7.6 \%$ of the accidents.

2. Sex

Table 19 also indicates the sex distribution of the same four categories of stopees. The 3128 stopees consisted of 2329 ( $74.5 \%)$ males and $799(25.5 \%)$ females. Males in this data may be overrepresented since male officers (only one deputy was female) showed a slight tendency not to give females tickets, which would be reflected in the number of forms completed for females.

Ore female out of every 19.0 female stopees was suspected of consuming alcobol prior to driving, as compared with one male out of every 6.8 male stopees. Thus, those suspected of driving after drinking congisted of 342 males $(89.1 \%)$ and 42 females $(10.9 \%)$.

If a female was suspected of DWI, then her chances of being arrested were slightly less than that of a male suspected of DWI. Of the 42 femsles suspected of driving after drinking, 21 ( $50 \%)$ vere arrested. Of the 342 males suspected of driving after drinking, $194(56.7 \%)$ were arrested. The DWI arrestees were $90.2 \%$ male and $9.8 \mathrm{f}$ female.

The population of stopees involved in an accident was $82.7 \%$ male and $17.3 \%$ female. Bowever, only 52 accidents were reported in our deta forms.

\section{Race}

The data on the racial makeup of the stopees may be the most biased of all of the population data in the field study. The cities represented in the field evaluation tended to have minority sections. If given deputy was asigned to a minority area, then most of his/her stopees would be minorities. Thus, the tendency for certain officers to fill out many more forms than others could bighly influence these data.

Our sample of stopees consisted of $53.3 \%$ Caucasians, primarily because two of the three cities from which most of our data came 
TABLE 19

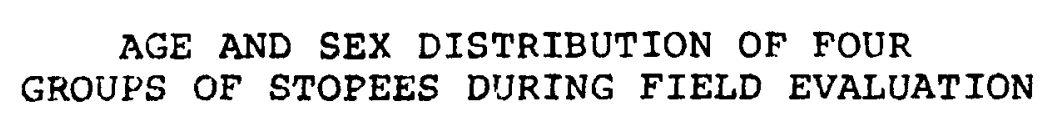

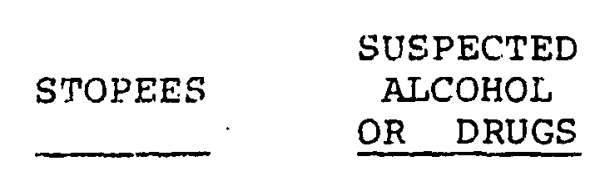

N

3128

396

$0 \%$

$9.7 \%$

$16-19$

$20-24$

$25-29$

$30-34$

$35-39$

$40-44$

$45-45$

$50-54$

$55-59$

$60-64$

$65-6 y$

$70-7 A$

$75+$

Missing

Maie

Female

$$
0.38
$$

17.28

24.58

16.68

$11.7 \%$

7.38

6.08

$4.5 \%$

4.38

2.08

1. 97

3. 07

0.38

0.28

1.78

74.58

25.58
22.68

$16.3 \%$

15.48

8.88

9.18

7.38

5.68

1.18

2.18

0.88

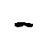

$-$

1. .08

89.18

10.98

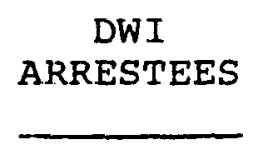

215

08

9.38

$15.8 \%$

15.88

15.48

$13.0 \%$

9.38

8.78

6.28

1.58

3.38

0.98

0 \&

$0 \%$

0.98

90.28

9.88
INVOLVED

IN

ACCIDENT

52

0 \%

$11.5 \%$

17.38

$11.4 \%$

17.28

3.8 웅

$7.6 \%$

$3.8 \%$

$17.3 \%$

$1.9 z$

$5.7 \%$

0 \%

$0 \quad z$

1.98

$0 \%$

$82.7 \%$

17.38 
consibted of largely Caucasian populations. Blacks, Litins, 0rientals, and other minorities constitute $19.0 \%, 17.8 \%, 3.9 \%$, and 3.37 of our stopees, respectively.

Interestingly, Caucasians and Latins were much more likely to be suspeted of consuming alcohol before driving than Blacks or orientals. The rates were one of 6.6 stopees for Caucasians; one of 6.8 stopees for Latins; one of 17.4 stopees for Blacks; and one of 24.6 stopees for Orientals. Once a stopee was suspected of DWI, however, we found no greater tendency for deputies to arrest any one group than any other.

\section{B. TEST BATTERI EFPECTIVENESS}

The most crucial questions to be answered during the field evaluation of the sobriety test battery include: (1) Will the percentage of stopees arrested increase after the test battery is introduced? (2) Will police officers make more accurate decisions witb respect to a BAC of $0.10 \%$ after being trained on the test batterg? ( 3 ) Will the mean BAC of arrested drivers be reduced after the test battery is introduced? (4) vill police officers more accurately estimate the BAC levels of stopees after being trained on the test battery? (5) In addition, the ridealong data should provide an estimate of the percentage of police stopees, as opposed to drivers on the highway who have been drinking and who are legally intoxicated.

In answering these questions, both ridealong data and officer-completed forms are available. The ridealong data are as complete as possible and provide BAC distributions of released stopees. However, the ridealong data represent only a small sample of the drivers stopped by the participating deputies during the field evaluation. In addition, these data may be somewhat biased because an observer was present. The officer-completed forms, on tbe other hand, cover the entire field evaluation. However, these data are less complete and do not provide actual BAC information on released stopees.

As discussed before, the biggest problem with the field evaluation was officer participation. We began with 20 deputies, but had to eliminate five because of poor attitude or lack of cooperation. Three of the remaining deputies filled out very few data forms (less than $40 z$ of their probable stops) and a fourth deputy made no DWI arreste during the entire field study. Thus, out of the original 20 deputies, only 11 provided us with sufficient arrest data to be of value. Even among these 11 officers, there was considerable variation in the number of arrests made. As a result, trends are reported, but the data are not appopriate for significance testing; the assumptions for underlging statistics which would be of interest are not met by the data. However, virtually every trend reported is in the direction of improved performance resulting from the test battery. The potential utility of the test battery appars to be supported. 

iraining en the test battery?

By examining the procedural steps in the officers' handing of the intoricated stopee, we can anticipate how the test battery might increase the percentage of stopees who are arrested. Many intoxicated drivers, especially those with a high alcohol tolerance, probably are never stopped by the police because cues for detecting them are not sensitive enough. Instead, most of the stopees will have made serious driving errors. Mang of these driving errors mas be attributable to impairment other than alcohol intoxication, such as a woman who has just had her purse stolen and is too upset to concentrate on driving; a diabetic person in need of insulin; a married couple arguing; an elderly mandriving too carefulig, etc. These people generally are not given sobriety tests, because they do not smell of alcohol or because their other problems are obvious.

If the officex detects an alcohol odor, then the driver probably will be asked to get out of the car. Once this occurs, the officer typically will continue a low-key interrogation of the stopee and administer behavioral tests. The officer then must make a decision to arrest or release the stopee based upon his/her estimate of how intoricated the driver is. Onfortunately, the arresting officer's decision is frequently based upon personal factors (see feasibility section), rather than upon the estimated BAC of the driver. For example, during the field evaluation, approximately $5 \%$ of the stopees suspected of drinking alcohol were released despite the fact that the stopee's officer-estimated BAC was over $0.10 \%$. These caees ircluded four stopees for whom the BAC was at least $0.20 \%$, as estimated by the officer.

The ayprige police officer does not, under any circumstances, wish $i n$ ar $s_{s} L_{\text {a }}$ Buspect with a low BAC (i.e., below $0.10 \%$ ) and will cften err by opting to release rather than risk a false arrest. The test battery probably will have its greatest impact at this point incressing the percentage of stopees who are arrested, redicing the false negatives.

Tabl $\varepsilon 2 C$ givef the number of stopees, the number of arrestees, and the pexcentage of stopees who are arrested for both groups of offjceIb, control and experimental, during each phase of the field evalurion. A larger percentage of stopees might have been al $x$ grted during Phase I because of the number of drinking drivers on the road during the Christmas-New Years Boliday Season. Indeed, the control officers arrested 6.67 of their stopees during Phace 1 , but only $2.2 \%$ of their stopees during Phase II. The ergerimental group officers, in contrast, increased the percentage of stopees arrested from $7.7 \%$ during Phase I to $9.1 \%$ after their training iu Phase II. The control group also increased their arreat percentage after their training from 2.27 in Phase II to $5.0 z$ in Pbae III. During Phase III the percentage of arrestees dropped from 9.17 to 8.27 for the already-trained experimental group officers, but remained above pretraining levels. 
TABLE 20

STOPS AND ARRESTS MADE DURING THE FIELD EVALUATION

AS A FUNCTION OF OFFICER GROUPING AND STUDY PHASE

CONTROL OFFICERS

STOPS

ARRESTS
732

319

PHASE II

$$
\text { Training }
$$

PHASE I
PHASE II
Praining
PHASE III

359
48

6.68

775

Training

7

2.28

502

18

5.08

441

36

8. 2 웅 
When all of the data are classified into trained versus untrained periods, the officers arrested $6.3 \%$ of their stopees prior to training and $7.6 \%$ of their stopees after training. This represents a 20.1\% increase in arrest rates which could have a substantial effect on DWI arresta nationally if a large number of trained officere were to maintain guch an increase.

2. Hill police officere make more accurate decisiong with to BAC of $0.10 z$ after being trained on the test battery?

respect

The finding that police officers arrested a greater percentage of their stopees efter being trained on the test battery could result from: (1) an increase in the exposure of the deputies to drinking drivers as a result of their training on the test battery (e.g.) officers might seek out intoxicated drivers by staying near bars or they wight alter the type of stops they make, both of which might increase tbe percentage of their stopees who were drinking); (2) a change in officers arrest criterion after training due to increased confidence in their ability to make accurate arrest decisiors; (3) pressure from superiors to perform well after they had been trained; or (4) a desire to make more arrests because they had jugt received training in field sobriety testing (i.e., the Hawthorne effect).

The BAC data obtained during the ridealongs may be biased. These data: as discuesed earlier in this chapter, represent only 59 eigbt-hour sbifts out of 685.5 shifts worked by the deputies during the three month study (i.e., or $8.6 \%$ of the 6 hifts). In addition, deputjes may have been influenced by the presence of an observer duriug the ridealongs and BAC information is available on only $72.67 \mathrm{C}$ ! the released and arrested stopees (although $85.3 \%$ of the releseed stopees asked agreed to provide breath samples). Nevertheless, the BAC data from the ridealongs is the best data availute to determine (a) if the deputies were more exposed to drirbing drivers after their training or (b) if the officers were atle tc a ake r.nre accurate decisons after being trained on the test $b a t t \in r y$.

a. Erefsure to nrinking Drivers Table 21 gives the number of

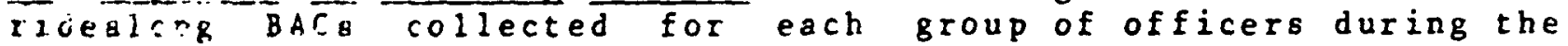
three fhaseg of the field evaluation. The percentage of drinking drixers cad legalig intoxicated drivers is also given in the table. Clearig: sur limited sample of BACs indicates that officers were not aure "exposed" to drinking drivers after training than before trainig. Driokiug drivers constituted $35.2 \%$ of the before training anfle of 125 BACs and $34.7 \%$ of the after training sample of lol BACs. Legally intoxicated drivers constituted $18.4 \%$ of the before training sample and 14.97 of the after training sample. Thus, the officers, if anything, are less exposed to drinking d-ivere fter training than before - primarily due to the high percentage of drinking drivers (i.e., 41.9\%) among police stopees duriag the Bo?iday beabon of Phase I.

bc Accuracz of Decisions Table 22 gives decision matrices before and after training for the rideslong stopees for whom a BAC is 
TABLE 21

\section{BACS OF RELEASED STOPEES AS A FUNCTION OF OFFICER GROUPING AND PHASE OF THE STUDY}

CONTROL OFFICERS

EXPERIMENTAL OFFICERS

\#BACs $\&$ DRINKING $\approx \geq .10 \%$ \#BACs $\&$ DRINKING $\approx \geq .10 \%$

\begin{tabular}{llccccc} 
PHASE I & 43 & $41.9 \%$ & $23.3 \%$ & 43 & $41.9 \%$ & $16.2 \%$ \\
PHASE II & 39 & $20.5 \%$ & 15.38 & 49 & $34.7 \%$ & $20.4 \%$ \\
& \multicolumn{9}{c}{ TRAINING } \\
PHASE III & 30 & $30.0 \%$ & $13.3 \%$ & 22 & $40.9 \%$ & $4.5 \%$
\end{tabular}


TABLE 22

I. BEFORE TRAINING DECISION MATRIX

Release Arrest

$B A C \geq .108$

$B A C<.10 z$

\begin{tabular}{|c|c|c|}
\hline 8 & 13 & 21 \\
\hline 104 & 0 & 104 \\
\hline 112 & 13 & 125 \\
\hline
\end{tabular}

II. AFTER-TRAINING DECISION MATRIX

\begin{tabular}{|c|c|c|c|c|}
\hline \multirow{2}{*}{\multicolumn{2}{|c|}{$B \pi: 2 \geq .108$}} & Release & \multicolumn{2}{|c|}{ Arrest } \\
\hline & & 4 & 9 & 13 \\
\hline \multirow[t]{2}{*}{$\mathrm{BAC}$} & $<.108$ & 86 & 2 & 88 \\
\hline & & 90 & 11 & 101 \\
\hline
\end{tabular}


known. These results indicate that officers were abie to wake more accurate decisions with respect to whether stopees were above or below a BAC of $0.10 \%$ after their training on the field sobriety tests. Before training the deputies correctly arrested 61.9\% of the stopees over $0.10 \%$, but improved to $69.2 \%$ after training. Overall, $93.6 \%$ of their decisions were correct before training and $94.1 \%$ of their decisions were correct after training.

The decision matrices indicate that the likelihood of a false positive decision is extremely low (1ess than 2\%). Thus, with field sobriety test training the officers appear to be willing to lower their criterion somewhat, but not enough so that there is any substantial change in the number of false positives.

3. Will the mean BAC of arrested drivers be reduced after the test battery is introduced?

Since borderline BACs produce most of the decision errors, those who are now arrested often have high BACs about which there was no uncertainty at the time of arrest. For example, the nationwide mean for DWI arrests is $0.17 \%$ (NHTSA, 1974). However, since there are mang more drivers on the road with BACs in the $0.10 \%$ to $0.15 \%$ range than at higher levels, a test battery which provides more certainty and produces more arrests in this range should substantially reduce the mean BAC of arrestees. Data relevant to this issue was obtained in a DOT study of portable breath test devices (DOT-HS-891-161, Final Report, 1974). The investigators reported that the average BAC for DWI arrests in their county-wide areas was $0.179 \%$ until 13 portable breath testing units were introduced at which time the average BAC dropped to $0.14 \%$. A Bensitive behavioral test battery should also lower the mean BAC of arrested drivers.

We examined the BAC data of the DWI arrestees obtained during the three month field evaluation. This information was available on 178 out of the 215 arrestees. BAC data were not available on 32 arrestees who refused to bubmit to a chemical test for alcohol and on five Phase I blood tests that were unavailable to us.

Table 23 gives the number of arrests, the number of available BACs, and the mean BAC for each group of officers during each phase of the field evaluation. These data suggest that the use of the test batterg had no effect on the average BAC. The mean BAC of the arrestees of the experimental group officers decreased from $0.169 \%$ during Phase I to $0.138 \%$ after their training in Phase II. Bowever, the mean BAC of the arrestees of these officers jumped to 0.1897 in phase III. The mean BAC of the arrestees of the control group officers did not change after the test battery was introduced at the end of Phase II, remaining at $0.161 \%$. Overall, the average BAC of the arrestees of untrained officers was $0.163 \%$ (i.e., for 86 cases) and the average BAC of the arrestees after training was $0.160 \%$ (i.e., for 92 cases).

The unexpected occurrence of a large number of arrests of stopees for driving under the influence of drugg makes the average BAC data 
TABLE 23

\begin{abstract}
ARRESTS, AVAILABLE BACS, AND MEAN BAC AS A FUNCTION OF OFFICER GROUPING AND STUDY PHASE
\end{abstract}

CONTROL

Arrest BAC Obtained $\bar{x}$ BAC

51

40

.1578

.1618

Phase II

Phase III
18

18

.1618
EXPERIMENTAL

Arrest BAC Obtained $\bar{x}$ BAC

60

40

.1698

46

42

$.138 \%$

36

32

$.189 \%$

\footnotetext{
Untrained officers .1638 (86 BACs obtained)

After Training $\quad .160 \%$ (92 BACs obtained)
} 
of the arrestees ambiguous in terms of alcohol alone. In adition. the occurrence of 32 chemical test refusals probably biases the data. These two Bources of error on the mean BAC of arrested drivers are discussed below.

a. Drug Arresto. Twenty four arrestees were suspected of being under the influence of drugs or under the influence of alcohol and drugs. Another six of the stopees were suspected of having taken drugs, but were not arrested. Four other arrestees were estimated by police officers to have BACs of 0.207 or greater, but bad actual BACs of zero. An arrestee must be very impaired for police officers, no matter how skilled, to estimate the BAC at $0.20 \%$ or greater.

The abcre cases could be excluded from the analysis, but not all of them legitimately should be excluded. Several officers routinely suspected their arrestees of being under the influence of both alcohol and drugs and we have no clear indication of how valid their suspicions were. Other officers suspect drugs only after they see a low BAC reading. These could be legitimate suspicions or attempts by officers to cover themselves for an arrestee with a low BAC reading.

b. Refubals. Thirty two of the arrestees refused any sort of chemical test. For example, many arrestees with prior DWI convictions, especially those driving under suspended licenses, routinelg refused all chemical tests. Sixty nine percent of the refusing drivers were over 30 years of age (as compared with only $58 \%$ of the arrestees) suggesting that life experience may play a role in refusing a chemical test.

The mean BAC, as estimated by the officers, for the refusals was $0.198 \%$, as compared with a mean estimated BAC of $0.171 \%$ for al 1 arrestees. Since $72 z$ of the refusals occurred during Phase I, the actual BAC of all of the arrestees before training may be much higher than the mean BACg given in Table 23 for Phase I. Thus, the refusals could have substantially altered the outcome of the field Evaluation.

4. Will police officers more accurately estimate the BAC levels of stopece after being trained on the test battery?

Police officers, trained in administering and scoring the test battery as part of the laboratory evaluation, were able to estimate the BAC of laboratory participants to within $0.03 \%$ (i.e., the mean absolute value difference). As part of the field evaluation, we were cnncerned with whether or not police officers in the field would be able to do as wellas in the laboratory once exposed to the test battery. In addition, we were interested in what changes migbt occur in police officer estimates of BACs in the field before and after the test battery was introduced. However, we encountered Beveral problems in gathering these data.

8. Pew stopees are tested. Our sample of laboratory participants probably represent the stopee population quite well, but those who 
were given sobriety tests in the field represent a subet of this population biaged toward high BACs. During the entire three month field evaluation, only 322 stopees (10.3\%) were given field sobriety test a compared with 441 fleld sobrietg tests given during the laboratory otudy. Since we eotimate that aproximately $30 \%$ of the topees had been drinking, only $37 \%$ of the drinking drivers who are topped are given field obriety testa. Before training, $10.2 \%$ of the topees were tested, and after training, 10.47 of the stopees were tested. Thus, while all participants in the laboratory eraluation were given the field sobriety testo, only a sual proportion of the stopees are actually given field oobiety tests. The stopees tested are those who smell strongly of alcohol or who look intoricated, so they are probably biased toward having a bigh BAC.

b. Most of the officers' BAC estimateg were inyalid. The only stopes for whom an actual BAC was available to compare with an officer's egtimate of the BAC were the DWI arrestees, since BAC data on releaged stopees taken during the ridealongs were anonyoua. Unfortunately, most officers filled in their data forms at the end of each shift, so they probably often knew the actual BACs of those arrestees who were given breath tests: Thus, the only valid data obtained in the field otudy comparing officer estinated BACs with actual BAC probably were for the 73 arrestees who were given blood or urine tests.

c. Blood and urine data were obtained on a biased sample of arrebtees, These 73 arrestees probably represent a very different population than our laboratorg subjects who were selected to represent tbe stopee population. Approximstely one third of the arrestres given blood or urine tests were suspected of being under tbe irfluence of drugs and all of them were considered to be highly impaired by the arresting officer. Moreover, these arrestees regresent a aucb wider range of BACs (0z to $0.30 \%$ ) than our 1 sboratorg participants $(0 \%$ to $0.18 \%)$. Thus, we would not expect tbe absilute ralue of the differences between the estimated and actual BACB for these subjects to be equivalent to the laboratory Bituation.

de Ceren tFege problemse the accurgcy of the officers' BAC eEfipete tended to be more accurate after training. Table 24 gijes tae absolute mean difference between the actual BAC and the eatinated BAC for each officer before and after training. Also given are the number of arrestees represented by each mean. In wonj iogtances the officer did not have an arrestee who requested a bloos or urine test during a particular phase of the study. There vere only six officers for whom we bave data both before and after training. These six officers improved their estimates by an -verege of 0.01757 (a = 0.028) after their training. For the ll officers for whom we bave some data, the average BAC estimate was off by $0.077 \%$ before training ( $=0.043, n=7)$ and the average BAC estimate was off by $0.0537 z$ after training $(s=0.031, n=10)$. Ibe effect cf training was not significant, but was in the expected direstion. 
TABLE 24

MEAN ABSOLUTE VALUE DIFFERENCE BETWEEN ESTIMATED

BACS AND ACTUAL BACS OF ARRESTEES GIVEN BLOOD OR URINE TESTS

\begin{tabular}{lcc} 
OFFICER & BEFORE TRAINING \\
\hline$\# 1$ (C)* & $.15 \%(1) * *$ \\
$\# 2$ (C) & $.0458(2)$ \\
$\# 3$ (C) & $.0858(4)$ \\
$\# 4$ & (C) & $.07 \%(3)$ \\
$\# 5$ & (E) & $.018 \%(6)$ \\
$\# 5$ & (E) & $.118(1)$ \\
$\# 7$ & (C) & $.06 \%(6)$ \\
$\# 8$ & (E) & - \\
$\# 9$ & (E) & - \\
$\# 10$ & (E) & - \\
$\# 11$ & (E)
\end{tabular}

\section{AFTER TRAINING}

.11 \& (1)

$.05 \div(2)$

$.10 \%(1)$

$.02 \&(1)$

$.02 \div$ (1)

$.0738 \quad(2)$

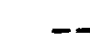

$.0158 \quad(2)$

$.0538 \quad(7)$

$.0488 \quad$ (4)

$.0428 \quad(2)$

$\bar{x}=.05378$

$s=.03118$
CHANGE

$-.04 \%$

$+.0058$

$+.015 \%$

$-.05 \%$

$+.002 \%$

$-.037 q$

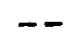

$-$

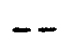

-

--

$\bar{x}=-.0175 \%$

$s=.0279 \%$ 


\section{BAC Distribution of Pelice Stopees}

The anonymous BAC readings of released: stopees and the police obtained BACs of arrested drivers during the 59 ridealong provides arrest probabilities which could be of some value to police agencies. The term atopee, in the remainder of this section, refers to those individuals stopped by the police during ridealongs for whom we were able to obtain BAC information. Table 25 gives the probability of a police stopee being within the listed BAC ranges. In addition, the table also gives the probability of a stopee being arrested, both before and after the test battery was introduced, as a fuction of his or her BAC.

a. A driver's BAC versus his arrest probability. Perhaps the most intezesting aspect of the data in Table 25 is the arrest probability associated with each BAC category before and after training. Before the test batterg was introduced, officers were arresting half of the stopees in the $0.10 \%$ to $0.149 \%$ range and the majority of the stopees above $0.15 \%$. No one under $0.10 \%$ ws arrested (unless drugs vere suspected). After the test battery was introduced, all stopees over $0.15 \%$ were arrested, half of the 6ropeer between $0.10 \%$ and $0.149 \%$ were arrested, and a few stopees under $0.10 \%$ were arrested. The probability of arrest in the $0.10 \%$ to $0.149 g^{\circ}$ range may not have changed after the test battery was introduced because many stopees in this BAC range are never given field gobriety test. Thus, an improved test battery cannot alter these decisions.

The errebt probabilities in Table 25 are quite rough, since they are based upon few data points. Nevertheless, we believe that the table represents the potential change in arrests once the tost battery is introduced.

be BAf during different phases of the study. During the three monthe of ridealongB, $34 \pi$ of the stopees had been drinking and about 15\% of them were legally intoxicated. During the early mornite shifts ( $i . e$, between 11 p.m. and 6 a.m.) $61 \%$ of the stopeeb had been drinking and $26 \%$ were legally intoxicated. We only edcoubtered 56 stopees during nine early morning ridealong shifts, so these estimates are based upon a very limited sample. During evening shifts (i.e., typically between 3 p.m. and 11 p.m.) 29\% of the otopees had been drinking and $13 \%$ were legally intcricared. Finally, part of the field evaluation occurred during the Christmas holidag season of 1979-80. We estimate that during the period between December 7, 1979, and February 2, 1980, 41\% of the stopees had been drinking and $19 \%$ were legally intoxicated.

A stopee does not represent the average driver on the road in terms of BAC. National roadside survey data, for example, indicate that only about 67 of the nighttime drivers are legally intoxicated (Lehman, Wolfe, and Ray, 1975). Thus, our stopees were 2.5 times more likely than the average driver to be legally intoxicated. The reason for this discrepancy is that the police stopee had made one or more driving errors. 
TABLE 25

DISTRIBUTION OF STOPEES ACCORDING TO BAC AND ARREST PROBABILITY BEFORE AND AFTER TRAINING AS A FUNCTION OF BAC

\section{BAC CATEGORIES}

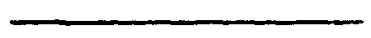

$$
\begin{gathered}
\text { Zero } \\
.01-.049 \\
.05-.099 \\
.10-.149 \\
.15-.199 \\
.20+
\end{gathered}
$$

PROBABILITY FOR A GIVEN STOPEE

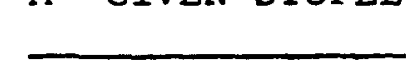

.664

.106

.080

.071

.053

.026
PROBABILITY OF ARREST

Before Training After Training

.000

.000

.000

.000

.000

.286

.500

.500

.625

1.000

.800

1.000 
TABLE 26

\section{MOST COMMON REASONS FOR STOPPING A DRIVER DURING THE FIELD EVALUATION}

REASON

$\&$ OF STOPS

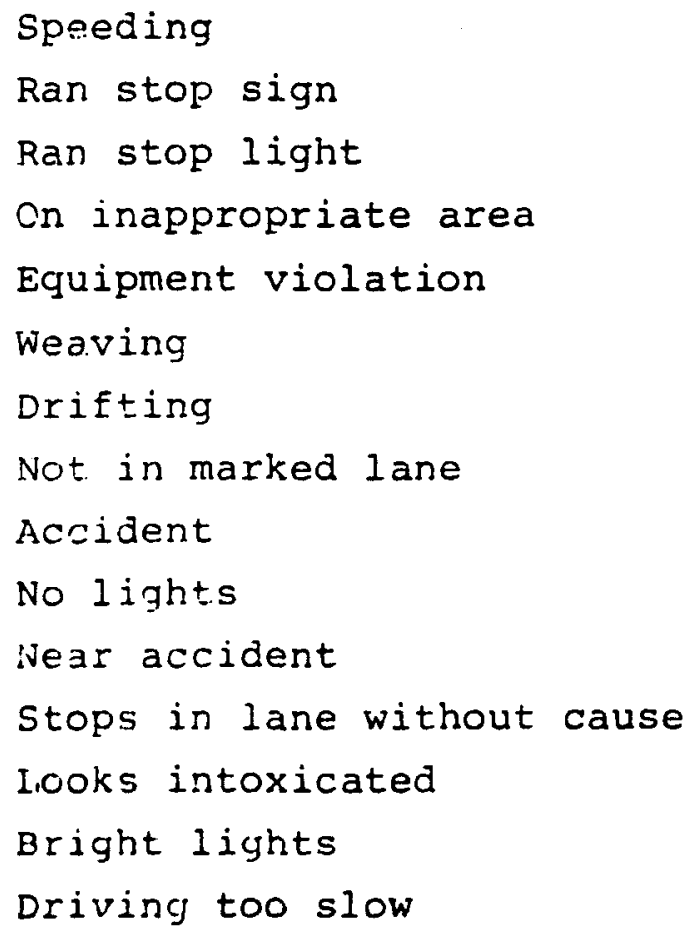

.514

.179

.087

.060

.051

.043

.034

.017

.017

.015

.013

.011

.010

.009

.008 
c. BAC refsus type of driving error. Table 26 gives the 15 most common driving errors made by all stopees during the field evaluation and the probability of occurrence during the field evaluation. More than half of the police stops werefor speeding, since most of the participating deputies had radar equipped cars. Harris et al. (1980) estimate that the probabilitg of someone driving $10 \mathrm{mph}$ over the speed 1 imit having a BAC over $0.10 \%$ is about 0.37 . Based upon our police officer estimates of the BAC of the stopees, only 5.17 of the speeders were over $0.10 \%$, which is probably less than the percentage of legally intoxicated drivers on the road. On the other hand, Harris estimates the probability of someone stopped for weaving having a BAC of $0.10 \%$ or greater to be 0.60 . During the field evaluation $58.5 \%$ of those stopped for weaving were estimated to be legally intoxicated by our police officers. Thus, a police officer has some control over the number of intoxicated stopees he or she encounters by controling the type of stops made during a shift. Generally, we believe that the distribution of stops indicated in Table 26 are probably quite representative of those made by the average traffic patrol.

\section{EEASIBILITY}

Virtualy every police officer known to us who is interested in enforcing DHI laws recognizes the need for a research based, atandardized field sobriety test battery. Thus, overalj acceptability of an improved test battery seems highly favorable.

A number of critical issues concerning the feasibility of the test batterg still exist and should be addressed before widespread introduction of the test battery occurs. These issues include: (1) the police attitude toward DWI arrests; (2) police acceptance

of standardized administration and scoring techniques; and preset BAC criteria for the test battery.

\section{Police Attitude toward DWI Arrests}

A police officer's attitude toward DWI arrests is of extreme importance in determining whether or not a standardized field sobriety test battery will be ubed. Law enforcement officere generalig reflect society's attitudes toward drunk drivers. Little (1968) found that while most people interviewed disapproved of DWI, tbey were not particularly concerned about any consequences to themblves. The druak driver is not particularly visible and the consequeuces of drunk driving do not impact directly on most people. Consequently, the public considers police activities other than trafic patrol, such as protecting lives and property from criminals, s8 being of prime importance. Frequently, even the drunk driver who kills is not considered to be a criminal by the public, or even by some police officers, but merely someone who was unfortunate.

Public attitude is bighly influential in determining police attitudes toward DWI. The potential influence on law enforcement is probably greatest at the municipal level where police respond 
directly to commuity demends. In areas with heavy crime rates and small budgets, the DWI problem is likely to be virtually ignored. In districts ith lower crime rates, such as those participating in the field evaluation, more emphasis usually is placed on traffic enforcement, including DWI enforcement. Even then, however, persons getting tickets for hazardous moving violations frequenty complain that the police should be catching criminals instead of harasing innocent citizens.

Individual police officers may also have their own personal reasons for not arresting for DWI. One participating deputy, for example, insisted that his primary life interest was in making his marriage work so that he avoided anything that might force him to work overtime, including DWI arrests. Other reasons police avoid such arrests include: they drink and drive themselves; they don't fully understand the consequences of alcohol impairment; the arrest process requires too much overtime for which they do not get extra pay; they receive poor support in the courts; DWI enforcement is not encouraged by their immediate supervisor; they prefer other kinds of enforcement activities; and/or many other reasons. Factors influencing DWI arrests have been studied previously j.n other NHTSA contracts (NBTSA, 1972; Young and Co., 1974; Oates, 1974; Hawkins et a1, 1976).

A standardized field sobriety test battery is not a cure for poor police attitudes. Officers who avoid DWI arrests will probably continue to avoid them for the same reasons. Officers who use the test battery and find that it makes their job easier and helps them get codictions may make more arrests once they are given the test batterg as a tool.

A number of factors also could cause the introduction of the test battezy to have a negative effect on police attitudes, including: (1) Officers may find they are arresting more drivers under $0.10 \%$ requiring ther to fill out an arrest report even though the driver is releaged at the otation. (2) officers may find that more arrests in the $0.10 \%$ to $0.15 \%$ range are being plea-bargained since they are more plentiful. Plea-bargaining discourages police officers from making similar arrests. (3) More DWI arrests may caube back up of cases in the courts and result in considerable plea-bergaining regardless of the BAC.

\section{Police Acceptance of Standardized Administration and scoring} ProcedurEB.

Most officers concerned with DWI enforcement see the need for a standardized test battery, in the sense that every officer would administer the same tests in the same way. However, officers are reluctant to use an elaborate scoring system or even ang scoring system. This resistance appears to be the result of a reluctance to use anything very complicated and the probable lack of understanding of the benefits and purpose of standardized scoring.

The training of officers during the field evaluation was very extensire. SCRI Btaff members were convinced that every officer 
completing the training could correctly administer and score the test battery. Onfortunately, some officers forgot or ignored most of the administration procedures, except those associated with nystagmu, by the time their second post-training ridealong occurred. These officers appeared to believe that they were still administering "the one-leg otand test" or the "walk and turn test" and that differences in the administration procedure were unimportant.

SCRI observers, when present during ridealongs, requested that all sobriety tests be scored immediately. Nevertheless, we suspect that many officers filled out their scoring sheets at the end of their shift or at the time they completed the arrest report for that individual. Most police officers have remarkable memories for detail, but we still suspect that many advantages of standardized scoring are $108 \mathrm{t}$ wen the scoring is left to memory.

Failure to have sobriety tests which are consistently administered and scored probably results in the acquittal of numerous DWI defendants. Pressure from the courts and from police superiors for consistency is one possible way for standardized procedures to be adopted. In order for this to happen, we believe that the standardized administration and scoring procedures should be incorporated into the police arrest forms.

3. Set BAC Leyelo

The sobrietg test battery wa introduced into the field evaluation using arrest criteria that were set to a BAC of $0.10 \%$ during the laboratory studies. Several problems arose with these criteria.

First, laboratory procedures are as exact as possible, while arrest procedures tend to err in favor of the arrestee. For example, in the laboratory a BAC reading of $0.099 \%$ is rounded to $0.10 \%$ except in figuring decision matrices where $0.099 \%$ is treated as being 1 ess than $0.10 \%$. For a DWI arrestee this reading would be considered 0.097 at all times.

Second, the field sobriety test is designed to help the police officer estimate whether tbe stopee is legally intoxicated at the time of the testing. Onfortunately, an actual BAC reading may not be obtained for over an hour after the decision to arrest is made. Thus, a stopee with a BAC correctig estimated at $0.12 \%$ may have a reading of 0.0987 ( $i . e$. , which is rounded to $0.09 \%$ ) when an actual cbemical test finally is obtained. In most cases, this individual vould be released immediately and no charges would be filed.

occasionally, an officer in California may still follow through with an arrest if the chemical test is in the $0.08 \%$ to $0.09 \%$ range. One officer informed us of such a case during the field study. The prosecutor handing the case, without consulting the arresting officer, merely asked the defendant if he would accept two moving violations. The defendant argued for just a speeding ticket and it was granted. 
SCRI has adjustable arrest criteria associated with the test battery. Local law enforcement officials might select their own arrest criteria, based upon what their courts will accept. Otherwise, many low BAC drivers may be arrested resulting in more plea-bargaining and negative police attitudes toward using the standardized tert battery. 


\section{CHAPTER VE CONCLOSIORS ARD RECOMMENDATIONS}

\section{A. CONCLOSIONS.}

The major objectives of this project have been to (1) complete the laboratory development and validation of the sobriety test battery, which was initially identified under Contract No. DOT-HS-5-01242, and to (2) assess in the field its feasibility and effectiveness when used by the police for estimating BAC and facilitating the identification of those drivers with BACs greater than or equal to $0.10 \%$.

Administration, scoring, and interpretation procedures and criteria for the three-test battery have been refined and evaluated. Under laboratory conditions, and in the hands of adequately trained personnel, the test battery is a sensitive index of BAC and of impairment. Based on exhaustive analysis of the laboratory evaluation data, we conclude that the tests are optimally developed and standardized, and no further laboratory work is recommended.

The laboratory data indicate that police officers established an average rest performance criterion such that they made "arrest" decisions at a mean BAC of $0.08 \%$ and higher. Their egtimateg of BACs differed from actual BACs, as measured by Intoximeter, by $0.037(s=0.005 \%)$. They also were able to correctly classify $81 \%$ of tbe laboratory subjects in terms of being above or below $0.10 \%$ BAC. Reliability measures produced correlations in the range of 0.60 to 0.80 for test-retest reliability and also for interrater reliabilitg.

This project bas confirmed the findings of DOT-HS-5-01242 that gaze aystagmus is an outstandingly useful tool for the officer at roadoide. An additional important finding is that 'angle of onset' of the cheracteristic jerking motion of the eyes, as a sole measure, enabled officers to correctly clasify $78 \%$ of the laboratory oubjects. Por this measure to be maximally useful, officers should be trained to estimate the angle of onset with considerable precision. With precise measurement of the angle of onset 887 of the laboratory participants could have been correctly clas a ified.

The second project objective, evalustion of the test battery in the field, aloo has been met with a limited sample. Additional field evaluation is recommended.

The limited field evaluation was carried out as a three-phase study. Officers were asigned to an experimental or control group, and over three time periods filled out data forms on all stopees. The variable of interest for the different time periods was "untrained" on the three-test battery versus "trained" to administer and score the tests. SCRI staft members also collected data by riding with participating officers to observe test administration and scoring and to obtain anongmous breath samples for BAC analgis from stopees who were released. 
The questions addressed by the anslysis of the field data were: (1) Did the number of arress increase after police officers were trained to use the test battery? (2) Nere the officers better able to discrininate $0.10 \%$ BAC as a result of using the test battery? (3) Did the nean BAC of arrested drivers decline after introduction of the test battery? (4) Here the officers better able to detect impairment as a result of using the test battery? Definitive anawere to the questions cannot be offered, based on the limited nature of this field atudy, but the data do clearly guggest positive results due to use of the battery. A $20 x$ increase in arreat rates occurred. Officers were able to make more accurate decisions relative to BACB of $0.10 \%$, and it appears that they were better able to estimate BACs.

\section{B. RECOMMERDATIONS}

Major effort is needed for a subsequent field evaluation, repeating essentially the same study design with a sample which is both larger and broader. Areas which caused difficulty in obtaining data and which are therefore critical issues in design of additional atudy, include the following:

1. Police Attitude and Motivation

Brtremely getioug problems result when there is a lack of interest and cooperation by individual officers, by supervisory personnel, or by agencies. Good data, and ultimately effective utilization of the test battery on a large scale, requires motivation at these varions levels to cooperate with the research and to give high priority to the arrest of alcohol-impaired drivers.

The greatest impact of the tests will be realized if law enforcement agencies and officers, recognizing the sensitivity of ngotagmis as an inder of BAC, routinely check the eyes of all stopees, As the data from the project have demonstrated, many alcobci-jmpaired drivers are being released without any testing at xoadeide. A routine examination of all otopees for nystagmus would more effectively detect the drinking driver than the current observationsl methods which relg on odor, slurred speech, or other obvious ugne of intoxication.

2. Adeguste Iime Frame for Data Collection

Expexience in the dos Angeles urban area, where traffic dengity is relativeiy beary, indicates that eight traffic stops per shift is the maximingerage number which can be expected. A project ochedule should be based on this estimate.

The disposition of arrested DWI cases by the courts is important data vbich has not been dealt with in this or earlier studies. officers, at the present, often express frustration orer what they perceive as lack of support by the courts and the futility of arresting DHI' who wili plea-bargain a lesser charge and experience only minimun penalty. The situation may be either 
worsened or improved by many more arrests and arrests at lower BACs, depending on action taken by the courts. Clearly, interactions with the courts is an important component of effective DVI deterreace, and thus should be included in the field evaluation. The project schedule should be longenough to permit development of contacto with the judiciary and the final disposition of DWI charges which arise during the evaluation period.

\section{Otber Considerations}

Mang law enforcement agencies continue to operate units with two officers, particularly on nighttime shifts. For example, both the California Higboy Patrol and the Los Angeles Police Department bave two officers in traffic patrol units. If ouch agencies are involved in the field evaluation (and to routinely exclude all of those witb two-officer units would introduce unacceptable biases into the data), then the number of officers would double, and clearly there will be a substantial increase in the costs of training and oupervision.

Obtaining lav enforcement cooperation is a major effort, in and of itgelf, requiring considerable time. The various agencies which have worked cooperatively with SCRI during the execution of two DWI projects bave had berious concerns about legal issues involved in tbe field evaluation, including the following: (1) If permission is given to obtain breath omples, the agencies require guarantees that the sanples be anongmous. Their legitimate concern is that if a driver wose BAC exceeds $0.10 \%$ is released and subsequently is involved in an accident, the BAC reading may be subpoenaed as eviderce and the police agency could be held liable for having releaned an impaired driver. (2) Stopees may feel embarrassed and barsoed by being asked for a breath sample. Agencies typically are acutely avare of public relations problems and thus object to introduciog researcb procedures which the public will not like. (3) If the field study reveals that officers actually are releasing a large proportion of higb BAC drivers, then this information may become videly known and may be used as criticism against the s gency.

Tbere iosues are neither trivial nor easily resolved. If the agency's policy makers rule that particiption in the research is not apfroved, then little recourge remains. The authority of agency directors is absolute, and local units of state police, for example, vill not cooperate without full approval of the appropriste upervisors and administrators.

The riderlong 8 ytem is an important component of the field study plan. SCBI recommends that bufficient personnel be assigned to the project to permit one observer for each Bix traffic patrol units.

In summity, SCRI recommends that the field evaluation of the three-test battery be completed with a major effort. A period of 18 month is recommended in order to carry out the study on a nationwide basis with diverse law enforcement agencies. 


\section{REFEREN CES}

Aschan, G. Different types of alcohol ngsagmus. Acta Otolargogele supelement, $1958,140,69-78$.

Aachan, G. and Bergatedt, M. Positional alcohol gystagmus (PAN) in man following repeated alcohol doses. Acta otolargarel. Supplemene, 1975, 330, 15-29.

Aschan, Go, Bergstedt, M, and Goldberg, L. The effect of some antibistaminic drags on positional alcohol nystagmu. Acta Otolargagol Supplement, $1958,140,79$.

Aschan, Go, Bergstedt, M., Goldberg, L., and Laurell, L. Positional ngatagmus in man during and after alcohol intoxication. Quarterly Journsl of Studies on Alcohol, 1956, 17, 381-405.

Balob, Ro, Konrad, H., and Honrubia, V. Vestibulo-ocular function in patients ith cerebellar atrophy. Neurologg., $1975,25$. $160-168$ 。

Bardy, A., Blomaa, E., Buhmer, E., and Lehtovoara, R. Postural Bvay ia adults: Normal values effect of alcohol ingestion. Acta Beurelosice Scandingyica Supplement., $1978,57,278$.

Barles, E., Cooke, N., Ring, A., and Passmore, R, Observations on the metabolism of alcohol in man. British Journgl of Nutrition, $1965,19,485-489$.

Begitie, G. The effects of alcohol and of varying amount of visual information on balancing test. Ergonomics, 1966, 9, 325-333.

Beitcl, G.: Sharp, M., and Glarez, W. Probability of arrest while driving under tbe influence of alcohol. Journsl of studies on Abschol, 1975, 36, 109-116.

Beader, M, ard Brien, F. The influence of barbiturates on vainu form of ngstagmu. American Journal of Opthalmology. 1946, 299. $1541-1552$.

Burag, M. ard Mcskowitz, B. Pgrchophysical tests for DWI grrest. (DOT-BS-5-01242). Washington, D. C.: O.S. Department of Transpert:iod, RETSA, 1977 .

Caha?n, D., Cisin, I., and Crossley, B. American drinking practice, New Brungwick: Rutgers Center of Alcohol Studies, 1969.

Colling, W. Manipulation of arousal and its effects on human vestibular ngstagmus induced by caloric irregation and angular occeleratious, Aerospace Medecine, 1963, 124-129.

Colling, Wo, Schroeder, D., and Bill, R. Some effects of alcohol on veatibular responses. Adpances in 0te-Rhino-Laryngology, 1973 , 
Cronbscb, L. Esegntials of psychological tegtinge New York: Harper and Rov, 1970 .

Pranke, H., Henoley, U., Hensley, W., Starmer, G., and Teo, R. The relationship between alcohol dosage and performance decrement in human. Jeurpal of studies on 1 cohol, $1976,37,3$.

Pregly, A., Bergotedt, M., and Graybiel, A. Relationships between blood alcohol, positional alcohol nystagmus and postural equilibrium. Quarterly Journal of studies on Alcohol, 1967, 28, $11-21$.

Rregly, A., Graybiel, A. and Suith, M. Walk on floor eyes closed (WOYEC): A new addition to an ataxia test battery. Aerospace Yedecine. 1972, 395-399.

Goldberg, L. Effects and after-effects of alcohol, tranquilizers, and fatigue on ocular phenomena. In J.D.J. Harvard (Ed.), Alcohol and rosd traffic. London: British Medical AsBociation; 1963.

Goldberg, L. Beherioral and physiological effects of alcohol on man. Poychoogmatic Medecine, $1966,28,570-595$.

Guilford, J. and Fruchter, B. Pundamentsl Btatistics in psychology and education, New York: McGraw-Bill, 1978.

Baris, D., Dick, R., Casey, S., and Jarosz, C. The yisual detection of driping phile intoxicated: field test of risuel cues and defection methods. (Contract No. DOT BS-7-1538). Washington, D. C.: Department of Transportation, NBTSA, 1980 .

Bawkirs, T., Scrimglour, G., Krenck, R., and Dreger, C. Summary of ASAP ItBylts EOE application to Btate and local programb (PoL. I). ASAF. Indings. (Contract No. DOT BS-5-01155). Washington, D. C.: Department of Trangportation, NBTSA, 1976.

Hill, R. Collins, W., and Schroeder, D. Influence of alcohol on positicsa! nyetagmus over 32 hour periods. Anpals of otology, Rhinulogy, and Largngology, $1973,82,103$.

Bowalo, 1. and Templetou, W. Buman spatial orientation, New York: Wiley, 1966.

leboar, B., Molfe, A., and Ray, R. A computer archive of ASAP resdejds bregch tegtiog gurveys, 1970-1974. Ann Arbor: Oniversity of Micbigan, Bigbvay Safety Research Institute, 1975.

Lebti, H. The effect of blood alcohol concentration of the onset of gnze nystegmas. Blutalkohol, 1976, 13, 411-414.

Lidev, $:$, loyejoy, F., and Costello, C. Nine cases of poisoning - pbengildine, Jgyrngl of the American Medical Association. $1975,2.34,5.3-5.16$. 
Little, J. A theory and empirical otudy of what deters drinking drivers, if, when, and why. Administretion Lay Reviev, 1968,23 , $23-57 ; \quad 167-193$.

Mizoi, Y., Bishida, S., and Maeba, Y. Diagnosis of alcohol intoxication by the optokinetic test. Qnarterly Journal of studies on Alcohol, $1969,30,1-14$.

Mones. H., and Myles, W. Heavy water nystagmus and effects of alcohol. Eature, 1974, 247, 404-405.

Money, R. and Myles, W. Motion sickness and other vestibulo-gastric illaess. In R. Nauton (Ed.): The vestibular Byszems Mew Jork: Academic Pres8, 1975.

Moskowit. Laboratory studies of the effects of alcohol on some variables related to driving. Jouraal of Safety Rebearch, $1973, \underline{5}$, $185-199$,

Murphree, $B$, Price, L., and Greenburg, L. Effect of congeners in alcoholic beverages on the incidence of nystagmus. Quarterly JouInel of Studies on Alcohol, $1966,26,201-213$.

Naticnal. Bigbway Traffic and Safety Administration. Alcohol safety action RIojects: Eyalustion of operations $=1972$. Volume II: deteiled anglygis, (DOT-BS-80C-874) Washington, D. C., 1972 .

National Aighway Traffic and Safety Administration. Alcohol safety actign Exojects: Braluation of operationg = 1974. (DOT-B5-801-707). Washington, D. C., 1974 .

Nijiakikrjien, C. The influence of an auditory task on Romberg's tef: ib bealtib people and neurological patiento. Procedures of the fol Syerosium International de Posturographic Smolenice. Seftember, 1973. Pp. 11-19.

Oater. $\quad$ Fecters influencing arrestg for alcohol related traffic yiojoline (Cantect No. DOT-BS-801-230). Wasbington, D. C.: Departaent of TIadsportation, NBTSA, 1974.

Oczte-veid, W. Effect of gravity on positional alcobol nyotagmus (FAR) clinical Aqiation and Aerospace Medecine, 1970,41 , $557-560$.

Peartias. A., Teobu, M., and Kataja, M. Clinical examination for intexictiga in cares of Buppected drunken drivinge statistical aEd BeRezcb Bureau of TALJA. Iso Roobertinkatu 20, Helsinki 13, Finleod. 1971 .

Penttila, ess Tenhu, M., and Rataja, M. Examination of alcohol intcrífing in cases of suspected dranken drivers II. liskenoturva, IBo Roobertinkatu 20,00120 Helsinki 12, Finland, 1974 . 
Rasbass, C. Barbiturate nystagmus and the mechanisms of visual firation. Nature, 1959, 183, 897-898.

Rasbass, C. The relationohip between saccadic and smootb tracking eje movements. Journal of Physiology, $1961,159,326-358$.

Robinson, D. Ege morement control in primates. Science, 1968 , 161, $1219-1224$.

Ryback, R. and Dowd, P. Aftereffects of various alcoholic beverages on positional nystagmus and coriolis acceleration. Clinical Ariation and Aerospace Medecine, 1970, 429-435.

Schroeder, D. Alcohol and disorientation related responses. I. Iystagnus and "rertigo" during caloric and optokinetic stimulation. (FAA-AM-71-6). Oklaboma City: Federal Aviation Administration, $1971 \mathrm{a}$.

8chroeder, D. Alcohol and disorientation related responses. II. Arstagmus and "vertigo" during angular accelergtion. (FAA-AM-71-16). Oklahoma City: Federal Aviation Administation, $1971 \mathrm{~b}$.

Simpon-Crawford, T., and Slater, S. Eye signs in suspected drinking drivers: clinical examination in relation to blood alcohol. Nev Zealand Medical Journal, 1971, 74, 92-96.

Sumers, L. and Harris, D. The general deterrence of driving while intoxicated $=$ Volumes $I$ and II. (Contract No. DOT-BS-803-582). Washington, D. C.: Department of Transportation, RBTSA, 1978 .

Toglia, J. Electronyetasmography: Techpical espects and atlas. Springfield, Ill.: C.C. Thomas, 1976.

Omeda, I. and Sakata, E. Alcohol and the oculomotor system. Annals of otology, Rhinology, and Laryngology, 1978, 87, 392-398.

Wilkinson, I., Rime, R. and Purnell, M. Alcohol and human eye movement. Brain, 1974, 97, 785-792.

Wilson, A., Barboriak, J., and Rass, W. Effects of alcoholic beverages and cogeners on psychomotor skills in old and young subjects. Quarterly Jourpal of Studies on Alcohole $1970, \underline{5}$ 115-129.

Young, A. C. and Co. Effective bighwar safety traffic offenge adjudicetion, (Contract No. DOT-BS-801-216). Washington, D.C.: Departaent of Transportation, NHTSA, 1974. 
Fystagnus refers to a jerking of the ejes which may be pendular (equal on both sides) or aspmetric with slow and fast phase $($ Toglia, 1976). Alcohol appears to influence a nuber of different kinds of nystagrus, including: positional nystagmus (ABchan, 1958; Goidberg, 1963), post-rotational nystagmu (Schroder, 1971b), caloric nystagmus (Schroeder, 1971a), optokinetic nystagmus (Schroeder, 1971a), gaze nystagmus (Aschan, 1958; Lehti, 1976).

If all of these forms of nyotagmus are considered, then the literature on alcohol and nystagms is quite large and somewhat contradictory. However, by studying the mechanisms producing ngstagms, the literature can easily be sorted.

Basentially, alcohol can influence nystagmus in two ways: mechanicalig by acting on the vestibular system, and nevrologically.

\section{Pestibj18T Mechanism8 (See Boward and Templeton, 1966)}

In man, three semicircular canals, joined at right angles, are located in each inner ear. The canals arefilled with fluid, called endolymph. A swelling or ampulla is located in each canal and contains the sensory transducer of the canal. Esentially, the cilia of number of sensory cells project into a commongelatinous m888: the cupula. This cupula is hinged at one end, so that it can oring from side to side with the ampulla. In the upright position, the cupuls forms an effective seal, preventing the leakage of endolygph past that point.

The semicircular canals respond to angular acceleration, such as in a head mopewent, which carbes the endolymph to lag behind the head movemeat. (i.e., the fluid moves) and deflects the cupula. Deflection of the cupula discharges the sensory cells and provides the oesation of movement. With constant angular acceleration, the B y so on then underestimates the amount of acceleration. If the persou io then beld at constant velocity, then the cupula catches up to the Bkull morement (i.e., it returno to normal position) and the cencation is one of soving down and eventually (in about 20 accordel of etopping. If the personis otopped, then he or bhe will cemos. oudder ascelesetiog in the opposite direction becaube the bead $\dot{a}$ apw lower than the endolymph, which caubes the cupula to deflect in the opposite direction. If the person remsins -topped, theo the cupola returns to ito level position giving a cencation of 8 lowing down and stopping.

Since the three semicircular canals in each ear are at right angles, we can sense angular acceleration in any direction. When visus information conflicts with the sensation of motion, one feels dizgy and may feel bick. However, the mere sensation of 
movement may produce illness in some individuals.

The vestibular gyotem interacts with the visual gyotem by producing alternating fast and slow eye movements (i.e., nystagmu) in addition to the sensation of movement. Nystagmus is produced because the eyes lag behind the angular acceleration, so a "brain center" makes periodic adjustments in order to maintain adequate foveal fixation. For example, one can move one's head back and forth and still maintain fixation.

Onfortunately, angular acceleration is not the only stimulus which will cause cupular deflection. The cupuls and endolymph both have the same specific gravity. A very slight change in the specific gravity of either the fluid or the cupula may result in a cupular deflection, because the system becomes sensitive to gravity with certain head positions. Money and Miles (1975) claim that a change in the specific gravity of 3 parts in 100,000 will make the system sensitive to gravity.

Alcohol and some other drugs can alter the balance in specific gravity (Money and Miles, 1974; 1975). The base of the cupula has $a$ Fich blood supply. Foreign substances in the blood will diffuse rapidly into the cupula because of itg proximity to the blood and alter the specific gravity of the cupula with respect to the endolgmph. The direction of the nystagmus (i.e.s the fast phase) will depend upon whether the drug makes the specific gravity of the cupula greater or less than that of the endolymph.

Por example, within one hour after consuming alcohol a positional alcohol nystagmus (PAN) will occur. That is, if from supine position one rolls one's head to the side (i.e.s so that the cupula is oubject to gravity), a nystagmus, called PAN I, occurs in which the fast eye movements are down (e.g., Aschan and Bergsted, 1975). Approximatelg four bours after drinking, the nystagmus stops. This i. probsbly because sufficient alcohol has defused into the endolsmph so that its specific gravity equals that of the cupula. Finally, as alcohol is eliminated from the blood stream, the endolyupb ende up with a greater concentration of alcohol than the cupula. At this point, s positional nystagmus occurs in which the fos eye morements are up (PAN II). PAN II may persist up to 20 hours after consuming alcohol -- long after alcohol has been elimiuated from the bloodstream (Bill, Collins, and schroeder, 1973). In fact, under conditions of increased gravity, PAN II has been found up to 40 hours after drinking alcohol (0osterveld, 1970). The chage in specific gravity also explains why the presence of congeners in alcohol can increase the amount of positional nystagmus (Murphree, Price, Greenberg, 1966; Ryback and Dowd, 1970). Excellent reviews of the PAN phenomenon are contained in Aschan, Bergatedt, Goldberg, and Laurell (1956); Pregly, Bergstedt, and Graybiel (1967); Hill, Colling, and Schroeder (1973); Aschan and Bergstedt (1975); Aschan (1958); and Goldberg $(1953)$.

PAN I intengity provides a rather good indication of the peak BAC (Goldberg, 1963), but not of the duration of the intoxication. PAN 
I intensity bas been correlated with hangover effects (Goldberg, 1963).

\section{Neural Mechanisms}

Alcohol affects nystagmug in an indirect way -- by inhibiting the neural mechanisms involved in maintaining visual fixation. In some instances, visual fixation acts to inhibit nystagmus. Thus, if a vestibular signal tells one that rotation is occurring while visual information conflicts, then the visual information usually wins but often at the expense of producing nausea.

Irrigating the ears with warm or cold water starts the endolymph fluid moving and produces a ngatagmus called caloric ngstagmus (e.8., Schroeder, 1971a). Visual fixation will inhibit this nystagmus, but not after taking alcohol (Schroeder 197la). Similarly, rotational aystagmus or post-rotational nystagmus can also be suppressed by visual fixation. But fixation again is ineffective after taking alcohol (Schroeder, 1971b). Both rotational and caloric nystagmus, however, are also reduced by low levels of arousal, ouggesting the alcohol suppression may also be due to the sedatioe effect of the drus (Collins, 1963; 1973).

In all of the above examples, nystagmus is produced by vestibular activation and alcohol acts to suppress that nystagmus. However, alcohol reduces nystagmus that is not produced by vestibular activation. Optokinetic nystagmus, for example, is produced by watching a rotating drum covered with alternating black and white vertical strips (Mizoi, Bishida, and Maeba, 1969). It consists of a slow component in the direction of the moving object (or strips) and a quick phase in the opposite direction. Mizoi, Hishida, and Maeba (1969) describe four phases of optokinetic nystagmus: First, the slow eye movements keep up with the movement of the object. second, the slow phase eye movements accelerate, but cannot keep up with the stimulus. Third, the slow phase attains its maximum speed. An average person can typically follow a moving object up to 30 degrees per second. Finally, the eye movement fails. Alcohol impairs optokinetic nystagmus by reducing the maximum speed tbat can be obtained (Mizoi et al., 1969).

The slow ege movements mentioned in connection with optokinetic nyst8gmus are called "smooth pursuit" movements (Rashbass, 1961; Robin8oD, 1968). This system for moving the eyes (1) requires a moving stimulus; (2) is virtually autonomic; and (3) is concerned primarilg vith matching the speed of the eye with the speed of the target (Robinsor, 1968). These movements appear to function in providing a stable image on the retina (Rashbass, 1961). Smooth movements do nothing to correct for the position of the target, which is the function of the much faster "saccadic" eye movement 8yotem (Rashbas, 1961 ; Robinson, 1968).

The smooth pursuit system appears to be particularly vulnerable to the effects of alcohol (Wilkinson, Rime, and Purnel1, 1974). This gystem normalig can track movement at up to 30 degrees per second. Alcohol, however, reduces the maximal tracking speed and, in 
Buficient concerntration, may eliminate smooth pursuit movements entirely. When the BAC is high enough, only the saccadic system (which adjusts the ege for target position when the position difference is above some threshold) remains. Thus, at a sufficiently high BAC, one can only follow a moving object with a series of saccadic jerks.

\section{Gyze Nystagmus}

Rasbbas (1959) claims that the inabilitg to maintain visual fixation is responsible for gaze nyatagmus, a jerking movement of the eyes when they are deviated laterally. He argues that only the smooth pursuit system is involved in bringing the eye to a single spot. When the eyes are deviated to the side, slow drifting movements will occur toward the center depending upon the amount of lateral deviation and the ability of the smooth pursuit system to counteract these drifts. When the smooth pursuit system is inhibited by drugs such as alcohol or barbiturates, the slow drifts become large enough that saccadic jerks are required to maintain the lateral gaze.

Gaze nystagmus can be seen in 50-60\% of all individuals if their eyes are deviated to the extremes, but it is considered to be patbological when it occurs at less extreme (i.e., 40 degrees) deviations (Toglia, 1976). Gaze nystagmus occurs with some types of brain damage (Baloh, Ronrad, and Honruba, 1975), but it provides little localizing value in detecting the brain damage except to direct one's attention away from the peripheral labyrinths of the vestibular system. The data of Baloh et al (1975) does support Rasbass'theory in that pathological gaze nyatagmus correlates with fixation instability. Five of their six patients with fixation instability also showed pathological gaze nystagmus.

Gaze ogstagmu occurs under beveral different drugs, including a lcobol (i.e., Aschan, 1958), barbiturates (e.g., Bender, o'brien, 1946), antihistamines (ABchan, Bergstedt, and Goldberg, 1958) and phencyclidine (Iinden, Lovejoy, and Costello, 1975). A number of otber drugs may also produce gaze ngstagmus, but most of the evidence is contained in clinical case reports.

Altbougn some articles mention the occurrence of alcohol gaze nystagmus, few detail which parameters are important. Lehti (1976) indicated that the angle of onset from the midpoint of the visual field decreases as a function of increasing BAC. His data suggest that at a BAC of $0.10 \%$, gaze nystagmus will occur at about 51 degrees and, at a BAC of $0.20 \%$, gaze nystagmus will occur at about 29 degrees. The correlation between the angle of onset and the BAC was - .788 for 56 individus 18 .

Most other studies in which gaze ngstagmus has been measured involve a cutoff point of $30-40$ degrees. Use of a cutoff may explain some of their conclusions. For example, Aschan (1958) used a cutoff of 40 degrees and reported that gaze nystagmus had a distinct threshold BAC of approximately $0.06 \%$. Omeda and Sakata (1978) used a cut of $f$ of 30 degrees and concluded that it was one of 
the least bensitive eye measures of alcohol intoxication. These conclusions are not at all burprising in view of the data that gaze nystagmus vill occur at appoximately 41 degrees at a BAC of $0.10 \%$.

Aschan (1958) has distinguished between "fine" gaze nystagmus and a "course" gaze nystagmus. The latter tends to be a slow, large amplitude movement of about 10 degrees. Fine nystagmus tends to be a much smaller amplitude of about 4 degrees. We would expect that the difference in amplitude would only occur at a sufficiently high BAC for saccadic eye movement (i.e., in addition to smooth movements) to be impaired (Wilkinson et al, 1974). When the saccadic system is. impaired, a larger drift off target may be required for saccadic correction.

Aschan (1958) also reports that gaze nystagmus is more evident with monocular fixation than with binocular fixation. Be reported that subjects showing monocular gaze nystagmus at 20 degrees would not show binocular gaze nystagmus until 40 degrees. Toglia (1976) reports that gaze nystagmus tends to be greater in the left eye upon gazing to the left and in the right eye upongazing to the right. These two phenomena may be the same.

B. Alcohol And Balance

While many studies use balance and coordination tests in conjunction with alcohol impairment, only a few studies have tried to mouipulate important parameters in these tests. Balance tests of various sorts show large individual differences in the performanse of gober individuals (i.e., Goldberg, 1963), with older suljecte (60-85 years) having much more difficulty than young (2l-35 years) subjects (Vilson, Barboriak, and Ros8, 1970). Wilson et 1 (1970) observed that alcohol (mean BAC = 0.06\%) improved performalice 20 the older subjects, but impaired performance in goutger subjects. Both groups of subjects were tested for baseline performatice and then given alcohol. The improvement seen in the intcaicated older subjects may be due to the fact that balance teato show distinct learning curves (Goldberg, 1963), and the older subjects have much more room for improvement (i.e., the baseline performance of older subjects was ten times worse than that of the vounger indisidusls). It should be noted that Bardy, Elomaa, iublat, and Lehtoraara (1978) reported that age (between 18 and 67 gears.) had $x$ o gignificant effect on body oway.

A nutbe: of variables, in addition to alcohol, increase body sway. These variables include exercise (Barnes, Cooke, Ring, and Pasticie, (965), sleep 1088 (Goldberg, 1963), increasing the room temperarute from 65-68 F to 79-86 F (Goldberg, 1963), eating (Gcldberg, 1903), and tranquilizers and antihistamines (Goldberg, 1966). In contrast, Nijiokikjien (1973), found that "controlled attevicz" (i.e.. counting background clicks) decreased body Bway.

One of the most important parameters in tests of balance and museular crordination is vision. Closing the eyes makes all of the balace teate much moxe difficult for sober and intoxicated inditidusle (Goldber8, 1963; Franks et al, 1976; Begbie, 1966; 
Fregly, Bergoted and Graybiel, 1967). Begbie (1966) investigated "balancing on a moving btand" under four conditions: (1) eyes closed, lights off, (2) monitoring an oscilloscope with the lights off (i.e., no peripheral vision), ( 3 ) monitoring an oscilloscope with light on (i.e., limited peripheral vision), and (4) eyes open, lights on, no task (i.e.s full peripheral vision). The conditions, in terms of difficulty, were ranked in the order presented ( $i . e$., eyes closed, lights off was the most difficult). These data suggest that peripheral vision plays a particularly important role in maintaining balance.

\section{Walk-The-Line}

Very few studies have looked specifically at the walk-the-line tests. Fregley, Graybiel, and Smith (1972) found that most individuals of both sexes could make 30 heel-to-toe steps with their eyes closed and arms folded across their chest without side stepping. In a second study, Fregley, Bergated, and Graybiel (1967) found that walk-the-line performance ( $i$.e., on 8-foot long, $3 / 4$ inch rail with eyes open) showed the maximum amount of deterioration just before subjects reached their peak BAC of $0.10 \%$ and returned to normal in about two hours.

\section{One-Leg-Stand}

Only a few studies have looked at variables affecting the one-legstand test. Fregley et a (1972) found that the leg used made no difference in the amount of time one could stand on one leg (eyes closed). Most of Goldberg's findings on standing steadiness involved this test. Thus, variables such as sleep loss, alcohol, tranquilizers, food intake and warm temperatures appar to influence one's ability to stand on one leg. Moreover, the test is very difficult even for sober individusls with the eyes closed. 
INSTRUCTIONS TO SUBJECTS, QUESTIONS ASKED SUBJECTS, AND SCORING AND DECISION SHEETS USED IN THE LABORATORY EVALUATION

WALK AND TURN

Instructions to the stopee:

Please assume a heel-to-toe position on the line with your arms at your sides (demonstrate). When I tell you to, make nine heel-to-toe steps on the line in front of you, turn around, and return in nine heel-to-toe steps. latch your feet at all times, making sure that you walk in a straight line and that every step is heel-to-toe, J.jke this (demonstrate). Do you understand? (One repetition of one or two parts of the instructions is fine, but the entire instructions should not be repeated unless there is an obvious language problem.) Now begin and count your steps outloud.

OIVE-LEE STAND

\section{Instructions to the stopee:}

Flssse stand with your heels together and your arms at Your sides (demonstrate and do not resume until the suspect is in the correct position). When I tell you to, $i$ wart you to raise one leg about 6 inches off the ground and holc that position while you count rapidly from 1001 to 1030 (demonstrate). Do you understand? Now begin by rising either you right or left foot.

\section{NYSTAGMUS}

\section{Instructions to the stopee:}

I. am going to check your eyes. Please keep your head still and follow this object (indicate what the stimulus is) to the side with your eyes. Keep your head straight and do not move your eyes back to center until I tell you to do so. 
Participant \# Sex

Officer

Date of birth

Date

Approx. weight

\section{QUESTIONS}

without looking, what time is it now?

Actual time

Have you been drinking? How much? Are you too drunk to drive? When did you last eat? What did you eat at that time?

When did you last sleep? How many hours?

Do you have any physical defects? Yes

If yes, describe:

Are you ill? Yes No Are you hurt? Yes No . If yes,

what is wrong?

Have you recently been to a doctor? Yes No ; a dentist? Yes No If yes, when?

Reason for seeing doctor or dentist

Are you taking medicine? Yes

No . If yes, what?

Last dose taken when?

a.m. p.m.

\section{OBSERVATIONS}

CLOTHES: Orderly Describe __ Mussed__ Soiled__ Disorderly Disarranged

BREATH (odor of alcoholic beverage): Strong ATTITUDE: Moderate Carefree Faint None Hilarious Talkative Indifferent Insulting. Cocky Sleepy Combative Polite Other

UNUSUAL ACTIONS: Hiccupping Profanity Belching Vomiting Fighting Other

SPEECH: Incoherent Mumbled Slurred Confused Thick tongued Stuttered Accented Good Fair

COLOR OF FACE: Normal Flushed Pale__ Other

$$
\text { Watery__ Bloodshot }
$$


Subject

Time

Date

BAC

Eye Problems

Contact lenses

Balance Problems

Scoring Sheet for Sobriety Test Battery

A. Walk and Turn

1. Carnot keep balance while listening to instructions

2. Starts befcre instructions are finished.

3. Keeps balance but does not remember instructions

4. Stops while walking to steady self

5. Does not touch heel-to-toe while walking

6. Loses balance while walking (i.e., steps off line)

7. Uses arms for balance

8. Loses balance whjle turning

9. Incorrect number of steps

10. Canret do the test (equal to 10 checkmarks)

A. TOTAL

B. One t.eg Stand

1. Smizing ahile balancing

2. Jser: àm.c to balance

3. Sli-rt?: un

4. O:i:e un:tead:

5. Eta: :s before instructions are finished

6. PutE igne ciann

7. Cannj: dr... test discontinued (equal to 7 checkmarks)

C. Alcohol Care Nistagmus (AGN)

i. Oriset of AGIN at less than $45^{\circ}$ and with at ieast $10 y$ of the white showing.

2. Estimated argle of onset.

3. Eyes cannot follow smoothly

4. AGN at maximum lateral deviation:
a. absent $R$
I
b. minimal
c. moderate $R$
$\mathrm{L}$
d. heavy

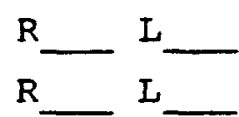

5. AGN at maximum lateral deviation is

moderate or stronger

B. TOTAL

A. +B. TOTAL

RIGHT EYE LEFT EYE 
WALK AND TURN

ONE-LEG STAND

BALANCE TOTAL

NYSTAGMUS

DECISION CRITERIA based upon our pilot work

A. 3 or more checks on balance plus at least a score of 2 on the nystagmus will correctly classify about $75 \%$ of those above $.10 \%$ and will incorrectly classify about $15 \%$. of those below . 10 \%

B. 2 or more checks on balance plus at least 2 on nystagmus will correctly classify about $75 \%$ of those above $.075 \%$ and will incorrectly classify about $10 \%$ of those below $.075 \%$.

C. I or more checks on balance plus nystagmus onset of $50^{\circ}$ or less will correctly classify $80 \%$ of those above .05\% and incorrectly classify about $15 \%$ of those below .05\%.

A. ESTIMATE THIS PERSON'S BAC TO WITHIN .01\%

ON A SCALE OF I TO 10 ( $1=$ uncertain; $10=$ very sure) ESTIMATE YOUR CONFIDENCE IN YOUR ESTIMATE OF THE BAC.

B. IS THIS PERSON IMPAIPED BY ALCOHOL?

YES

ON THE SAME SCALE WHAT IS YOUR CONFIDENCE

NO

IN THE ABOVE?

C. WOULD YOU ARREST THIS PERSON UNDER YOUR NORMAL CRITERIA? 